Florida International University FIU Digital Commons

$11-7-2012$

\title{
Factors Influencing the Implementation of Substance Use Prevention Programs in Elementary Schools
}

Jackie Cruz Wagener

Florida International University, Jackie@forceconstant.com

DOI: $10.25148 /$ etd.FI12120409

Follow this and additional works at: https://digitalcommons.fiu.edu/etd

\section{Recommended Citation}

Cruz Wagener, Jackie, "Factors Influencing the Implementation of Substance Use Prevention Programs in Elementary Schools" (2012). FIU Electronic Theses and Dissertations. 768.

https://digitalcommons.fiu.edu/etd/768 


\title{
FLORIDA INTERNATIONAL UNIVERSITY
}

Miami, Florida

\section{FACTORS INFLUENCING THE IMPLEMENTATION OF SUBSTANCE USE PREVENTION PROGRAMS IN ELEMENTARY SCHOOLS}

\author{
A dissertation submitted in partial fulfillment of \\ the requirements for the degree of \\ DOCTOR OF PHILOSOPHY \\ in \\ SOCIAL WELFARE \\ by
}

Jackie Cruz Wagener 
To: Interim Dean Michele Ciccazzo

Robert Stempel College of Public Health and Social Work

This dissertation, written by Jackie Cruz Wagener, and entitled Factors Influencing the Implementation of Substance Use Prevention Programs in Elementary Schools, having been approved in respect to style and intellectual content, is referred to you for judgment.

We have read this dissertation and recommend that it be approved.

Mario de la Rosa

Mark Macgowan

Maureen Kenny

Eric Wagner, Major Professor

Date of Defense: November 7, 2012

The dissertation of Jackie Cruz Wagener is approved.

Interim Dean Michele Ciccazzo

Robert Stempel College of Public Health and Social Work

Dean Lakshmi N. Reddi

University Graduate School

Florida International University, 2012 


\section{ACKNOWLEDGMENTS}

I would like to thank the following individuals for the role they played in helping me complete my dissertation:

To my advisor, Eric Wagner, for his guidance and wisdom these past four years - from helping me narrow down my topic to developing quality scholarly work - and for everything in between. Thank you also for being my advocate.

To Mark Macgowan for his support throughout the program and for giving me the opportunity to work with him on research projects.

To Mario de la Rosa for his assistance in raising the quality of my methodology and for helping to shape my problem/policy qualifying paper.

To Maureen Kenny for her expertise in schools and children, as well as for her help in coordinating the pre-testing of my survey.

To Paul Stuart for his support throughout my program and for his willingness and availability to offer assistance. Thank you as well for pairing me up with Dr. Wagner based on our research interests.

To Paulette Johnson for her time, expertise, and patience in assisting me with my statistical analyses. I couldn't have done it without you, Paulette!

To Francisco Sastre for acting as the second coder in the qualitative interviews, and for his diligence, willingness to help, and positive attitude. You helped me tremendously, Francisco, and I will be forever appreciative.

To Richard Beaulaurier for his assistance on last minute edits to the dissertation to ensure that the methods section accurately reflected the steps that I took. 
To those professors and staff in the School of Social Work, as well as FIU, who played a role in imparting their knowledge, experience, and help from my first day in the program and throughout my attendance.

To FIU and the University Graduate School for the generous support offered by the Dissertation Year Fellowship which allowed me to make significant strides in completing my dissertation.

To my cohort and friends in the program for their support and advice.

To my husband, Brian, for his constant support and encouragement.

To my family for believing in me and for their positive words. 
ABSTRACT OF THE DISSERTATION

FACTORS INFLUENCING THE IMPLEMENTATION OF SUBSTANCE USE PREVENTION PROGRAMS IN ELEMENTARY SCHOOLS

\author{
by \\ Jackie Cruz Wagener \\ Florida International University, 2012 \\ Miami, Florida \\ Professor Eric Wagner, Major Professor
}

Prevention scientists have called for more research on the factors affecting the implementation of substance use prevention programs. Given the lack of literature in this area, coupled with evidence that children as early as elementary school engage in substance use, the purpose of this study was to identify the factors that influence the implementation of substance use prevention programs in elementary schools. This study involved a mixed methods approach comprised of a survey and inperson interviews. Sixty-five guidance counselors and teachers completed the survey, and 9 guidance counselors who completed the survey were interviewed individually. Correlation analyses and hierarchical multiple regression were conducted. Quantitative findings revealed ease of implementation most frequently influenced program implementation, followed by beliefs about the program's effectiveness. Qualitative findings showed curriculum modification as an important theme, as well as difficulty of program implementation. The in-person interviews also shed light on three interrelated themes influencing program implementation - The Wheel, time, and scheduling. Results indicate the majority of program providers modified the curriculum in some way. Implications for research, policy, and practice are discussed, and areas for future research are suggested. 


\section{TABLE OF CONTENTS}

CHAPTER

PAGE

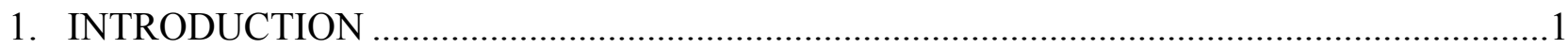

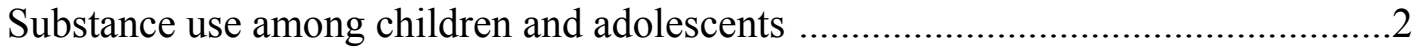

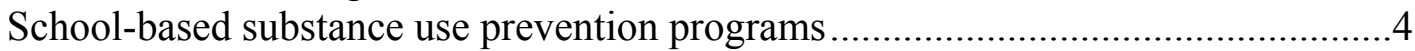

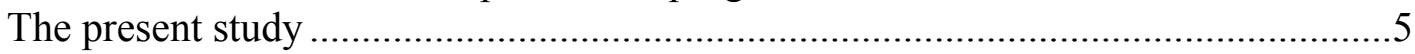

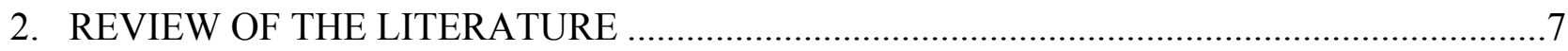

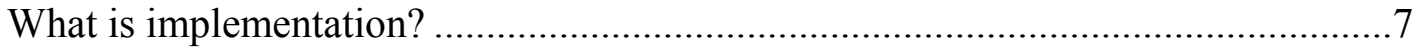

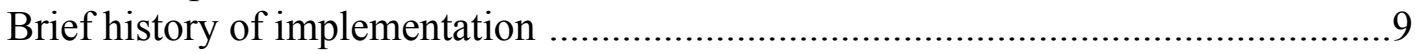

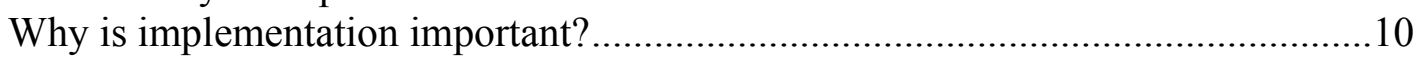

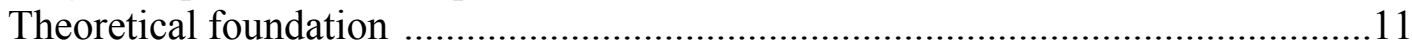

The association between program fidelity and program outcomes .......................14

Program fidelity among teachers and other program providers ..........................16

The role of the school social worker ...........................................................20

Criteria for the literature review on factors influencing the implementation of substance use prevention programs in elementary schools...................................22

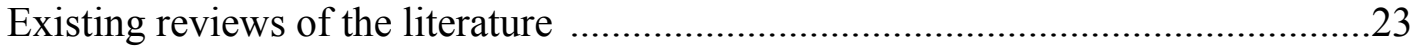

Findings from the current literature review: Factors influencing the implementation of substance use prevention programs in elementary schools ..............................26

Similarities and differences in methodology across studies ..............................40

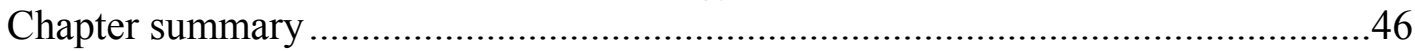

Objective of study, research questions, and hypotheses ...................................47

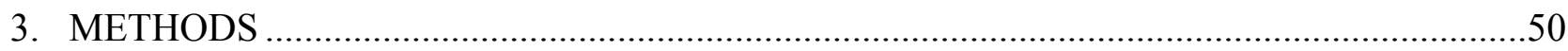

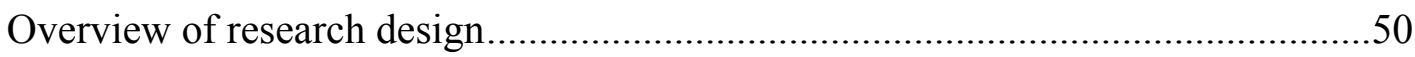

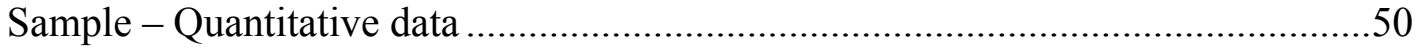

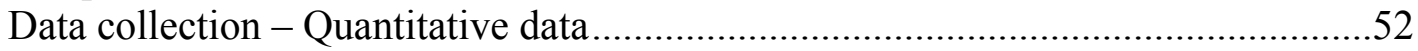

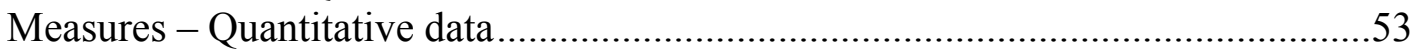

Data management and analysis - Quantitative data ........................................57

Sample - Qualitative data .................................................................60

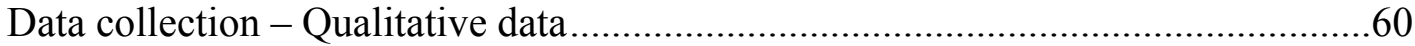

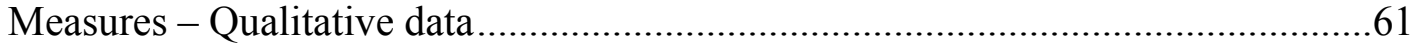

Data management and analysis - Qualitative data .......................................62

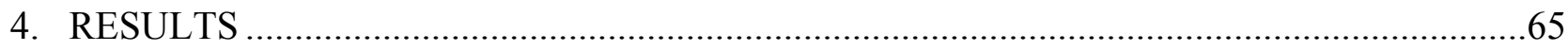

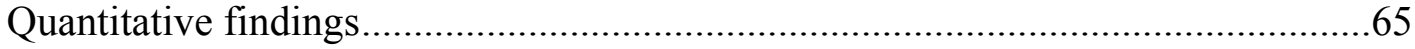

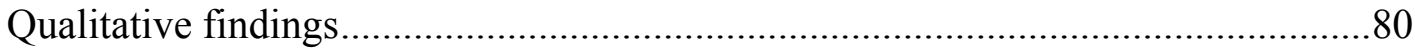

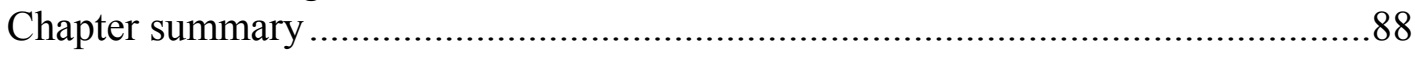

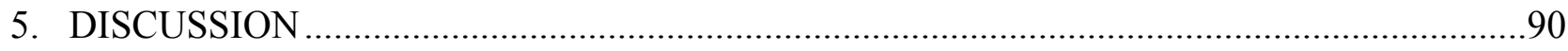

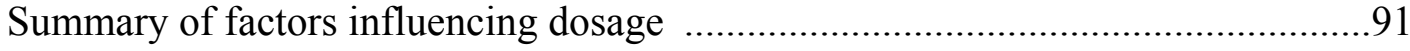

Summary of factors influencing adherence ................................................. 95 
Additional factors influencing implementation .............................................99

Implementation differences between providers ............................................. 103

Relationship between dependent and independent variables ............................105

Relationship among independent variables .....................................................107

Relationship between independent and demographic variables ...........................107

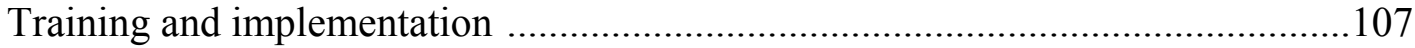

Time spent by guidance counselors on responsibilities ...................................111

Findings in light of the theoretical framework .................................................. 112

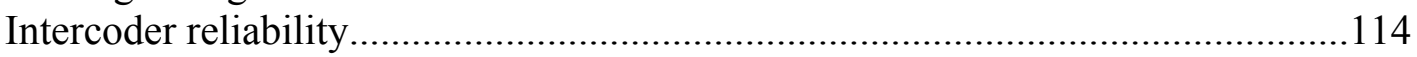

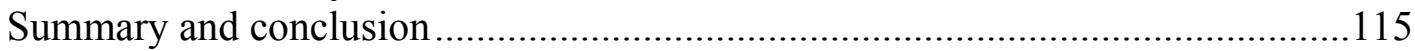

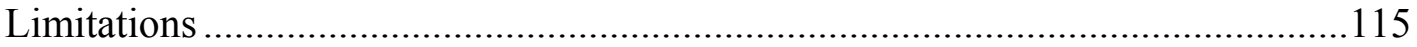

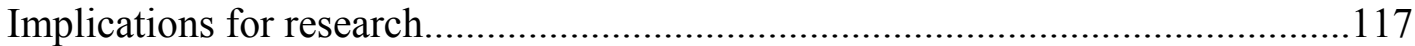

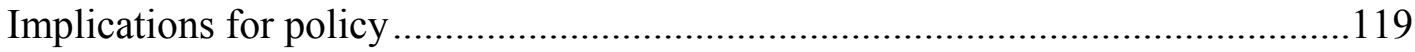

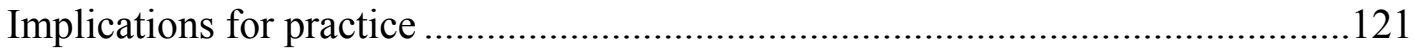

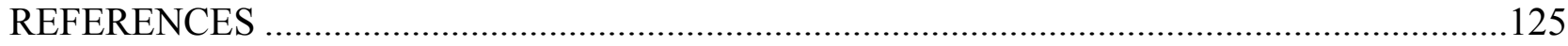

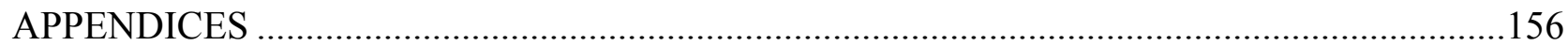

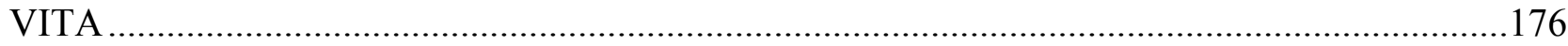




\section{LIST OF TABLES}

TABLE

PAGE

1. Factors Affecting Program Implementation

2. Factors Influencing Implementation of School-Based Substance Use Prevention Programs in Elementary Schools

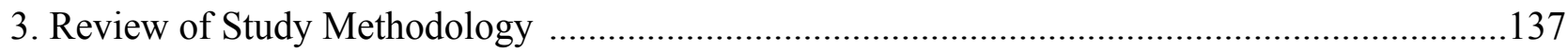

4. Self-Report Data Collection Method and Corresponding Response Rates ............................139

5. Demographic Characteristics of Respondents ..............................................................141

6. Means and Reliabilities of Independent Variables ...........................................................143

7. Pearson Correlations Between Dependent, Independent, and Demographic Variables .............149

8. Dosage and Adherence by Job Title ............................................................................ 150

9. Pearson Correlations Among Dependent Variables .........................................................150

10. Pearson Correlations Among Independent and Demographic Variables .............................151

11. Regression Findings for Amount of Program Delivery (Dosage) .......................................152

12. Regression Findings for Following Curriculum Guide (Adherence) ..................................153

13. Regression Findings for Frequency Using Interactive Components (Adherence) ................154

14. Level of Encouragement from Principals and District Prevention Coordinator ....................155 


\section{LIST OF FIGURES}

FIGURE

PAGE

1. Ecological Framework for Understanding Effective Implementation.................................. 132

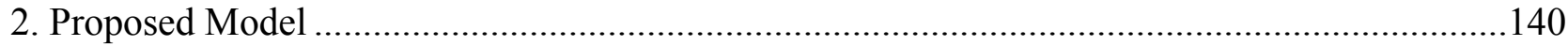

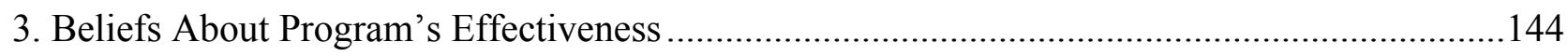

4. Beliefs About School's Responsibility to Teach Substance Use Prevention Lessons ...............145

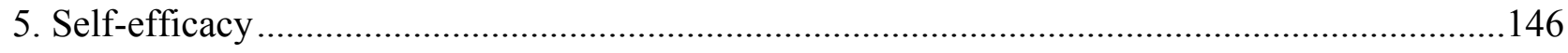

6. Ease of Program Implementation (Program Complexity) ...................................................147

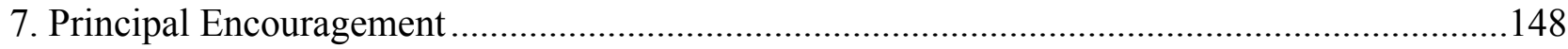

8. Mean Percent Time Guidance Counselors Spend Per Week on Activities ............................155 


\section{CHAPTER 1}

\section{INTRODUCTION}

Although effective school-based substance use prevention programs have been identified (Center for Substance Abuse Prevention, 2002; National Institute on Drug Abuse, 1997; USDOE, 2001), many schools either do not implement these programs or implement these programs poorly (Hallfors \& Godette, 2002; Ringwalt et al., 2002; Rohrbach et al., 2005). Implementation is considered so crucial that researchers have concluded that regardless of the effectiveness of a prevention program, the program is not likely to produce the desired results unless it is properly implemented (Botvin \& Griffin, 2003a; Mihalic et al., 2008). In fact, implementation fidelity, or the degree to which a program is delivered as intended by program developers (Dusenbury et al., 2003), has been directly tied to program outcomes (Durlak \& DuPre, 2008).

School-based programs are the primary method by which children and adolescents are presented with substance use prevention programming (Botvin \& Griffin, 2003a; Ringwalt et al., 2009). Childhood and adolescence are critical time periods to reach this young population with prevention efforts, as they are forming attitudes and intentions towards substance use, and many are already using substances (Johnston et al., 2012). While the number of effective school-based substance use prevention programs has increased, a gap remains in what is known about how to effectively translate these programs into school settings (Botvin \& Griffin, 2004; Mihalic et al., 2008). To address this gap, researchers have called for further research to identify and confirm factors that 
influence the implementation of prevention programs (Durlak, 1998; Dusenbury et al., 2003).

This dissertation is organized into five sections. First, an overview of the literature on substance use among children and adolescents is presented. In addition, a summary of school-based substance use prevention programs will be offered. Second, the topic of implementation is discussed, and a review of the empirical findings related to prevention program implementation will be presented. Third, the methodology of this study is given, including information about the data collection and analyses. Fourth, the results of the study are presented. Fifth, and lastly, the discussion section sums up the findings of the study and discusses implications for social work.

\section{Substance use among children and adolescents}

Although licit and illicit substance use among adolescents has declined in the past decade (Johnston et al., 2012), prevalence rates remain high and are a cause for concern. Among $12^{\text {th }}$ graders, $50 \%$ report having tried an illicit drug and $46 \%$ report having tried marijuana in their lifetime (Johnston et al., 2012). Concerning alcohol and tobacco, the legal substances for adults, $70 \%$ of $12^{\text {th }}$ graders reported alcohol use and $51 \%$ admitted to being drunk in their lifetime (Johnston et al., 2012). Lifetime prevalence rates for cigarette use among senior high school students were 40\% (Johnston et al., 2012).

Unfortunately, substance use occurs even earlier than high school. For example, among $8^{\text {th }}$ graders, $20 \%$ report having tried an illicit drug and $16 \%$ report having tried marijuana in their lifetime (Johnston et al., 2012). Thirty-three percent reported alcohol use and 15\% reported having been drunk in their lifetime (Johnston et al., 2012). Lifetime prevalence rates for cigarette use among $8^{\text {th }}$ graders were $18 \%$ (Johnston et al., 2012). 
While prevalence rates for $8^{\text {th }}$ graders are alarming, of perhaps greater concern is the occurrence of these behaviors among younger children. The annual Monitoring the Future Study asks $8^{\text {th }}$ graders in what grade they first used certain substances. Of the approximately 16,000 eighth graders that responded, 5\% reported using alcohol and 3\% admitted to both smoking cigarettes and using inhalants for the first time by $4^{\text {th }}$ grade (Johnston et al., 2012). Although initiation rates peak in the middle and high school grades depending on the substance (Johnston et al., 2012), it is clear from these statistics that children begin to experiment with cigarettes, alcohol, marijuana, and other drugs at very early ages.

Research has also shown that children begin to form attitudes and intentions related to substance use prior to engaging in the behavior (Botvin et al., 2003b; Johnston et al., 2012). In other words, attitudes and intentions towards substance use are considered a precursor to using tobacco, alcohol, marijuana, and other drugs. Johnston et al. (2012) echo these findings as they conclude that "changes in beliefs and attitudes about drugs have been important determinants of trends, both upwards and downward, in the use of many drugs (p. 352)." To illustrate this point, in the Monitoring the Future Study, these researchers draw attention to the association between: (a) students who perceived the risk of engaging in substance use to be high and who disapproved of it, and (b) lower rates of substance use; that is, students who perceived the risk of engaging in substance use to be high and who disapproved of it were less likely to engage in substance use (Johnston et al., 2012).

Engaging in substance use has many detrimental consequences for children and adolescents, including physical, emotional, and social costs. Substance use among this 
population is associated with health ailments such as lung and heart problems, mental health issues such as depression and suicide, and social consequences such as violent crime and unemployment (Hawkins et al., 1992; USDHHS, 2004). In addition, students who do not engage in illicit substance use are more likely to say they will complete four years of college compared to substance-using peers (Johnston et al., 2012). Additional costs related to engaging in tobacco, alcohol, or other drug use include lost productivity, destruction of families, and loss of life (Biglan et al., 2005; Dryfoos, 1990).

\section{School-based substance use prevention programs}

Schools are the focus of most attempts to develop and implement substance use prevention programs (Botvin \& Griffin, 2003a; Ringwalt et al., 2009), as they offer one of the most reliable and efficient locations to reach a large number of individuals with broad-scale prevention efforts (Botvin \& Griffin, 2003a; Coie et al., 1993; Mihalic et al., 2008; Wagner, Tubman, \& Gil, 2004). Recognizing this, federal agencies and national organizations, with the help of researchers, have identified a number of effective substance use prevention programs for children and adolescents (Center for Substance Abuse Prevention, 2002; Drug Strategies, 1999; National Institute on Drug Abuse, 1997; USDOE, 2001). Substance use prevention programs that are deemed effective are those that focus on psychosocial factors and teach resistance skills, social skills, and personal skills (Botvin \& Griffin, 2003a), and that are interactive in their delivery (e.g., role playing, group discussion) (Tobler et al., 2000). 


\section{The present study}

Given the need to start prevention efforts early, and that numerous effective school-based substance use prevention programs have been identified, the next major challenge lies in how to implement these programs with high fidelity (Botvin \& Griffin, 2004). How well a prevention program is implemented by teachers and other program providers has been shown to affect program outcomes (Durlak \& DuPre, 2008). In other words, well-implemented programs are more likely to yield positive outcomes in children and adolescents compared to poorly-implemented programs.

Since the majority of school-based substance use prevention programs are geared towards middle school students (Botvin \& Griffin, 2003a), the existing literature on program implementation primarily focuses on middle schools; there is a shortage of studies that focus on factors that influence the implementation of substance use prevention programs in elementary schools. This is a concern since, as previously mentioned, children begin to form attitudes and intentions related to substance use, and engage in this behavior, as early as elementary school. Researchers recommend targeting prevention programs early in an individual's life before negative behaviors crystallize (Coie et al., 1993; Webster-Stratton \& Taylor, 2001).

Prevention scientists have called for more research to identify and confirm factors that influence the implementation of prevention programs (Durlak, 1998; Durlak \& DuPre, 2008; Dusenbury et al., 2003). In response to this call, the proposed study aims to expand the scarce literature on factors that influence elementary school program providers' implementation of substance use prevention programs. As such, this research 
explored which factors are important predictors of program implementation among program providers in elementary schools. 


\section{CHAPTER 2}

\section{REVIEW OF THE LITERATURE}

This section has several goals. First, the concept of implementation is presented and explained, including its importance. Second, the theoretical foundation guiding the current study will be discussed. Third, the association between implementation fidelity and program outcomes is examined. Fourth, the role of the school social worker is considered. Fifth, the criteria for reviewing the literature on factors that influence the implementation of substance use prevention programs in elementary schools is presented, along with those findings. Lastly, the objectives, research questions, and hypotheses of the current study are proposed.

\section{What is Implementation?}

Implementation refers to the method by which organizations use an innovation (Rogers, 1995). Implementation is one of the four stages of Rogers' (1995) diffusion of innovations theory, a framework that guides the diffusion of innovations - or new programs - to organizations. Implementation may be distinguished from the other stages in this model, those being: (a) dissemination, or how organizations become aware of an innovation; (b) adoption, or how organizations decide to offer an innovation; and (c) sustainability, or how organizations maintain an innovation.

As researchers point out, the fact that a school adopts a prevention program does not imply that the school will implement the program as intended (Ennett et al., 2003; Rohrbach et al., 1993). To illustrate, Hallfors and Godette (2002) found that out of 81 district coordinators in Safe and Drug Free Schools across 11 states, 59\% had adopted an 
evidence-based substance use prevention program, yet only $19 \%$ of schools were implementing the program with fidelity. Part of the reason for this discrepancy between program adoption and program implementation may be explained by the fact that, generally, different individuals are involved in making decisions in these two stages of the diffusion process. For example, in most school districts, individuals at the senior administrative level typically make decisions about whether a program will be adopted (Huberman \& Miles, 1984), while teachers in the individual schools determine whether and how the curriculum will be used (Rohrbach et al., 1996).

Fidelity of implementation, or whether the program was delivered as intended by program developers (Dusenbury et al., 2003), has generally been measured in five ways: (1) adherence, or the extent to which program components were delivered as specified in the program manual; (2) exposure/dosage, or the amount of the program that was delivered; (3) quality of program delivery, or aspects of the program delivery that are not related to implementation of content specified in program manuals, such as implementer enthusiasm, leader preparedness, and leader attitudes toward the program; (4) participant responsiveness, or the level of participation in the program by individuals; and (5) program differentiation, or the unique characteristics of different components or programs that are reliably differentiated from one another (Dusenbury et al., 2003; Dane and Schneider, 1998). It is not clear from the literature whether all five types of program implementation must be present for a prevention program to accomplish its goals (Dusenbury et al., 2003).

A review of 59 studies by Durlak and DuPre (2008) found that the majority of studies (69\%) assessed only one aspect of implementation, and 31\% assessed at least two 
aspects, with adherence evaluated most often, followed by dosage. Durlak and DuPre (2008) point out that researchers have assessed factors that influence implementation by focusing on only a few variables at a time. They further state that this is understandable since investigators cannot study everything at one time.

Brief History of Implementation

Dusenbury et al. (2003) provide an excellent overview on the history of prevention program implementation. These researchers report that during the 1960's and 1970's, the Research, Development, and Diffusion (RD\&D) model was often used to research, develop, and diffuse research findings and programs to consumers, or program adopters. The model, which was popular with federal policymakers around this time (Havelock 1969), was partly inspired by the accomplishments of federally-sponsored RD\&D efforts in space exploration (Blakely et al., 1987). The predominant thinking during this time was that researchers tested interventions and published the findings, while providers were expected to find these interventions, adopt, and implement them on their own (Fixsen \& Blase, 2009). Another assumption was that providers would naturally implement programs as intended by program developers. The emphasis was on research, development, and diffusion, with little assistance provided to organizations to implement the program once it had been adopted. In other words, implementation was considered a given, therefore not requiring attention from those who developed the programming to offer implementation assistance to program recipients.

In the late 1970's, Berman and McLaughlin (1976) released a report, which is acknowledged as the first systematic examination of implementation fidelity. These researchers looked at educational programs supported by federal funds and concluded 
that program fidelity in schools varied widely and was inconsistent. Around this time, researchers began to recognize that organizations possess various characteristics that influence whether programs were adopted and how they were implemented (Blakely et al., 1987). Research by Rogers (1995) also advanced the implementation knowledge-base when he demonstrated that "local adopters" reinvented or modified innovations to meet their own needs. In light of these findings, the RD\&D model was modified by researchers, including Rogers (1977) (see Blakely et al., 1987), who then began to view the diffusion process, including the implementation stage, as more of an active process.

The shift in viewing the diffusion process as active rather than passive resulted in program adopters taking a greater role in the diffusion process. Examples of such activities included potential program adopters visiting the site of the developer's programs, conferences to inform interested organizations of new findings and programs that may be relevant to them, and attending training workshops offered by program developers (Blakely et al., 1987). The purpose of these activities was to increase the adoption and implementation of new programs (Blakely et al., 1987).

\section{Why is Implementation Important?}

Today, implementation is considered such a crucial factor that Botvin and Griffin (2003a) conclude that regardless of the effectiveness of a prevention program, the program is not likely to produce the desired results unless it is properly implemented. In fact, implementation fidelity, or the degree to which the program is delivered as intended by program developers (Dusenbury et al., 2003), has been directly linked to program 
outcomes (Durlak \& DuPre, 2008). Stated succinctly, well-implemented programs generally yield more positive outcomes than poorly-implemented programs.

Assessing implementation is important for several reasons. First, it assists researchers in understanding why prevention programs succeed or fail. Second, it notifies researchers as to what has been modified in the program, and how that change influences the outcomes of the program. Third, it demonstrates the feasibility of delivering a prevention program (Dusenbury et al., 2003).

To illustrate the importance of measuring program implementation, consider the following example. A school decides to discontinue a substance use prevention program because the program did not produce positive outcomes. The school views this program as ineffective. However, if the school did not assess the implementation process while the program was delivered to students, it is not known whether the program was taught with fidelity (i.e., as originally intended by program developers). The negative outcomes may be attributed to not delivering all the components of the program, or to modifying the program in some other way (Durlak \& DuPre, 2008). Determining that a program is ineffective without assessing the implementation process can lead to a Type III error (Resnicow et al., 1998); that is, incorrectly concluding that a program is ineffective because of weak outcomes that were the result of poor implementation.

\section{Theoretical foundation}

Durlak and DuPre's (2008) Ecological Model for Effective Implementation provides a useful framework for understanding and assessing the implementation process in organizations. The model, which is depicted in Figure 1, posits that implementation is influenced by factors in five categories: (1) the innovation (e.g., prevention program); (2) 
the program provider (e.g., teachers or counselors); (3) the community-level (e.g., funding availability); (4) the prevention delivery system (e.g., school leadership); and (5) the prevention support system (e.g., teacher training). Within the prevention delivery system, lies organizational capacity and within the prevention support system lies training and technical assistance.

Durlak and DuPre (2008) state that in order to achieve effective implementation, factors in all five categories interact with and influence each other. These researchers developed this model after reviewing 81 studies that contained quantitative and qualitative data on factors affecting the implementation process. Their review identified 23 factors that are associated with the five categories in the model. These factors can be found in Table 1.

It is important to note that this model is not specific to schools or to substance use prevention programs. Durlak and DuPre (2008) proposed this model after reviewing studies that focused on prevention and health promotion programs for children and adolescents in a variety of settings. Programs included those aimed at physical health and development, academic performance, and drug use, in addition to other areas. Settings included schools, community organizations, and clinics. To the author's knowledge, no comprehensive model exists concerning factors that influence the implementation of substance use prevention programs.

Nonetheless, Durlak and DuPre's model provides a useful guide in pointing out which factors influence implementation, as well as the method by which these factors lead to successful implementation (Durlak \& DuPre, 2008). The findings yielded from the current study have the potential to either support or modify Durlak \& DuPre's (2008) 
Ecological Model for Effective Implementation to more accurately reflect the factors that influence implementation in a specific setting (i.e., schools) concerning a specific issue (i.e., substance use prevention programs).

Although the factors identified by Durlak and DuPre (2008) are not specific to schools or substance use prevention programs, Table 1 represents the most extensive list that is currently available on factors related to the implementation process. Durlak and DuPre (2008) point out that there is considerable overlap among the factors, which may lead to the list being reduced in the future as more research is conducted in this area.

Similar categories affecting implementation were found by Dusenbury and her colleagues in their review of studies across 25 years (Dusenbury et al., 2003). These researchers examined factors related to implementation from the disciplines of mental health, prevention of psychopathology, personal and social competence promotion, education, and drug abuse treatment and prevention. The authors identified factors in four categories that influenced program implementation: teacher characteristics, program characteristics, organizational characteristics, and teacher training.

The four categories identified by Dusenbury et al. (2003) are almost identical to those found by Durlak and DuPre (2008) except that the former do not specifically mention community-level factors. However, recognizing the importance of this factor on implementation, one of the recommendations offered by Dusenbury and her colleagues is that more research is needed on community and environmental factors that may influence the implementation of prevention programs (Dusenbury et al., 2003). There are also differences among the factors identified by both reviews. For example, while Durlak and 
DuPre (2008) cite technical assistance as important in the implementation process, Dusenbury et al. (2003) do not.

Like Durlak and DuPre's (2008) findings, Dusenbury et al.’s factors are not necessarily specific to school-based programs or substance use. It is not clear which settings were included in Dusenbury et al.'s (2003) review. In addition, implementation factors across multiple disciplines, including drug use, were examined. Furthermore, it appears that Dusenbury and her colleagues cited factors even if they were present in only one study, unlike Durlak and DuPre (2008) who stipulated that a factor must be mentioned in at least five articles to be identified as important. Despite these shortcomings, the findings add to the knowledge-base concerning the factors that influence the implementation of prevention programs.

The Association Between Program Fidelity and Program Outcomes

Several studies have documented the association between well-implemented prevention programs and program outcomes. Durlak and DuPre (2008) reviewed five meta-analyses, which looked at nearly 500 studies ranging from preventing aggressive behaviors to substance use among children and adolescents. These researchers found that when programs were well-implemented, the mean effect sizes were two to three times greater compared to programs that were not properly implemented (specific information on these meta-analyses are presented below). Furthermore, a review of 59 additional studies supported the finding that higher levels of implementation were typically associated with more effective outcomes (Durlak \& DuPre, 2008).

Wilson et al. (2003) reviewed 221 school-based programs to address aggressive behaviors in children and adolescents and found significant differences between control 
and intervention conditions $(\mathrm{ES}=-.01$ and $\mathrm{ES}=.22$, respectively). In addition, implementation quality was reported to be the second most important factor ${ }^{1}$ overall in predicting pre-post test effect size - and the most important program feature - that influenced outcomes. In a different meta-analysis of 143 drug prevention studies, Tobler (1986) found that well-implemented programs obtained effect sizes 0.34 greater than poorly-implemented programs. In another study, Smith et al. (2004) reported that although 14 whole-school anti-bullying programs achieved small effects overall, programs that monitored the implementation process reported more positive outcomes (for victimization self-reports[p=.02], but not bullying self-reports $[\mathrm{p}=.09]$ ) than programs that did not monitor implementation.

While these studies support the relationship between well-implemented prevention programs and positive outcomes, researchers point out that expecting perfect or near perfect implementation is not realistic (Durlak \& DuPre, 2008; Dusenbury et al., 2003). Durlak and DuPre (2008) propose that implementation exists on a continuum from $0 \%$ to $100 \%$, and state that it is extremely difficult to achieve $100 \%$ implementation. These researchers also report that few studies have produced implementation levels of $80 \%$ or greater. Fortunately, they assert, positive outcomes have been achieved with implementation levels as low as $60 \%^{2}$ (Botvin et al., 1990).

These findings speak to the ongoing debate concerning whether prevention programs may be modified or whether they should be implemented exactly as the

\footnotetext{
${ }^{1}$ The most important factor was the risk level of students, with high-risk students showing better outcomes than low-risk students.

${ }^{2}$ Botvin et al. (1990) found that middle school students who had received at least $60 \%$ of the drug use prevention program had significantly lower levels of substance use than did control subjects. These researchers concluded that even a modest level of implementation can impact drug use.
} 
program developers intended. Proponents of allowing programs to be adapted point out that if schools are not permitted to modify the program to fit their local needs, they may be less likely to adopt and implement the program (Dusenbury et al., 2003). Supporters of strictly adhering to the prevention program protocol hold that if schools modify the program, they may omit effective program components (Dusenbury et al., 2003). A third stance, which offers a compromise between the two camps, suggests that program developers should clearly state the components in the prevention program that may and may not be modified (Dusenbury et al., 2003). This would offer schools a guide as to what portion of the curriculum may be altered should the need arise to adapt the program. Researchers point out that more research is needed to determine the extent to which psychosocial-based prevention programs may be adapted to local conditions without compromising program effectiveness (Rohrbach et al., 1993). However, enough evidence may now be available to inform program providers of the necessary components of effective substance use prevention programs (Botvin \& Griffin, 2003a; Dusenbury \& Falco, 1995; Tobler et al., 2000).

\section{Program Fidelity Among Teachers and Other Program Providers}

The majority of instructors who deliver a prevention program modify the program in some way (Ringwalt et al., 2003). Botvin et al. (1989) reported that teachers implemented between $44 \%$ and $83 \%$ of a smoking curriculum to middle school students, with an average program implementation of $65 \%$. Similar findings were demonstrated by Botvin et al. (1990) in an evaluation of the Life Skills Training Program. Teachers delivered an average of $75 \%$ of the program during the first year. However, most teachers (84\%) reported they had not taught at least one of the program modules, and by the 
second year, only $25 \%$ of teachers taught any part of the program. This speaks to the wide and inconsistent variation among program providers when delivering substance use prevention curricula. In another evaluation of the Life Skills Training Program, Mihalic et al. (2008) found that instructors who delivered the program in 432 middle schools taught $86 \%$ of the required curriculum. Individual teachers varied in the amount of the material taught which ranged from $0 \%$ to $100 \%$. Seventy-one percent reported teaching all the required program lessons.

Although Sobeck et al. (2006) did not find significant program effects when evaluating the Michigan Model for Comprehensive Health Education, an evidence-based substance use prevention program in schools, they opted to share lessons learned when the program was implemented. Included in these findings were that middle school teachers delivering substance use prevention curricula did not teach all the lessons, skipped lessons, omitted activities, and combined lessons to save time. The lessons least likely to be delivered were those that involved role playing, group work, and open-ended questions. This finding is similar to other research that has found that teachers emphasize non-interactive methods over interactive methods (Botvin et al., 1990; Ennett et al., 2003; Hahn et al., 2002). Reasons for this may be that teachers lack sufficient time to deliver these components, which may be more time-intensive than lecture-type presentations, or that teachers may need training in order to develop and hone the skills necessary to deliver interactive components.

In addition, in an evaluation of the implementation of the Strengthening Families Program, an empirically-supported, community-based prevention program, Hill et al. (2007) found that of all the program's components (i.e., activities, lectures, videos, 
discussions, role-playing, and homework), the most frequently adapted portion was the games component. Indeed, some teachers view interactive activities to be unnecessary and time-consuming (St. Pierre \& Kaltreider, 2004), and therefore are more likely to modify or skip over these components. The finding that some program presenters chose to omit interactive elements has important implications concerning program outcomes since research has demonstrated that the most effective substance use prevention programs are those that are interactive, relying less on didactic methods (Botvin \& Griffin, 2003a; Tobler et al., 2000).

Pankratz et al. (2006) found that elementary school teachers who implemented Protecting You, Protecting Me - an evidence-based alcohol use prevention program delivered between $73 \%-88 \%$ of each lesson. The authors point out that these results are higher than is typically reported in studies measuring implementation and speculate that it could be due to one of three reasons: (1) prior to delivering the program, teachers attended a booster training which emphasized the importance of implementation fidelity; (2) teachers were aware they were being videotaped which may have prompted them to teach the program with greater fidelity; or (3) the determination of whether a curriculum section was completed was defined as 'any effort put forth to address the section content,' which may have been more lenient than definitions used by other researchers. Pankratz and her colleagues also found that the majority of teachers did not deliver all the portions of the lessons. In fact, these researchers found that every teacher in their study modified either the content of the lesson or the teaching method (Pankratz et al., 2006). In a qualitative study of eight middle schools, administrators and teachers admitted that the substance use prevention program (Project Alert) would not be 
implemented with fidelity (St. Pierre \& Kaltreider, 2004). The majority of teachers said they would either add or omit content from the lessons, reduce the number of class periods to teach the lesson, or modify the lessons in some other way to fit the existing curriculum. These teachers also cited that substance use prevention programs should be comprised primarily of information-only approaches and felt that it was overload to offer prevention programs across the grades (St. Pierre \& Kaltreider, 2004). Again, teachers may not be aware that information-only approaches are not effective in deterring substance use and that prevention programs may be warranted across grades (Botvin \& Griffin, 2003a; Tobler et al., 2000). These beliefs may influence the content and delivery method that teachers emphasize when delivering the prevention program, as well as how much of the program they deliver to students. In a similar study, only $15 \%$ of teachers were found to follow a prevention program curriculum guide "very closely" and most teachers used discretion in the portions of the lessons they taught, leading Ringwalt et al. (2003) to conclude that some degree of program adaptation is inevitable.

The previous findings concerning program fidelity among teachers and other program providers demonstrate the considerable variability among program providers when implementing prevention programs. It is clear that many teachers and other providers do not deliver the program as intended, while others do not deliver the program at all. These scenarios significantly undermine the ability of programs to prevent substance use among children and adolescents.

The finding that many program providers either modify the prevention program or do not teach it at all, coupled with the recognition that the level of program implementation affects the quality of program outcomes, underscores the need to 
understand the factors that influence teachers and other program providers to deliver effective substance use prevention programs as they were intended to be delivered (i.e., with fidelity). This is the express research focus of the current study. As previously mentioned, although senior school administrators typically decide which prevention programs their schools will offer, it is program providers who decide whether and how much of the program will be presented to students. This reality is what most likely led Mihalic et al. (2008) to point out that whether school-based prevention programs succeed or fail may ultimately rest with teachers.

\section{The Role of the School Social Worker}

The majority of prevention programs discussed up to this point were delivered by regular classroom teachers. Another group who is in a key position to implement substance use prevention programs are school social workers. These individuals possess specialized education and experience in psychosocial issues and can either implement or help teachers or other program providers deliver substance use prevention programs. But have schools, in fact, utilized school social workers for this purpose? In a recent article, Kelly et al. (2010) examined this issue which is summarized below.

Over the past century, the school social work profession has evolved from conducting home visits and linking the student, home, and school to a clinical casework model in which individual students already manifesting social, emotional, or behavioral problems are served by school social workers (Kelly et al., 2010). However, within the past 15 years, there has been a shift in practice models, policy, and research from a clinical orientation to a perspective that focused at least equally on primary prevention on 
factors influencing the academic, social, and emotional functioning of individuals (Kelly et al., 2010).

The existing school social work literature emphasizes the importance of the following: (1) integrated, sustainable intervention efforts that emphasize primary prevention; (2) early screening and intervention; and (3) comprehensive approaches (Dunlap et al., 2008; Nelson et al., 2004; Scott et al., 2008; Walker et al., 1996). For example, the "response to intervention" and "positive behavior support" practice models encourage schools to evaluate academic, social, and emotional learning through a threetier perspective. Students in each of the tiers receive services based on their need (i.e., Tier $1=$ universal programs; Tier $2=$ selective programs; Tier $3=$ indicated programs) (Kelly et al., 2010).

In an effort to determine whether the current practice and interventions used by school social workers reflect the existing recommendations from research and policy, Kelly et al. (2010) conducted a national survey of school social workers. Respondents reported spending more time delivering Tier 3 activities, and not enough time on Tier 1 or Tier 2 activities, as they would ideally like. School social workers reported the following specific information concerning how much time they spent on doing each activity: over $60 \%$ conducted individual counseling all or most of the time, $31 \%$ engaged in group counseling, $21 \%$ took part in family work, $12 \%$ taught in classroom groups, and $9 \%$ were involved in teacher sessions.

The discrepancy between actual and ideal time spent on activities by school social workers was attributed to serving too many students and spending time on administrative tasks. In fact, school social workers reported spending an average of 30\% of their time on 
administrative duties. Other interesting findings were: (1) the majority of the sample (44\%) was comprised of school social workers in elementary schools; (2) respondents reported that most of the referrals they received were from teachers; and (3) the primary reasons for referrals were behavioral (58\%) and emotional (56\%) problems.

Researchers concluded that school social workers may still be practicing with a clinical casework framework, serving students who are already experiencing social, emotional, and academic problems (Kelly et al., 2010). They further note that although there has been a shift in practice models, education policy, and research, this is not currently reflected among the activities engaged in by school social workers.

Returning to the question of whether schools are utilizing social workers to implement school-based substance use prevention programs, the answer seems to be "not that much," as over $60 \%$ of school social workers engage in individual counseling and only $12 \%$ report conducting classroom activities. In addition, there appears to be a discrepancy between the primary activities school social workers are engaged in (i.e., individual counseling) and the activities they prefer to be engaged in (i.e., prevention).

\section{Criteria for the Literature Review on Factors Influencing the Implementation of}

\section{Substance Use Prevention Programs in Elementary Schools}

Studies included in the following literature review were identified via database searches and reference lists from relevant studies. Databases searched were ERIC, PsycINFO, Medline, Social Services Abstracts, and Sociological Abstracts, using the terms: (a) school* or grade* or student*; (b) implement* or fidelity; (c) substance*, drug*, tobacco, cigarette*, smok*, alcohol, drink*, marijuana, cannabis, or inhalant*; and 
(d) elementary or primary. Studies also had to meet the following criteria: (1) be written in English; (2) report on factors that focus on a substance use prevention program; (3) assess the implementation stage of the diffusion process (studies examining other stages of the diffusion process [i.e., dissemination, adoption, or sustainability] were not included); and (4) conduct inferential statistical analyses to identify factors that influence program implementation. [Criterion number four was included after the author read a handful of studies that met criteria 1-3, yet did not conduct inferential statistics. It was determined that unless studies used this kind of analysis, at minimum, it was impossible to ascertain the factors that statistically influenced program implementation. For instance, some studies (e.g., Dent et al., 1998; Thaker et al., 2008; Tricker \& Davis, 1988) reported the factors that may affect implementation, but did not attempt to examine the relationship between these factors and implementation fidelity (e.g., adherence, dose, etc.)]. Studies from the 1970 's to May 2010 were included.

Abstracts were read to determine if the study met the review criteria. When it was unclear from the abstract whether a study met the criteria, the article was examined. Seven studies matched the review criteria. Existing reviews of the literature

Two reviews were identified concerning implementation as it relates to schoolbased substance use prevention programs (Dusenbury et al., 2003; Rohrbach et al., 1996). In the first study, Dusenbury et al. (2003) conducted a review of the fidelity of implementation literature across a 25 -year period. In addition to discussing other topics, the study identified characteristics that have been found to influence implementation. These factors were organized into four categories: teacher characteristics, program 
characteristics, organizational characteristics, and teacher training. In the second study, Rohrbach et al. (1996) conducted a review of the determinants of the diffusion process (i.e., dissemination, adoption, implementation, and maintenance).

Although both studies offer valuable information (e.g., sections on program reinvention vs. program adherence and recommendations for strengthening the research on fidelity of implementation [Dusenbury et al., 2003], and interventions to increase diffusion and implications for policy and practice [Rohrbach et al., 1996]), they have several limitations. First, in identifying characteristics that influence program implementation, neither study focused solely on substance use in its review. Instead, researchers included topics such as mental health, prevention of psychopathology, personal and social competence promotion, and education (Dusenbury et al., 2003), as well as sexuality and AIDS (Rohrbach et al., 1996). Second, the researchers reviewed studies that took place in settings other than schools. These two issues are a concern because including problem areas other than substance use and other settings in addition to the school may not accurately reflect the specific factors that influence program implementation of substance use prevention programs in school settings. For example, implementing a prevention program in a school may be influenced by different factors compared implementing a program in the community. Third, neither review was specific to the implementation stage of the diffusion process. When Dusenbury et al. (2003) and Rohrbach et al. (1996) discuss the factors they found to be related to implementation, they also mention factors associated with the adoption and maintenance stages. This is a problem because factors that influence these stages may not be the same as those that influence the implementation stage. Therefore, it can be confusing to differentiate which 
factors influence the different stages of the diffusion process. Fourth, neither of the reports are thorough reviews of the literature in the area of factors that may influence the implementation of school-based substance use prevention programs. That is, neither study conducted an exhaustive search of the literature concerning the factors that influence the implementation of school-based substance use prevention programs. As such, these two reviews are incomplete insofar as comprehensively identifying the factors that influence the implementation of school-based substance use prevention programs.

The current review aims to address these limitations. As previously mentioned in the criteria for the literature review, this review focuses solely on substance use prevention programs in elementary school settings. The rationale for this being that students have already begun experimenting with substance use in these grades. Additionally, children in elementary school begin to form attitudes and intentions towards substance use which guide their behaviors. As the substance use statistics cited earlier illustrate, drug use increases through middle and high school. Researchers recommend starting prevention efforts as early as possible to nip problems in the bud and to ensure destructive behaviors do not crystallize (Coie et al., 1993; Webster-Stratton \& Taylor, 2001). Second, only the implementation stage of the diffusion process was examined. Third, this review aims to be comprehensive, including all studies that: (a) take place in elementary schools; (b) target substance use; and (c) focus on the implementation stage. 
Findings from the current literature review: Factors influencing the implementation of substance use prevention programs in elementary schools

The process undertaken for this review was to read each study and document the factors that researchers found to influence the implementation of substance use prevention programs. Once all the factors were documented, the next step was to group them into intuitive categories. The categories chosen for this review, which were influenced by Dusenbury et al. (2003) and Durlak and DuPre (2008), were: (1) provider characteristics, (2) program characteristics, (3) school characteristics, (4) training and technical assistance, and (5) community-level characteristics. The factors that were found in this review to influence the implementation of substance use prevention programs can be seen in Table 2. A review of the seven studies is presented below in alphabetical order. Beets et al. (2008)

The aim of this study was to assess the factors that influence elementary school teachers in implementing the Positive Action Program, a social and character development program, whose goal is to prevent child and adolescent problem behaviors, including substance use. As part of a randomized multi-year trial, 10 schools were randomly assigned to receive the Positive Action Program. The Program consisted of sequenced lessons in addition to other program-related materials to be delivered in the classroom and school-wide. At the end of years two and three of the multi-year program, teachers in grades K-6 completed self-report process evaluation surveys. The dependent variables (i.e., exposure/dosage, adherence, and quality of delivery) and independent variables (i.e., factors that influence implementation) were assessed via the self-report surveys. Exposure/dosage was defined as the amount of curriculum delivered to students; 
adherence was defined as the amount of classroom-wide and school-wide materials used; and quality of program delivery was defined as teachers' attitudes towards the Positive Action Program. Measures used in this study were both developed for this study and modified from existing surveys.

Structural equation modeling found several significant relationships. First, teacher attitudes toward the Positive Action Program were related to the amount of curriculum delivered. More positive attitudes translated into more of the program delivered to students. Second, teacher perceptions of school climate were related to school-wide material usage and teacher beliefs about their responsibility to teach social and character development concepts. Third, teacher beliefs about their responsibility to teach social and character development concepts were related to their attitudes towards the Positive Action Program. Lastly, the amount of curriculum delivered was related to both classroom material usage and school-wide material usage.

Implications of these findings, as stated by study researchers, are: (1) an understanding of the factors that influence providers in delivering a prevention program can inform program developers and can therefore be addressed through training; (2) given the importance of school climate, school administrators should develop a shared vision and be supportive of the prevention program; and (3) assessing teacher attitudes prior to implementation can identify teachers who may deliver the program with lower fidelity. Once identified, appropriate steps can be taken to increase the likelihood of higher program fidelity, including receiving intensive program support from an on-site coordinator or providing these teachers with evidence of the program's effectiveness. 
An observation concerning this study was noted, and involves the issue of implementation versus maintenance. This study surveyed teachers at the end of years two and three of a multi-year trial. Given that Beets et al. (2008) did not assess teachers in year one, the question may naturally arise: did the study measure the implementation or maintenance stage? Implementation refers to the method by which organizations use an innovation, while maintenance (or sustainability) refers to how organizations maintain an innovation (Rogers, 1995). The argument can be made that since this is a multi-year trial, all the years within the trial period in which the program is delivered can be considered the implementation stage. Another argument is that regardless of whether it is a multiyear trial, only year one is considered the implementation stage and the subsequent years represent the maintenance stage. Clarification of this issue, particularly concerning multiyear trials, is imperative since researchers have pointed out that different factors may influence the different stages of diffusion (Rogers, 1995).

Flannery and Torquati (1993)

The purpose of this study was to assess teacher and administrator perspectives on the factors that influence the implementation of Project Pride, a substance use prevention program. Teachers and administrators (i.e., principals and assistant principals) in eight elementary schools completed self-report questionnaires that were distributed by and returned to administrative school personnel. The questionnaires were designed for the purposes of this study. The dependent variables - dosage and adherence - as well as the independent variables (i.e., factors that influence implementation) were assessed through these two questionnaires. 
Pearson correlation analyses revealed that ease of implementation and teachers' perceptions of whether students were benefiting from the program were significantly related to how frequently teachers used program materials and frequency of program implementation (i.e., dosage/exposure). Inferential statistics were not used to examine the influence of the independent variables on adherence, the second dependent variable. Factors unrelated to teachers' frequency of using program materials were whether teachers participated in training and teachers' perceptions of administrator support. Also informative were findings from an open-ended question in which teachers were asked to report ways the project activities could be better incorporated into their curriculum. Three main themes emerged: (1) updated and continued training; (2) the need for more ageappropriate materials; and (3) assistance in incorporating the prevention program into their subject areas. Although the study did not appear to specifically ask teachers the barriers they faced when implementing the program, over half (58\%) of the teachers reported they needed more time to teach the lessons.

Researchers point out that a selection bias may have influenced results since $69 \%$ of teachers did not return questionnaires, likely because teachers were asked to complete the questionnaires on their own time. Researchers concede that teachers who responded to the survey may have had a more favorable opinion towards the prevention program.

Two observations concerning the design of the study are noteworthy. First, Flannery and Torquati (1993) state the aim of the study was to assess the "degree and manner" of implementation of the prevention program. This concept, which can be broken down into two further concepts (i.e., degree of implementation and manner of implementation), was not defined. Therefore, it is ambiguous whether researchers meant 
dosage, adherence, or another aspect of implementation. Given that this study was published before Dane and Schneider (1998) proposed and defined the five aspects of program implementation (i.e., exposure/dosage, adherence, quality of program delivery, student responsiveness, and program differentiation), it may not be surprising that Flannery and Torquati (1993) did not use familiar terminology. It may also partially explain the difficulty in neatly categorizing the dependent variables (e.g., dosage, adherence) into the existing terminology. Second, it was unclear whether teachers, administrators, or both provided the data concerning the level of program implementation (i.e., how often the program was delivered to students). This is an important point since in their study, teachers delivered the prevention program, and it stands to reason that the individual who delivers the program is most aware of how much of the program was delivered to students.

Gingiss et al. (1994)

The purpose of this study was to examine teacher receptivity to tobacco prevention education and the association of those views on teachers' classroom behaviors. Specifically, the study gauged the factors that influenced the diffusion of the Smoke-Free Class of 2000, a 12-year program that provided students graduating in 2000 and their parents and teachers with tobacco prevention education. The dependent variable (i.e., dosage) and independent variables (i.e., factors that influence implementation) were measured via a self-report survey. First-grade teachers statewide were randomly selected and mailed the following items: a letter explaining the study; an incentive; a two-page self-report questionnaire; and a self-addressed stamped envelope. It was unclear whether 
the survey was developed for the purpose of this study, however, the survey was pretested with teachers and school nurses.

Analyses of variance found that three factors were significantly associated with use of tobacco prevention materials: personal involvement in teaching tobacco prevention education; teacher perceptions of intra- and inter-personal support for teaching tobacco prevention education; and school involvement in tobacco prevention. Study researchers point out that the teacher receptivity scales used in their study can help identify teachers who are both highly and poorly receptive to teaching tobacco prevention education. Highly receptive teachers can serve as leaders in the school or in training workshops, while the non-receptive teachers can be identified and steps can be taken to increase their receptivity (e.g., attend training and booster workshops).

\section{Klimes-Dougan et al. (2009)}

This study assessed provider and school characteristics that were associated with implementing the Early Risers Program, an indicated prevention program. The program, which is comprised of both family and child components, targeted aggressive children in order to prevent a number of problem behaviors, including substance use. Family advocates in 27 rural elementary schools delivered the program to students who were identified as aggressive by teachers, and their families. Exposure and adherence, two of the three dependent variables measured in the study, were assessed by family advocates logging in weekly to a Web-based monitoring system and recording their activities. Quality of delivery, the third dependent variable (which researchers later changed the terminology to quality of implementation), was measured via telephone by research personnel asking family advocates scripted questions. Independent variables were 
multiple factors that may be related to implementation and were supplied by family advocates and teachers. For the measures, researchers either adapted existing instruments or used existing measures.

Correlation analyses reported the following statistically significant factors by family advocates as associated with implementation (please note that the following abbreviations are used: $\mathrm{EX}=$ exposure/dosage; $\mathrm{AD}=$ adherence; $\mathrm{QU}=$ quality of implementation): (1) age (EX); (2) neuroticism (negative relationship) (EX, AD, QU); (3) extroversion (EX); (4) openness (EX); (5) conscientiousness (EX, AD); (6) preimplementation expectancies about the expected success of the program (EX); (7) postimplementation attitudes, such as self-efficacy and program acceptance (EX, QU); (8) reappraisal coping (i.e., how family advocates managed adversities) (EX); (9) avoidant coping (i.e., putting off attempts to solve the problem) (EX, QU); and (10) Early Risers supervisor support (EX, QU).

Correlation analyses also found the following statistically significant factors for program implementation as reported by teachers: (1) job satisfaction (negative relationship) (EX, AD); (2) motivated school culture (negative relationship) (EX); (3) individualistic school culture (negative relationship) (EX, QU); (4) supportive school culture (negative relationship) (EX, AD); (5) school culture comprised of conformity (EX); and (6) subservient school culture (EX). In other words, greater fidelity was associated when teachers reported: (a) low job satisfaction, (b) school cultures that did not promote motivation, individualism, and support, and (c) school cultures that were passive or subservient. 
It is important to keep in mind that the findings above are for both the child and family components of the Early Risers Program. It is also worth noting, as researchers point out, that family advocate and teacher characteristics most strongly correlated with exposure, moderately correlated with quality of implementation, and seldomly associated with adherence.

Klimes-Dougan et al. (2009) concluded that their findings point to specific characteristics of program providers and schools that can promote or hinder the implementation of the Early Risers Program. For instance, providers who reported low neuroticism and high openness and extroversion had higher levels of program fidelity. Given these findings, researchers bring attention to the importance of evaluating individuals and schools prior to delivering prevention programs in order to identify those most likely to possess characteristics conducive to implementing prevention programs with fidelity. As for the unexpected findings concerning some of the negative responses by teachers and fidelity of program implementation, Klimes-Dougan et al. (2009) speculated that in light of it being the first year of program delivery, and that some schools may have experienced poor organizational structures or been overwhelmed with student needs, that the family advocates confronted this challenge in a positive way. Lochman et al. (2009)

This study explored the effects of counselor and school characteristics on the implementation of an elementary school antisocial behavior prevention program that has been shown effective in reducing rates of substance use. Thirty-two counselors, who had been randomly assigned by schools to receive either basic or intensive training, delivered the Coping Power Program to: (a) students identified as aggressive by their teachers; and 
(b) their parents. (The researchers chose to pool the two training conditions for the purposes of their study.) The Coping Power Program has two components, a child component delivered during the school day, and a family component. The dependent variables were "program delivery" and "quality of counselor engagement and delivery," as stated by researchers. Program delivery was defined as the intervention objectives completed and the number of sessions scheduled. Quality of counselor engagement and delivery included aspects of the counselor's behavior, including “counselor's tone is warm and positive," and "stimulates discussion." The dependent variables were measured through audiotapes and coded by research staff. The independent variables (i.e., factors that influence implementation) were assessed by self-report surveys and completed by counselors and teachers using existing measures.

Regression analyses ${ }^{3}$ revealed that higher levels of counselor agreeableness predicted the number of objectives completed for each session by counselors. In addition, counselors who were more agreeable tended to schedule more intervention sessions. Counselor agreeableness was also positively related to engaging with parents during the parent-component sessions; engaging with parents was a measure of quality of delivery as identified by researchers. Schools that had high levels of managerial control had counselors who poorly engaged with children and parents; as previously mentioned, engagement with children and families was a measure of quality of delivery, as specified by study researchers. Lastly, counselor conscientiousness was associated with more actively engaging with children during intervention sessions.

\footnotetext{
${ }^{3}$ Lochman et al. (2009) included predictor variables in the regression analyses only if they had a significant or trend $(\mathrm{p}<.15)$ relationship to the criterion variable (p. 479).
} 
Other findings were: cynical counselors and schools permitting low levels of autonomy predicted poor engagement with children during sessions; and cynical counselors, and schools that had high levels of managerial control, had poor engagement with parents in the sessions. None of the school characteristics (i.e., cohesion, autonomy, or managerial control) influenced the number of sessions that counselors scheduled.

Lochman et al. point to two implications of the findings to increase program implementation. First, it may be helpful to screen staff and settings where the program will be implemented to identify individuals and settings that exhibit characteristics conducive to higher implementation rates (e.g., agreeable counselors and non-excessively high levels of managerial control in schools). Second, and related to the first suggestion, training workshops can inform program providers and school leadership about how personality and school factors influence implementation and work towards developing positive characteristics in order to increase program implementation.

The dependent variables examined in this study - program delivery and quality of counselor engagement and delivery - were not explicitly named as one of the five aspects of implementation as cited by Dane and Schneider (1998). Program delivery, as measured by the intervention objectives completed and by the number of sessions scheduled, may be either exposure/dosage or adherence. Unfortunately, this remains unclear. Similarly, the second dependent variable, quality of counselor engagement and delivery, may be quality of delivery, however, this too remains ambiguous. It is important for researchers to be consistent in using the same terminology when referring to the different aspects of implementation, as the different factors that predict exposure, for example, may be different than those that influence adherence (Rogers, 1995). 
Rohrbach et al. (1993)

The purpose of this study was to explore the adoption, implementation, and maintenance stages of the Adolescent Alcohol Prevention Trial program delivered by fifth grade teachers. The results presented here will focus on the findings from the implementation stage. School districts were randomly assigned to either an intensive or brief teacher training condition, in which schools were then randomly assigned to a principal intervention or no principal intervention. Participating districts were those that had taken part in Year One of the efficacy trial. Dependent variables were quantity and quality of program implementation. Quantity of program implementation was defined as exposure, or the number of program lessons delivered, and quality of implementation was defined as the extent to which a program was implemented as designed. Quantity of implementation was measured via self-report by fifth grade teachers. Quality of implementation was gauged by observers rating the teachers while they delivered the program. Items measured included class control, teacher enthusiasm, and class enthusiasm. Independent variables (i.e., factors that influence implementation) were measured via teacher and school principal self-reports. All measures were developed for purposes of this study.

Univariate tests of group differences compared non-implementers (i.e., teachers who delivered none of the 13 lessons) to implementers (i.e., teachers who delivered one or more lessons) and found that implementers reported significantly: (a) less teaching experience; (b) more experience with teaching methods that were appropriate for psychosocial-based programs; (c) more enthusiasm for the program; (d) more active participation during training; (e) stronger implementation self-efficacy; (f) better 
prepared to implement the program at the end of training; and $(\mathrm{g})$ greater encouragement from their school principal.

While the previous findings concern the quantity of program implementation, correlation analyses found the following factors that influenced the quality of program implementation by teachers: (a) overall teaching skills; (b) implementation self-efficacy; (c) program acceptance; and (d) years of teaching experience, with more years of teaching experience yielding less program integrity.

Whereas no effects were found for the teacher training condition on quantity of implementation, the principal intervention was found to significantly affect the quantity of implementation. At the end of the training, $78 \%$ of teachers had implemented one or more lessons. Yet by Year 2, only 25\% of teachers reported the delivering lessons.

Rohrbach et al. concluded that some teachers may be more appropriate than others to deliver substance use prevention programs and recommend that schools recruit and train teachers or other providers (e.g., counselors, nurses) who are skilled in interactive teaching methods and possess characteristics found in their study (e.g., selfefficacy) to increase quantity and quality of program implementation (Rohrbach et al.,1993). Given that not all teachers implemented the substance use prevention program in Year One, and that only a quarter delivered it in Year Two, researchers point out that a reason for this may be that teachers are generally held less accountable for non-academic classes and activities. To ensure widespread implementation and maintenance of prevention curricula, study researchers suggest that school districts may need to mandate these programs and develop criteria to evaluate them. 
Rohrbach et al. speculate that no differences were found between the basic and intensive teacher training on quantity of implementation because the two trainings may not have been significantly different from each other, or that teachers in the intensive training condition may have had lower levels of skills and motivation compared to teachers in the basic training condition (Rohrbach et al.,1993). The fact that the principal intervention condition was found to have higher levels of implementation suggests that 'principal encouragement' is an important factor in the amount of a prevention program that is delivered.

Although Rohrbach and her colleagues stated that quality of implementation was measured in their study, the definition proposed by these researchers (i.e., the extent to which a program was implemented as designed) does not appear to match with the items (e.g., class control, teacher enthusiasm, and class enthusiasm) that were used to assess this aspect of implementation. In fact, Rohrbach et al.'s definition appears more closely related to adherence and the items used to measure what they call 'quality of implementation' appears more closely related to the aspect of implementation called quality of program delivery, as denoted by Dane and Schneider (1998). Once again, there is confusion concerning the terminology used when referring to aspects of implementation. However, the confusion may be partially explained given that this study was published before Dane and Schneider (1998) proposed the five aspects of program implementation.

Young et al. (1986)

The purpose of this study was to determine the factors that influenced elementary school teachers in delivering a drug prevention program to students. After elementary 
school teachers attended a five-day workshop on drug prevention education, researchers mailed them a masked questionnaire from a bogus research institute with the intention that teachers would be more likely to respond in an unbiased manner if the survey was sent by an independent institution. Both the dependent variable (i.e., dosage) and the independent variables (i.e., multiple factors that may influence implementation) were measured with this questionnaire. Respondents were placed into two categories: (1) curriculum implementers (i.e., those who implemented the majority of activities); and (2) limited or non-implementers (i.e., those who never implemented activities or implemented them in a limited way).

Regression results showed that four factors influenced whether teachers implemented drug prevention education activities: perception of parental interest; perceived freedom in deciding what to teach; perception of the value of continuing education activities; and gender of the respondent. Unfortunately, researchers did not specify which gender was more likely to deliver the program.

An observation concerning the survey that researchers used is that it asked teachers questions on three different types of trainings they may have attended in the past, those being: a classroom management workshop, a basic skills area workshop, and a drug education workshop. When teachers responded to the factors that may have influenced their implementation of the drug prevention program, it appears the teachers were not responding specifically to drug prevention education activities, but in fact to all three types of workshops. If this is the case, how can it be certain that the four factors identified by teachers in the study to influence implementation of drug prevention activities are actually related to the drug prevention activities and not to the other two 
types of workshops (i.e., classroom management workshop and basic skills area workshop)?

\section{Similarities and Differences in Methodology Across Studies}

This section presents similarities and differences in the methodology and findings across the seven studies. As can be seen in Table 3, all the studies utilized a crosssectional, non-experimental research design. At times, this was a challenge to determine since at least three studies were part of a larger randomized study. For instance, although the purpose of the Beets et al. (2008) article was to assess school and teacher characteristics that influence program implementation, the ten intervention schools in which the teachers delivered the prevention program to students had been previously randomly assigned. Therefore, while random assignment was employed to evaluate the effectiveness of the intervention, random assignment was not utilized to assess the factors that influenced implementation among teachers.

Of the seven studies, all sought information from teachers, two surveyed administrators (e.g., principals, assistant principals), and one study each gathered information from family advocates, counselors, and students. Overall, three studies sought information from one group of individuals, three studies surveyed two groups of individuals, and one study collected data from three groups of respondents.

Concerning the measures utilized by researchers, all seven studies used self-report questionnaires. Most surveys were developed for the purposes of the study, while a handful either modified or used existing instruments. Statistical methods employed to analyze the data included correlational analyses, ANOVA, multiple regression, and structural equation modeling (SEM). Among the seven studies, the most advanced 
statistical technique to analyze the data was SEM and only one study employed this analysis.

The data collection method for the self-report surveys and the corresponding response rates can be found in Table 4 . Three studies mailed the self-report questionnaire to respondents, one study asked administrative personnel to distribute and collect the surveys, and three studies did not cite how survey data was obtained. Five of the seven studies reported response rates, which ranged from $31 \%$ to $85 \%$.

The seven studies identified factors that influence the implementation of substance use prevention programs in elementary schools. These factors represent the following categories: provider characteristics, program characteristics, school characteristics, training and technical assistance characteristics, and community-level characteristics.

Across the seven studies, the two categories of characteristics that were most represented by the factors that influence implementation were provider characteristics and school characteristics, as reported by program providers and other respondents (see Table 2). Provider characteristics included openness, self-efficacy, and enthusiasm of the program provider, while school characteristics included providers' perceptions of the school climate, principal support, and perceived freedom in deciding what to teach.

Overall, across studies, of the five categories of characteristics that may influence program implementation, the category of program provider yielded the most factors. In other words, of the seven studies included in the current review, the factors related to the program provider were cited most often by respondents. However, this finding does not suggest that characteristics related to the program provider most closely relate to program 
implementation. It may be that researchers across the seven studies were more interested in exploring provider factors than in program characteristics, for example. More research needs to be conducted to determine if, in fact, provider characteristics influence program implementation more than any of the four other categories.

Among the studies, there were mixed findings for several characteristics. For instance, while Beets et al. (2008) and Flannery and Torquati (1993) found that providers' beliefs about the prevention program were significant in affecting implementation, Rohrbach et al. (1993) and Young et al. (1986) did not. As for principal encouragement, Rohrbach et al. (1993) found this to be significant in influencing program implementation, yet Flannery and Torquati (1993) and Young et al. (1986) did not. Other characteristics that also displayed mixed findings were self-efficacy, training, and parent interest in the program.

A common issue across the majority of the seven studies was the inconsistent use of terminology referring to the dependent variables measured (i.e., the five aspects of implementation: exposure/dosage, adherence, quality of program delivery, participant responsiveness, and program differentiation). In fact, this issue has been repeatedly mentioned in the literature (Dane \& Schneider, 1998; Dusenbury et al., 2003). This is a problem because the factors that influence how much of the program is implemented (i.e., exposure/dosage), for example, may not be the same as those that influence how closely the program was followed the program manual (i.e., adherence). It is important for researchers to clearly state which aspect of implementation their study will assess, operationalize the concept, and specify how it will be measured. In addition, there must 
be consistent use of terminology among researchers. This is a prerequisite to identifying the factors that influence the different aspects of program implementation.

Another issue that is confusing and may warrant attention is Dane and Schneider's (1998) decision to include "quality of delivery" as one of the five ways to assess program implementation. As previously mentioned, these researchers defined this aspect of program implementation as "a measure of qualitative aspects of program delivery that are not directly related to the implementation of prescribed content, such as implementer enthusiasm, leader preparedness, global estimates of session effectiveness, and leader attitudes toward program" (p. 45). The confusion lies in the way this aspect, which is most often treated as a dependent variable in the literature, is defined. Quality of program delivery is remarkably similar to "provider characteristics," which is one of the categories found by Durlak and DuPre (2008) and Dusenbury et al. (2003) to influence implementation, and is most often used as an independent variable in studies. For instance, "implementer enthusiasm," "leader preparedness," and "attitudes towards the program" may all be construed as provider characteristics and therefore considered an independent variable. If this line of thinking is accurate, the question may naturally arise: Is it necessary to measure characteristics of the program provider as both an independent variable and a dependent variable? The method that Dane and Schneider (1998) used to identify the five aspects of program implementation was to review outcome studies that evaluated a social, behavioral, and/or academic intervention that provided sufficient information to verify program integrity. Only one study in their review (Pentz et al., 1990) used a "pure" (as cited by study researchers, p. 35) measure of quality of delivery and no significant effects of this aspect were reported. This is an issue that warrants 
further attention and clarification in the literature, specifically whether to continue to use "quality of delivery" as a dependent variable, only use provider characteristics as the independent variable, or continue to utilize both. A potential solution may be not to use the term "quality of delivery" as a dependent variable, and instead to treat provider characteristics as both an independent variable and dependent variable. This would clear up the confusion while still allowing the characteristics of the program provider to be evaluated as a potential contributor to how well a prevention program is implemented.

Yet another issue that needs clarification in the field concerns multi-year trials and whether the implementation or maintenance stage of the diffusion process is being assessed. For instance, Beets et al. (2008) surveyed teachers during years two and three of a multi-year substance use prevention trial. It is not clear from the literature whether this time period constitutes the implementation stage or the maintenance stage (M. Beets, personal communication, May 25, 2010). One potential resolution to this may be viewing the implementation stage as all the years that comprise the multi-year trial, since a single year of program implementation may not be sufficient time for teachers to develop a level of comfort in delivering the program with fidelity; after the prevention trial is over, and to determine whether schools will continue to use the program, this may be considered the maintenance stage (M. Beets, personal communication, May 25, 2010). Clarification of this point is important as research has found that different factors may influence the five stages of diffusion (Rogers, 1995).

It is interesting to note that the majority of the seven studies recommended that either program providers and/or school settings be pre-screened to identify individuals and settings that may or may not be receptive to implementing substance use prevention 
programs. Doing so can help identify: (a) providers who may be more receptive than others to teaching the program, in addition to individuals who may serve as leaders in trainings; (b) providers who have low receptivity and may need additional training or other support prior to delivering the program; and (c) schools that may need assistance in becoming more conducive to delivering a substance use prevention program.

Although only two studies (Klimes-Dougan et al., 2009; Rohrbach et al., 1993) identified training and technical assistance as a factor important in influencing program providers to implement a substance use prevention program, all seven studies recommended training prior to delivering a program. Workshop training prior to program implementation has many benefits, including offering program providers the opportunity to share solutions to implementation problems with each other (Rohrbach et al., 1993).

Rohrbach et al. (1993) also examined which individuals delivered the substance use prevention program to students. Of the seven prevention programs, five (71\%) were implemented by classroom teachers. The remaining two programs were delivered by family advocates and regular school counselors. For the prevention program implemented by family advocates, approximately half (48\%) of the family advocates were trained as social workers. None of the seven prevention programs reviewed were delivered by school social workers. These results may not be surprising given Kelly et al.'s finding that most school social workers report engaging in individual counseling sessions most of the time and not as much time as they would ideally like in prevention activities (Kelly et al., 2010).

Concerning data collection, the majority of the studies developed their own instruments. This finding may be expected given that most studies evaluate a specific 
prevention program, and therefore, measures are tailored to gauge implementation data for that program (Dusenbury et al., 2003). As these researchers point out, the challenge in developing measures has to take into account both the concept being measured and the ability to use the instrument across different types of programs (Dusenbury et al,., 2003). As Basch (1984) calls attention to, more valid measures of implementation are needed.

\section{Chapter summary}

The first part of this chapter discussed the concept of implementation and its importance. Simply put, if substance use prevention programs are not well-implemented, the likelihood increases that the program will result in poor outcomes. This translates to a diminished capacity in preventing or reducing substance use among children and adolescents. Evidence-based substance use prevention programs have been developed. The next challenge lies in identifying the factors that influence program providers in effectively delivering substance use prevention programs to students.

The findings presented in this chapter shed light on an area that is lacking in the literature - factors that influence elementary school providers in implementing substance use prevention programs - yet gaps remain. Only seven studies examining this topic exist in the literature. Additional research is sorely needed to confirm or identify new factors that influence the implementation of substance use prevention curricula in the elementary grades.

As such, the primary objective of this study was to determine the factors that influence elementary school program providers to implement effective substance use prevention programs. In selecting the independent variables for the current study, particular emphasis was placed on examining factors that have either resulted in mixed 
findings in the literature (e.g., beliefs about the program's effectiveness) or that have not received adequate attention (e.g., program complexity). The following research questions and hypotheses were informed by the existing literature previously reviewed (please see Figure 2 for the proposed model).

Objective of Study, Research Questions, and Hypotheses

QUESTION 1: What factors influence the amount (i.e., exposure/dosage) of the substance use prevention program providers delivered to students?

Hypothesis 1a: Program providers who report stronger beliefs about the program's effectiveness will report higher rates of program delivery.

Hypothesis 1b: Program providers who report stronger beliefs in their responsibility to teach substance use prevention concepts will report higher rates of program delivery.

Hypothesis 1c: Program providers who report more self-efficacy will report higher rates of program delivery.

Hypothesis 1d: Program providers who report more program complexity will report lower rates of program delivery.

Hypothesis 1e: Program providers who report more encouragement from their principal and/or district prevention coordinator will report higher rates of program delivery.

QUESTION 2: What factors influence program providers to adhere to the program manual when delivering the substance use prevention program (i.e., adherence)? 
Hypothesis 2a: Program providers who report stronger beliefs about the program's effectiveness will report higher rates of program adherence.

Hypothesis $2 \mathrm{~b}$ : Program providers who report stronger beliefs in their responsibility to teach substance use prevention concepts will report higher rates of program adherence.

Hypothesis 2c: Program providers who report more self-efficacy will report higher rates of program adherence.

Hypothesis 2d: Program providers who report more program complexity will report lower rates of program adherence.

QUESTION 3: Which group of program providers will be more likely to deliver a greater amount of the program to students?

Hypothesis 3a: Guidance counselors will deliver a greater amount of the prevention program compared to teachers.

QUESTION 4: Which group of program providers will be more likely to adhere to the program manual?

Hypothesis 4a: Guidance counselors will report greater rates of adhering to the program manual compared to teachers.

QUESTION 5: Program providers in what grades will deliver more of the substance use prevention program to students? 
Although this was an exploratory question since, to the author's knowledge, no published findings are available on this topic, a hypothesis was offered. The hypothesis is based on the limited time available to teachers in the late elementary grades (i.e., 3-5) to instruct students in subjects other than those tested in the Florida Comprehensive Assessment Test. As Rohrbach et al. (1993) point out, teachers are typically held less accountable for non-academic classes and activities.

Hypothesis 5a: Program providers teaching in the lower elementary grades (i.e., $\mathrm{K}-2^{\text {nd }}$ ) will report higher rates of program delivery compared to program providers in the upper elementary grades (i.e., $3^{\text {rd }}-5^{\text {th }}$ ).

QUESTION 6: What is the relationship between dosage and adherence among program providers?

This will be an exploratory question to examine whether and to what degree there is an association between dosage and adherence. 


\section{CHAPTER 3}

\section{METHODS}

\section{Overview of research design}

This study used a cross-sectional, mixed methods research design to assess the factors that influenced elementary school program providers when implementing a substance use prevention program. This design: (a) allowed relationships to be analyzed between the predictor variables (i.e., provider, program, and school) and dependent variables (i.e., exposure/dosage, adherence) and represented the quantitative data, and (b) provided the opportunity to explore more deeply the association between these variables via the qualitative data.

The quantitative data was collected by a self-report questionnaire which was completed by program providers in elementary schools. The IBM SPSS software (v. 19) was used for the quantitative data analysis. Pearson correlation coefficient and multiple regression analysis were employed to analyze the data. The qualitative data was gathered via in-person interviews and was analyzed with ATLAS.ti. Approval for this study was obtained from Florida International University’s Institutional Review Board (IRB) for research involving human subjects, as well as from the School District of Palm Beach County (PBCSD).

Sample - Quantitative data

Data were collected from 65 program providers who taught a substance use prevention program in elementary schools in Palm Beach County, Florida. To design a strong research methodology, the author established and maintained contact with the 
Assistant Director of the Prevention Center for the PBCSD during the 2010-2011 school year. This Department is responsible for creating a safe and drug-free environment to foster student achievement, and includes overseeing the delivery of prevention programs. Through these communications, the author was informed that two sets of individuals delivered substance use prevention programs in elementary schools - guidance counselors and teachers (K. Williams, personal communication, November 11, 2010). After obtaining approval to proceed with the study, the first step was to identify the elementary schools and individuals who taught a substance use prevention program. The Assistant Director of the PBCSD Prevention Center and her staff provided the author with a list of these schools and individuals. The list was primarily composed of guidance counselors. The PBCSD charges guidance counselors with delivering substance use prevention programs to students, as stated by the Assistant Director of the PBCSD Prevention Center. Some teachers may teach substance use prevention programs in PBCSD elementary schools, but this information was not available to the author. The second step was to contact these individuals to make sure they had, indeed, taught a substance use prevention program. Of the 105 elementary schools in Palm Beach County, 80 schools ( $76 \%$ of $\mathrm{PBC}$ elementary schools) taught a substance use prevention program during the 2010-2011 school year. Typically, one person - usually the guidance counselor - delivered the program to students. The third step was to obtain the email addresses of these program providers since the data collection was to be conducted mostly online. 


\section{Data collection - Quantitative data}

Quantitative data collection occurred during May 2011 and was gathered two ways. Participants either completed an online version of the survey via the web site, Survey Monkey or they filled out a paper version. For the online version of the survey, guidance counselors and teachers who taught a substance use prevention program were emailed a request to complete the survey, along with a link that directed them to the questionnaire and an informational memo about informed consent. Sixty-one emails were sent inviting individuals to complete the survey. Forty-eight respondents filled out the online survey (guidance counselors: $n=35$; teachers: $n=13$ ). While it may appear that the response rate was $79 \%$, the true response rate is unknown. The reason for this is because a teacher asked the author to send her a link to the survey which she would share with other teachers who had taught a substance use prevention program in her school. Although it is unknown how many teachers received the email with the survey link sent by the teacher, it is known that 13 teachers completed a survey from that link. For individuals who had not completed the survey in a timely manner, two reminders were emailed to them. The first reminder was sent one week after the survey was emailed, the second reminder was sent one week after that.

For administration of the paper version, the author attended a monthly guidance counselor meeting where program providers who taught a substance use prevention program were given an informed consent information sheet explaining the study's purpose and then completed the survey. Although 17 guidance counselors completed a survey, there were more counselors in attendance; a total count was not obtained since counselors arrived and departed the meeting throughout the day, even while the meeting 
was in progress. It was not feasible for the author to both administer and collect the survey as well as track the varied attendance of every guidance counselor. Counselors made the choice whether to complete a survey. In total, 52 guidance counselors and 13 teachers completed either an online or hard-copy version of the survey. Measures - Quantitative data

For the quantitative data collection, a 68-question survey was developed comprised mostly of closed-ended questions. Please see Appendix A for the survey. As discussed below, the survey was composed of: (a) questions gleaned from existing surveys; (b) modified questions from existing surveys; (c) and new questions developed for the purposes of this study. To ensure questions on a measure are clear and easy to understand, pre-testing the instrument is recommended (Rubin \& Babbie, 2005). As such, the survey was pre-tested with a group of 15 students from Florida International University's College of Education, including students in counseling and education who were attending a research class. Using the information gathered from pre-testing the survey, several modifications to the instrument were made to ensure it was user-friendly and easy to comprehend.

Measurement of dependent variables. This study measured the two dependent variables below.

(1) Exposure/dosage. This variable was assessed by asking program providers the following question:

$\diamond$ "How much of the substance use prevention program did you deliver to students?" Program providers chose from the following responses: (a) all program lessons; (b) most program lessons; (c) some program lessons; and 
(d) none of the program lessons. This question was developed for this study. Using the Ringwalt et al. (2003) study as a guide, respondents answered this question based on the most recent substance use prevention program they delivered to students.

(2) Adherence. This variable was assessed with the following questions:

$\diamond$ "How closely did you follow the curriculum guide in teaching the substance use

lessons?" Responses included: (a) I did not use a curriculum guide; (b) not very closely [I frequently adapted the material as appropriate]; (c) somewhat closely [I sometimes adapted the material as appropriate]; and (d) very closely [I taught the material as specified]. This question was used from Ringwalt et al.'s (2003) study and served as a continuous (4point scale) measure of program fidelity. Respondents were also asked to answer these questions based on the most recent substance use prevention program they delivered to students.

$\diamond$ "How often did you use interactive components (e.g., role playing, small group activities) during delivery of the substance use prevention program?" Responses included: (a) not at all; (b) sometimes; (c) most of the time; (d) all the time; and (e) the program did not require use of interactive components. This question was developed for this study.

$\diamond \quad$ "When delivering a substance use prevention program to students, I think it is more important to": (a) follow the program curriculum guide closely; or (b) modify the curriculum according to the needs of my students, time, 
or other considerations. This question, developed for this study, was guided by Ringwalt et al.'s (2003) previous query concerning how closely program providers followed the curriculum guide.

Measurement of independent variables. The independent variables representing the categories of provider, program, and school were assessed. The survey and interview questions were constructed by modifying existing instruments, as well as by developing new questions. Both instruments assessed factors in six areas: (1) beliefs about the program's effectiveness; (2) beliefs in their responsibility to teach substance use prevention concepts; (3) self-efficacy; (4) program complexity; (5) principal and district prevention coordinator encouragement; and (6) demographic characteristics (e.g., age, gender, grade taught).

The subscale assessing beliefs about the program's effectiveness was developed for the purposes of this study and was comprised of five items, including "My students benefit from the substance use prevention program I delivered to them," and "The program has positively affected students' classroom behavior.” Responses ranged from $1=$ strongly agree to $5=$ strongly disagree.

The subscale measuring beliefs in the program provider's responsibility to teach substance use prevention was modified from Beets et al. (2008), and was comprised of six items, including "How much responsibility should schools have in teaching students decision-making skills and peer pressure resistance skills." Responses range from $1=\mathrm{a}$ lot to $3=$ none.

The subscale evaluating self-efficacy was modified from Rohrbach et al. (1993), and was comprised of three items, including "How confident are you that you can do a 
good job teaching the substance use prevention program?" and "How confident are you that you can do a good job teaching the interactive components of the program (e.g., puppets, role-playing, etc.)?” Responses ranged from 1=very confident to $4=$ not at all confident.

The subscale assessing program complexity was developed for this study, and was comprised of six items, including "The substance use prevention program had clear goals" and "The interactive components (e.g., puppets, role-playing, etc.) were easy to implement." Responses ranged from $1=$ strongly agree to $5=$ strongly disagree. Some items included additional response choices, such as "There were no interactive components."

The subscale measuring encouragement from the principal and district prevention coordinator was modified from Rohrbach et al. (1993) and was comprised of four items, including "The principal supports substance use prevention programs being taught at my school" and "The district prevention coordinator encouraged me to teach the substance use prevention program." Responses ranged from $1=$ strongly agree to $5=$ strongly disagree.

Measurement of social desirability bias. When self-report measures are used, this opens the possibility that the study will be exposed to response bias (e.g., social desirability) (Loo \& Loewen, 2004). Simply stated, social desirability is when individuals do or say something to communicate a positive view of themselves (Rubin \& Babbie, 2005). To account for this bias, researchers have developed and tested numerous measures (Ballard, 1992; Crowne \& Marlowe, 1960; Reynolds, 1982), including long and short form scales with items ranging from 9 to 39 . While one of the most common 
instruments that measures social desirability bias is the Marlowe-Crowne Social Desirability Scale (MC-SDS) with 33 items (Crowne \& Marlowe, 1960), researchers recognize the value of using shorter scales (Loo \& Loewen, 2004), especially if multiple self-report measures will be used in a study. In an effort to evaluate and identify briefer scales, Loo and Loewen (2004) used confirmatory factor analysis, and item and scale analysis, to assess the effectiveness of numerous versions of these scales. They concluded the following: "researchers who decide to use a short version as a timesaver for participants should seriously consider using Ballard's (1992) Scale 1 or composite versions because the present study identified these as the best short versions" (Loo \& Loewen, 2004, p. 2350).

Therefore, to assess social desirability bias in this study, Ballard's (1992) Scale 1 was used. The scale is comprised of 11 items, all of which appear in the original MCSDS, and includes statements such as, "I sometimes feel resentful when I don't get my way," and "I'm always willing to admit it when I make a mistake." Respondents chose either true or false. The reliability for this scale, as demonstrated in Ballard's (1992) study, was .69.

Data management and analysis - Quantitative data

For the quantitative data, an Excel spreadsheet was used to keep track of all the program providers who completed the survey. In addition, the author created a database in SPSS with all the questions asked in the survey. After participants completed either the hard copy or the online version of the survey, the author entered all their responses into the SPSS database. Analyses were subsequently run from this database. 
Missing data. Since respondents did not answer some questions in the survey, there was

missing data associated with several questions. In these instances, values were imputed using the mean substitution, a valid option for handling missing data (Rubin \& Babbie, 2005).

Covariates/Control Variables. Analyses were conducted with and without covariates (e.g., job title, gender of respondent) in order to determine if conclusions are robust. Any demographic variable found to significantly influence findings will be included as a covariate in the primary analyses.

Descriptive statistics. Descriptive statistics were run for participants who reported responses on the dependent variables, as well as for all independent variables in the proposed model. These included the frequency, mean, median, and variance, among other statistics.

Inferential statistics. Correlation analyses were conducted to examine the relationships among study variables. When a correlation was detected, findings were reported using the Pearson correlation coefficient and two-tailed p-values. Attention was also focused on potential issues of multi-collinearity and whether hypothesized relations were as predicted. If multi-collinearity was detected, appropriate steps were taken to address it.

The primary analytical approach used in this study was hierarchical multiple regression (HMR). HMR was particularly appropriate for examining the associations hypothesized in the study's model. A host of independent variables and potential covariates were examined in separate HMR analyses with dosage/exposure and 
adherence as the criterion outcomes (i.e., the dependent variables). Separate HMR analyses were run on dosage/exposure and adherence. Variables were entered into the regression equation in the following order: (1) covariates/controls, and (2) the focal dependent variable (e.g., beliefs about program's effective). In addition, HMR analyses was conducted controlling for each of the other hypothesized predictors (e.g., beliefs about program's effectiveness controlling for self-efficacy) in order to estimate the proportion of variance independently accounted for by the focal dependent variable. Multiple logistic regression was also employed for one of the analyses in which dichotomous variables were used, and the Wilcoxon rank sum test was used to compare respondents' ordinally-valued answers.

Power analysis. Power analysis was calculated using Dr. Daniel Soper's Hierarchical Multiple Regression Power Calculator (http://www.danielsoper.com/statcalc/calc09.aspx). A priori, power analysis was conducted assuming an alpha level of $.05,3$ independent variables (i.e., a focal predictor and two covariates/controls), an observed $R^{2} \geq .05$, and a sample size of 200. Based on these assumptions, power for each HMR analysis was .78. Thus, sufficient power to detect a small-to-medium effect was expected. However, because the final sample size for the quantitative data collection was smaller than expected $(N=65)$, this led to the inclusion of the qualitative portion of the study. A posteriori, analyses using $\mathrm{p} \leq .05$, with 12 predictors ${ }^{4}$ and an observed $\mathrm{R}^{2}$ ranging from .25 to .41 with $N=65$, resulted in power ranging from .82 to .99 .

\footnotetext{
${ }^{4}$ The 12 predictors were: 6 independent variables, 5 covariates, and social desirability.
} 


\section{Sample - Qualitative data}

To recruit participants for the qualitative phase of the study, an email was sent to the 52 guidance counselors who completed the survey with a request for an in-person interview. When selecting the number of counselors to participate in the interviews, it was important to include a large enough sample to adequately explore the study variables, but also small enough to keep the study focused and manageable. Of the 13 counselors who replied and expressed interest in participating in the study, nine were chosen randomly. As an incentive to increase participation in the qualitative interviews, a $\$ 20$ gift card was offered to any local major restaurant or department store. Interviews were set up with program providers in nine different public elementary schools in Palm Beach County at a day and time that was convenient to them.

\section{Data collection - Qualitative data}

Qualitative data collection occurred during January and February 2012. Qualitative data was collected for two principal reasons. First, this method of data collection allowed the author to add depth to the quantitative findings. During this phase of the data collection, topics that were assessed during the quantitative data collection were explored at greater length and in greater profundity than that allowed by the quantitative data collection to provide a richer understanding of the phenomena conveyed by respondents. In addition, qualitative data collection permitted identification and exploration of concepts and themes not originally part of the interview questions. Second, qualitative data collection served as a method to employ triangulation of the data. One of the purposes of triangulation is to increase the validity of research findings by seeking verification between two or more sources for the data and its interpretations (Rubin \& 
Babbie, 2005). Triangulation was used in the current study in the following ways: (a) more than one method was used to collect the data (i.e., surveys for the quantitative data collection and in-person interviews for the qualitative data collection); and (b) two individuals coded the qualitative interviews (Please see Appendix C for a detailed description of the intercoder assessment procedure).

The author met individually with program providers at their school. Semistructured interviews, comprised of open-ended and close-ended questions, were conducted in either the guidance counselor's office, classroom, or other room in the school. The interviews were private between the author and the guidance counselor. Participants were given information concerning informed consent and all agreed to be tape-recorded. To record the interviews, a small battery-operated digital Sony recorder was used. A copy of all nine audio interviews were saved as a back-up. The process for each interview was generally the same and included the author asking the questions from the instrument, probing when appropriate, allowing time and space to explore digressions from the interview questions, and bringing the conversation back to focus as necessary. The interviews lasted approximately 30 minutes. After all the interviews were conducted, the author sent all nine program providers a thank you note with a $\$ 20$ gift card.

\section{Measures - Qualitative Data}

For the qualitative data collection, the interview was comprised of 10 questions, including six open-ended questions that explored the independent variables (i.e., beliefs in program's effectiveness, beliefs in school's responsibility to teach substance use prevention concepts, self-efficacy, ease of program implementation, and principal and 
district coordinator encouragement) and represented the core of the interview. Please see Appendix B for the qualitative instrument. In addition, the questions also examined the dependent variables (i.e., dosage and adherence). A detailed description of the study variables was presented in an earlier section (i.e., Measures - Quantitative data). While the quantitative and qualitative instruments were comprised of the same core questions, the qualitative data collection included several probing questions that were not part of the survey. These questions arose naturally from the interviews and were intended to delve deeper into both the quantitative findings as well as the responses interview participants provided.

Data management and analysis - Qualitative data

For the qualitative data, the author transcribed the nine interviews by playing each audio file from the back-up on the computer and typing from audio to text using the word processing program, Microsoft Word. On the transcribed files, the author noted which of the two individuals were speaking (i.e., author or guidance counselor) to ensure clarity when reading and analyzing the interviews. The nine transcripts were saved as individual files.

Once the interviews were transcribed, ATLAS.ti (v. 6) was used to analyze the data. The first step in analyzing the data was to read each interview to obtain a sense of the information provided by the participant. The second step was to begin assigning codes to phrases or sections that were considered important. A priori codes, gathered from the literature in this area, were assigned to the text in the interviews when the use of such codes was warranted (Bernard, 2011). Open codes were assigned to passages reflecting concepts that emerged from the interviews (Bernard, 2011). The third step was 
to repeat step two. Saturation was reached when the interviews yielded no further information concerning either the study variables or new topics that warranted additional exploration (Glaser \& Strauss, 1967). In the fourth step, the author merged codes if two or more codes were assigned to similar phrases or passages. Once all the interviews were coded, and codes merged as necessary, the final step was to identify themes that emerged from the interviews. In addition to noting similar, general ideas throughout the interviews, this was done in four ways (Bernard, 2011): (1) taking note of words and phrases in the interviews that were important; (2) using general themes drawn from the literature and the research questions (e.g., program effectiveness, confidence), as well as allowing more themes and subthemes to emerge while analyzing the transcripts; (3) identifying repetitions among the interviewees (e.g., time); and (4) looking for unusual words or common words used in unfamiliar ways (e.g., The Wheel).

To increase the validity and trustworthiness of the data, an independent coder also coded the data (Rubin \& Babbie, 2005) (please see Appendix C for a detailed description of the intercoder assessment procedure). Intercoder reliability is the degree to which an independent coder evaluates characteristics of text, for example, and arrives at the same conclusions as another coder (Lombard et al., 2002). Intercoder reliability is said to be "near the heart of content analysis; if the coding is not reliable, the analysis cannot be trusted" (Singletary, 1993, p. 294). To measure intercoder reliability, two or more coders categorize units - or words, in the current study - and use the categorizations to calculate a numerical index of the degree of agreement between the coders (Lombard et al., 2002). A widely accepted index is the Cohen's kappa (Lombard et al., 2002). The kappa reflecting intercoder agreement can range from -1 to 1 , with 1 signifying perfect 
agreement. The kappa coefficient was calculated using SPSS. It is important to note that while there are no set requirements to determine an acceptable level of reliability, there are rules of thumb (Lombard et al., 2002). The following standards were originally proposed by Landis and Koch (1977) and are still cited by present-day researchers (Hruschka et al., 2004): almost perfect $=0.81-1.00 ;$ substantial $=0.61-0.80 ;$ moderate $=$ $0.41-0.60 ;$ fair $=0.21-0.40 ;$ slight $=0.00-0.20 ;$ and poor $<0.00$. Following Burla et al.'s (2008) lead in which the researchers randomly selected $20 \%$ of interviews for coding by a second coder and achieved a ““substantial” kappa (i.e., 0.67), the present study randomly selected $33 \%$ of the interviews to be coded by a second coder. Results are presented in the next chapter. 


\section{CHAPTER 4}

\section{RESULTS}

This section presents the findings for both the quantitative and qualitative data. Presented first will be the quantitative analysis, followed by the qualitative findings. Quantitative Findings

The IBM SPSS software (v.19) was used to analyze the quantitative data. A total of 65 respondents completed the survey. Of these, 48 individuals (74\%) completed the survey online on the Survey Monkey web site, while the remaining 17 respondents (26\%) filled out a hard copy version.

\section{Demographic Characteristics}

Table 5 shows the demographic characteristics of participants. The majority of the sample was female (91\%) and White (85\%). Sixteen percent were Hispanic. Guidance counselors comprised $77 \%$ of the sample, while teachers made up the remaining $23 \%$. The mean age of participants was 47.34 years $(S D=11.50)$. Over three-quarters of respondents held a Master's Degree (76\%), and 74\% had taught substance use prevention curricula for more than six years $(M=11.44 ; S D=8.28)$.

When asked to identify the most recent time they taught a substance use prevention program, $78 \%$ of respondents $(n=50)$ reported it was during the year in which data was collected, while $16 \%(n=10)$ said within one of the three years prior to data collection. Six percent $(n=4)$ did not implement a substance use prevention curricula to students within the past four years. Ninety percent $(n=45)$ of respondents taught the substance use prevention program Too Good for Drugs - the primary substance use 
prevention program used by the SDPBC, $-13 \%(n=7)$ delivered other programs, and $2 \%$ $(n=1)$ were not sure which substance use prevention program they delivered to students. Preliminary Findings and Scale Reliabilities

Dependent variables

\section{$\underline{\text { Dosage }}$}

When respondents were asked "How much of the substance use prevention program did you deliver to students?," $34 \%(n=20)$ reported all program lessons, 37\% $(n=22)$ reported most program lessons, and 29\% $(n=17)$ implemented some of the lessons. No reliabilities are reported for this variable since only one question assessed the dependent variable.

\section{Adherence}

Three items were used to measure this outcome. When asked "How closely did you follow the curriculum guide in delivering the substance use prevention lessons?," $27 \%(n=16)$ followed it "very closely," $61 \%(n=36)$ of respondents reported "somewhat closely," 7\% $(n=4)$ reported "not very closely," and 5\% $(n=3)$ decided not to use a curriculum guide. Concerning how often program providers used interactive activities such as puppets or role playing, $29 \%(n=17)$ reported all of the time, $37 \%(n=22)$ reported most of the time, $27 \%(n=16)$ sometimes, $3.4 \%(n=2)$ not at all, and 3.4\% $(n=2)$ said the program did not involve using interactive components. When asked whether it was more important to follow the curriculum guide closely in implementing a program or to modify it according to the needs of students, time, or other considerations, $86 \%(n=50)$ reported modifying the curriculum was more important compared to $14 \%(n=8)$ who said following it exactly was more important. No reliabilities are reported for this variable 
since the three questions used to measure adherence were treated individually, and not combined, because different scales were used for the questions. For instance, for the three questions measuring adherence, the answer choices ranged from two to five choices, with none of the answer choices being the same across the questions.

\section{Independent variables}

Five independent variables were measured. The means, standard deviations, and internal consistencies, as measured by Cronbach's alpha, yielded the following which can also be seen in Table 6: "beliefs about the program's effectiveness," (ex., "My students benefit from the substance use prevention program I delivered to them.") with answer choices ranging from 1 to 5 ( $5=$ strongly agree): $M=4.10, S D=.51, \alpha=.89$; "beliefs about the school's responsibility to teach substance use prevention," (ex., "How much responsibility should schools have in teaching students to develop peer pressure resistance skills?") with answer choices ranging from 1 to 3 ( $3=\mathrm{a}$ lot): $M=2.75, S D=.38$, $\alpha=.94)$; "self-efficacy," (ex., "How confident are you that you can do a good job teaching the substance use prevention program?") with answer choices ranging from 1 to 4 (4=very confident): $M=3.65, S D=.49, \alpha=.84$; "ease of program implementation"," (ex., "The substance use prevention lessons were easy to implement.") with answer choices ranging from 1 to 5 ( $5=$ strongly agree): $M=4.37, S D=.59, \alpha=.86$; and "principal encouragement," (ex., "The principal encouraged me to teach the substance use prevention program.”) with answer choices ranging from 1 to 5 (5=strongly agree): $M=3.89, S D=.79, \alpha=.77$. Originally, the variable "principal and district prevention

\footnotetext{
${ }^{5}$ From this point on, the variable "program complexity" will be referred to as "ease of program implementation." This was done to make the results easier to understand given that the questions on the survey to assess this variable were phrased in a positive manner (e.g., The substance use prevention lessons were easy to implement.).
} 
coordinator encouragement" was to be measured together. However, since a small Cronbach's alpha (.61) resulted for this variable, a decision was made to separate the principal encouragement variable from the district prevention coordinator variable, resulting in $\alpha=.77$ for principal encouragement, which included two questions. Findings for both principal encouragement and district prevention encouragement will be presented. Frequency plots for the independent variables can be found in Figures 3-7.

\section{Social desirability}

Social desirability scores for the measure used could range from 0 to 13 , with low scores indicating someone who has low reporting bias and is not answering questions in a socially-desirable manner. In research studies, the goal is typically to demonstrate low social desirability to ensure participants are not responding to questions in order to convey a positive view of themselves (Rubin \& Babbie, 2005). This study revealed participants scored on the higher end of social desirability $(M=8.14 ; S D=2.84)$, suggesting a higher response bias. As such, social desirability was controlled for in all the correlation analyses. Internal consistency for this scale, as estimated by Cronbach's alpha, was .72.

\section{Correlation Findings}

Next, results for each of the research questions are presented. Pearson correlations can be found in Tables 7 and 9-10.

Research Question 1: What factors influence the amount of the program delivered to students? (This question measures the dependent variable 'dosage.') Years working at current school $(r=-0.29, p<.05)$ and ease of program implementation $(r=0.32, p<.05)$ were associated with more program delivery (Table 7). Program providers who had 
worked at their current school for less time, and those who believed the program was easy to implement, reported greater rates of program delivery. Factors not related to program delivery were gender, race, Hispanic status, age, years working at schools overall, years teaching substance use prevention curricula at current school and overall, beliefs about program's effectiveness, beliefs about the school's responsibility to teach substance use prevention curricula, self-efficacy, principal and district prevention coordinator encouragement, and social desirability.

Research Question 2: What factors influence program providers to adhere to the program manual when delivering a substance use prevention program? (This question measures the dependent variable 'adherence.') Following the curriculum guide closely was associated with stronger beliefs that the program was easy to implement $(r=0.56, p$ $<.001)$, stronger beliefs about the program's effectiveness $(r=.31, p<.05)$, and marginally associated with being non-White $(r=-0.25, p=.07)$ (Table 7). In other words, participants were more likely to adhere to the curriculum guide if they reported the program was easy to implement, believed the program was effective, and were not White. Factors not related to following the curriculum guide closely were gender, Hispanic status, age, years teaching at current school and overall, years teaching substance use prevention curricula at current school and overall, beliefs about school's responsibility to teach substance use prevention, self-efficacy, principal and district prevention coordinator encouragement, and social desirability.

Frequency using interactive components was correlated with stronger beliefs that the program was easy to implement $(r=0.54, p<.001)$, stronger beliefs about the program's effectiveness $(r=0.32, p<.05)$, and higher self-efficacy $(r=0.33, p<.05)$ 
(Table 7). In other words, interactive components were used more often by participants who believed the program was easy to implement, believed the program was effective, and reported more self-confidence in their ability to implement the program. Frequency using interactive components was also marginally associated with being non-White $(r=-$ $0.25, p<.10$ ) and receiving less encouragement from the district prevention coordinator $(r=-0.23, p<.10)$. Participants who reported a race other than White used interactive components more frequently than those who were White. Interestingly, less encouragement from the district prevention coordinator was associated with higher rates of using interactive components. Factors not related to frequency using interactive components were gender, Hispanic, status, age, years teaching at current school and overall, years teaching substance use prevention curricula at current school and overall, beliefs about school's responsibility to teach substance use prevention, principal encouragement, and social desirability.

Lastly, beliefs that it was more important to modify the curriculum according to the needs of students, time, or other considerations compared to following it closely was associated with more years working in schools overall $(r=0.33, p<.05)$, and marginally associated with age $(r=0.26, p<.10)$ and ease of program implementation $(r=0.24, p<$ .10) (Table 7). Participants who had worked in schools longer, were older, and believed the program was easy to implement were more likely to modify the curriculum. Factors not related to this variable were gender, race, Hispanic status, years teaching substance use prevention curricula at current school and overall, beliefs about program's effectiveness, beliefs about the school's responsibility to teach substance use prevention curricula, self-efficacy, principal encouragement, and social desirability. 
Research Question 3: Which group of program providers will be more likely to

deliver a greater amount of the substance use prevention program to students?

No significant findings were found for this question. Table 8 illustrates the percentage of lessons taught by program providers. Of participants, $93 \%$ of teachers implemented 'all' or 'most' program lessons compared to $65 \%$ of guidance counselors. While these findings suggest that teachers delivered more of the curriculum to students compared to guidance counselors, mean rank scores at .05 alpha level using Wilcoxon rank sum test did not find a significant difference $(z=0.87, p=.38)$. It is also important to note the small sample size of teachers for this question ( $n=13$ teachers compared to $n=46$ guidance counselors).

Research Question 4: Which group of program providers will be more likely to adhere to the substance use prevention program manual?

No significant findings were found for this question. Table 8 shows the percentage of adherence based on the type of program provider. All teachers (100\%) followed the curriculum guide either 'very closely' or 'somewhat closely' compared to $85 \%$ of guidance counselors. As for using interactive components, $78 \%$ of teachers used these components compared to $66 \%$ of guidance counselors. Lastly, $77 \%$ of teachers reported it was more important to modify the curriculum according to the needs of their students, time, and other considerations compared to $89 \%$ of guidance counselors. Although teachers, compared to guidance counselors, followed the curriculum guide more closely, used interactive components more frequently, and were more likely to believe it was more important to follow the curriculum guide closely, mean rank scores at a .05 alpha level using Wilcoxon rank sum test did not find a significant difference for 
any of these findings $(z=0.41, p=.68 ; z=.76, p=.45$; and $z=1.09, p=.28$, respectively). As previously mentioned, it is important to note the small sample size of teachers for these questions ( $n=13$ teachers compared to $n=44-46$ guidance counselors).

$\underline{\text { Research Question 5: In what grades will program providers deliver more of the }}$ substance use prevention program to students?

It was not possible to analyze this question with the quantitative data. Too few teachers took part in the study to allow for comparisons between teachers and guidance counselors. For example, only one teacher reported teaching Kindergarten or third grade, and five teachers reported teaching fifth grade. Despite the lack of quantitative findings, this question was explored via interviews with guidance counselors to determine if the interviews shed light on this question.

Research Question 6: What is the relationship between dosage and adherence among program providers? A Pearson product-moment correlation was computed to assess the two dependent variables - dosage and adherence (Table 9). Greater amount of program delivery was associated with frequency using interactive program components $(r$ $=0.30, p<.05)$. Also, closely following the curriculum guide $(r=0.27, p=.05)$ approached significance. In other words, guidance counselors and teachers who used interactive components such as puppets and role playing more frequently and those who adhered to the curriculum guide delivered more of the substance use prevention program.

In addition, a correlation among the adherence variables was also found. Following the curriculum guide closely was associated with greater frequency of using interactive components $(r=0.39, p=.01)$, meaning that participants who adhered to the program were more likely to use interactive components. In addition, following the 
curriculum guide closely was also correlated to beliefs that it is more important to modify the curriculum based on time, students, or other considerations when delivering a substance use prevention program $(r=0.35, p<.05)$.

\section{Findings - Independent variables}

Several significant relationships were also found among the independent variables (Table 10). Stronger beliefs about the program's effectiveness was associated with beliefs that the program was easy to implement $(r=0.54, p<.001)$, and marginally associated with higher self-efficacy among program providers $(r=0.26, p<.10)$, and receiving support from both the principal $(r=0.26, p<.10)$ and the district prevention coordinator $(r=0.27, p<.10)$ to teach the program. In other words, participants who believed in the effectiveness of the program reported that the program was easy to implement, high selfconfidence, and received more support from the principal and district prevention coordinator to implement the program. In addition, stronger beliefs that the program was easy to implement was related to higher self-efficacy among program providers $(r=0.40$, $p<.01)$, meaning that participants who believed the program was easy to implement reported more self-confidence. The only independent variable not associated with any other independent variable was beliefs about the school's responsibility to teach substance use curricula.

Significant relationships were also observed between the demographic and independent variables (Table 10). Older respondents $(r=0.33, p<.05)$ were more likely to report that the program was easy to implement. Also, program providers who had more years teaching substance use prevention overall, including in their current school, reported higher self-efficacy $(r=0.35, p=.01)$, as well as receiving encouragement from 
their principal to teach the program $(r=0.36, p=.01)$. In addition, respondents who had a Bachelor's degree reported receiving more encouragement from the district prevention coordinator compared to respondents who had a Master's degree $(r=0.34, p<.05)$. Lastly, there was a marginal significance between providers who had worked in their current schools for more years and higher self-efficacy rates $(r=0.23, p<.10)$.

No significant relationships were found for gender, race, Hispanic status, years working at schools overall - including their current school - and years teaching substance use curricula at current school.

\section{Regression Findings}

Hierarchical multiple regression was employed to further analyze the strength of the relationships among study variables. Due to the small sample size $(N=65)$, mean substitution for missing data was used in the regression analyses (Rubin \& Babbie, 2005). For every variable with missing data, the average of all the values for that variable was used (Rubin \& Babbie, 2005). This procedure allowed the sample size to increase from 48 to both 59 and 65 in the regression analyses. Missing observations ranged from one on

the variable, Years Working At Current School and Overall, to nine on the variables age, ease of program implementation, and self-efficacy.

For each regression, two models were run. The variables entered into each model were determined by the variables found to be significant in the correlation analyses. An effort was made to use the fewest number of significantly correlated variables to predict the dependent outcomes. These steps allowed for a more parsimonious model to emerge.

For the first model, variables entered consisted of gender, race (White), possessing a Bachelor's or Master's Degree, years teaching overall, including in their 
current school, and years teaching substance use prevention overall. For the second model, variables entered consisted of the independent variables - beliefs about the program's effectiveness, beliefs about ease of program implementation, self-efficacy, beliefs about school's responsibility to teach substance use prevention, principal encouragement and district prevention coordinator encouragement - as well as social desirability. Results are presented next and appear in Tables 11-13.

\section{$\underline{\text { Dosage }}$}

The multiple regression model for 'dosage' consisting of all the independent variables, including social desirability, was not significant, $R^{2}=.25, F(12,52)=1.42, p=$ .19. Significance may have been detected if the sample size had been larger. However,

results revealed ease of program implementation marginally predicted amount of program delivery when all other variables were held constant $, \beta=.30, p=.08$. In other words, ease of program implementation emerged as a marginally significant predictor, indicating that participants who reported the program was easy to implement delivered more of the program.

\section{Following the curriculum guide}

The multiple regression model for 'following the curriculum guide' consisting of all the independent variables, including social desirability, was significant, $R^{2}=.39$, $F(12,52)=2.74, p=.01$. Control variables accounted for $13 \%$ of the variability in following the curriculum guide, while the independent variables added another $26 \%$ and were significant $[F(7,52)=3.10, p=.001]$. Ease of program implementation $(\beta=.54, p$ $<.01)$ significantly predicted following the curriculum guide closely. In other words, 
participants who followed the curriculum guide closely reported the program was easy to implement.

\section{Frequency using interactive components}

The multiple regression model for 'frequency using interactive components' consisting of all the independent variables, including social desirability, was significant, $R^{2}=.41, F(12,52)=2.95, p=.003$. Control variables accounted for $8 \%$ of the variability of frequency using interactive components, while the independent variables added another $33 \%$ and were significant $[F(7,52)=4.12, p=.001]$. Frequency using interactive components was significantly predicted by receiving less encouragement from the district prevention coordinator $(\beta=-.32, p=.011)$, and marginally predicted by being non-White $(\beta=-.20, p=.07)$, self-efficacy $(\beta=.22, p<.10)$, and ease of program implementation $(\beta=.26, p<.10)$. In other words, interactive components were used more often when participants reported less encouragement from the district prevention coordinator, belonged to a race other than White, had more self-confidence in their ability to implement the program, and believed the program was easy to implement.

What is more important - Following the curriculum guide closely or modifying the curriculum guide

The multiple logistic regression testing whether it was more important for participants to follow the curriculum guide closely or modify it according to time, the needs of students, or other considerations was not significant, $\chi^{2}(12, N=65)=15.17, p=$ .232. The independent variables explained between 27\% (Cox and Snell) and 46\% (Nagelkerke) of the variability of whether it was more important to follow the curriculum

guide closely or to modify it, but it was not significant, $\chi^{2}(7, N=65)=5.54, p=.594$. 
Years working at school overall approached significance, $p=.055, \mathrm{OR}=1.19$, meaning that for each additional year of teaching overall, participants were 1.19 times more likely to follow the curriculum guide closely.

\section{Other Findings}

$\underline{\text { Comparisons between guidance counselors and teachers }}$

Respondents who participated in this study were either guidance counselors or teachers. Only three individuals in the sample possessed a degree in social work; two guidance counselors and one teacher held an MSW. When comparisons were made between these two groups using an independent samples t-test, several significant differences were found. Compared to teachers, guidance counselors were older $t(53)=-$ $2.02, p=.05$, and reported receiving more encouragement from the district prevention coordinator $t(54)=2.03, p=.05$, but less encouragement from the principal $t(54)=2.37, p$ $=.02$. In addition, significantly more guidance counselors $(100 \%)$ had a Master's degree compared to teachers $(14 \%)\left(\chi^{2}(1, n=59)=48.42, p<.001\right)$.

\section{$\underline{\text { Training }}$}

When participants were asked the most recent time they received training to teach the substance use prevention program, only $15 \%$ reported the current school year, $16 \%$ said the previous school year, and $42 \%$ reported two or more years before. Twenty seven percent of participants $(n=15)$ did not receive training to implement the substance use prevention program, while $73 \%(n=40)$ received training. No significant differences were found between guidance counselors and teachers on training status as tested by ChiSquare at a .05 alpha level. 
Participants were significantly more likely to report the program was easier to implement if they had not received training $(M=4.62)(5=$ strongly agree $)$ compared to those who received training $(M=4.24), t(52)=2.15, p<.05$. Potential explanations for this finding may be that: participants who attended training were more realistic about the effort and time involved to teach the program effectively; training negatively affected performance by participants; and non-trained participants implemented an easier program.

In addition, a marginally significant finding was demonstrated concerning amount of program lessons implemented by training status. Sixty percent of participants who had not received training to implement the program $(n=9)$ delivered "all program lessons" compared to $28 \%(n=11)$ who received training $\chi^{2}(2, n=55)=5.09, p=.08$. Potential explanations for this outcome include the same as those mentioned in the previous paragraph, as well as the possibility that non-trained participants overestimated the amount of lessons they implemented. Despite the previous finding, results also showed that of participants who received training, $43 \%(n=17)$ implemented "most program lessons," compared to $20 \%(n=3)$ who had not received training.

\section{Encouragement to teach substance use curricula}

Table 14 shows the level of encouragement offered by the principal or district prevention coordinator to respondents to teach the substance use prevention program. As the table shows, $79 \%$ of program providers either strongly agreed or agreed that the district prevention coordinator encouraged them to implement the program, while $50 \%$ either strongly agreed or agreed that the principal encouraged them to deliver the program. When asked what other individuals encouraged them to implement the 
program, participants reported the following: guidance counselor (35\%), assistant principal (20\%), classroom teachers (20\%), parents (12\%), and others $(8 \%)$.

\section{$\underline{\text { Program sections not implemented }}$}

When asked in an open-ended question in the survey to identify the most challenging aspect about delivering the substance use prevention program, $47 \%(n=16)$ of participants reported 'time.' Several program providers noted that they are given 30 minutes to deliver the lessons, yet many times, the lessons take 45 minutes to implement. The second most common answer, given by $9 \%(n=3)$ of respondents, was making sure the lessons were developmentally-appropriate for students. For example, all three program providers expressed concern over ensuring the program fit the needs and grade level expectations for their students.

When asked in an open-ended question in the survey to identify which sections or components of the substance use prevention program they did not implement, participants reported the following examples: games or activities $(n=3)$, home-based component or worksheets $(n=2)$, and marijuana lessons to intermediate classes $(n=1)$. Qualitative research findings discussed shortly may shed light on potential reasons for these responses.

\section{$\underline{\text { Percentage of time guidance counselors spend per week on responsibilities }}$}

Lastly, Figure 8 shows the mean percent time guidance counselors spend per week on activities (it should be noted that counselors' responses did not always add up to $100 \%$ ). When counselors were asked to respond with percentages to the open-ended question "How much of your time per week do you dedicate to the following activities?," they reported the following: classroom activities (41\%), individual counseling (36\%), 
administrative tasks (20\%), group activities (14\%), family-based practice (8\%), and other activities (19\%), which included responsibilities such as attending meetings, teaching character education classes, performing lunch duty, and tutoring.

\section{Qualitative Findings}

Up until this point, the quantitative results of the current study have been discussed. This section presents the qualitative findings. The findings are based on nine interviews with elementary school guidance counselors in Palm Beach County schools that taught a substance use prevention program. Eight of the counselors were female; one was male. All counselors taught the Too Good for Drugs (TGFD) program. Intercoder reliability, as measured by Cohen's kappa, was 0.61 . This represents “moderate to substantial" agreement as proposed by Landis and Koch (1977) and cited by Hruschka et al. (2004) (please see Appendix C for a detailed description of the intercoder assessment procedure).

Following is a discussion of the themes that emerged from the interviews. To illustrate these themes, excerpts from participants are presented.

Curriculum modification. All nine counselors altered the TGFD program when delivering it to students. Modifying the curriculum included two main activities: (1) changing the amount of the program lessons delivered to students; and (2) changing how closely the program provider followed the curriculum guide. It is important to point out that these two activities represent both of the dependent variables of this study - dosage and adherence. Specific examples of modifying the curriculum included: not delivering the whole program; skipping, combining, and rearranging lessons; not teaching the entire 
lesson; not using the interactive components (e.g., puppets); not adhering to the curriculum manual; adding material other than the TGFD program to the lessons; and not teaching the program to all grade levels. Six of the nine counselors (67\%) added supplementary substance use prevention material when teaching the TGFD program. The reasons why counselors modified the program, another theme that emerged from the analysis, will be discussed later.

I extract certain lessons out of it and try to skip over some...So in other words, yeah, I teach it. I don't teach it page per page, lesson per lesson.

I just pick a couple of lessons, you know, I pick a few lessons that I think are important, and then I just work off of that.

You take what you want to use. Make it yours.

[I taught] most [of the lessons] and plus supplemental [material, such as the video] Natural High, and I have other things that I get from the company, and things that I pulled offline, things from the prevention center...

Puppets are not really always accepted.

Difficulty of program implementation. Another theme in the interviews was difficulty implementing the program. This was mentioned by all of the guidance counselors and was also the most prevalent theme representing the independent variables. (For the purposes of coding the interviews, the author decided to separate one of the independent variables - 'ease of program implementation' - into two variables, that being 'difficulty of program implementation' and 'ease of program implementation.' The rationale behind this was to determine the factors that made the program both easier and 
more difficult to implement.) Frequently cited reasons for running into challenges when delivering the program were time constraints, scheduling, and figuring out how to respond to personal stories or questions related to substance use that students shared in class. Other reasons included differences in students' maturity and developmental learning abilities.

It's principally time. The lessons are pretty in-depth, and I only have about 20 minutes to do a lesson when I see them. And I have a lot of other requirements human growth and development, different bullying, I do a whole character education with them, respect, responsibility. Substance abuse and alcohol is not getting in my curriculum. But I put it in as much as I can. [the last two sentences referred mostly to $3^{\text {rd }}-5^{\text {th }}$ grade classes]

The hardest thing was scheduling. Scheduling time and making [the lesson] 20 minutes to 30 minutes and not taking up the whole... whatever it is... 50 minutes of the classroom time. Now it's even worse because of the FCAT clash.

Maybe I have difficulty with... knowing the boundaries between this is what I'm teaching you at school, and that is your home life. There's a fine line between telling their parents what they need to do, or not do, right?... I had difficulty trying to get the kids to understand that [I, as] the guidance counselor, isn't saying to you that your mom needs to stop smoking, or she is going to have cancer. And that was difficult for me because the next day, this little first grader would come to school in tears and say, "My mom won't quit smoking." So I preface...the lesson... and say [I'm] not telling your parents, your parents are making their choices.

Justification for curriculum modification. A third theme that emerged was

guidance counselors explaining why they had modified implementing the TGFD program. Responses included: it depends on the needs of the students; their demographics; their maturity level; whether the lesson was appropriate; time constraints; scheduling; disadvantaged neighborhood surrounding school; and counselors' beliefs that they had latitude when delivering the program. 
If you don't modify your curriculum according to the needs of the kids, you are practically not meeting the needs for those kids. So you definitely have to customize it.

I suspect with certain kids you have to make it a little bit more relevant, or some kids are more mature and the puppets may not be relevant, the puppets might not be cool so to speak, so you'd have to change.

I think they really need to see current role models in life. Like I added... [Natural High] ... a DVD and they're real stories, tragedies that stars have had. They're everyday people like athletes... There are singers, there are athletes, there are professionals. I think it was a lot more meaningful for the $5^{\text {th }}$ graders, versus the silly aspects of what the younger kids are learning.

It's just the scheduling...that determines how many lessons are taught.

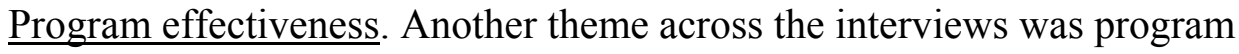

effectiveness. It was also the second most prevalent theme of the independent variables.

All nine guidance counselors had their own beliefs as to the effectiveness of the substance use prevention program. When asked about their thoughts concerning the effectiveness of the TGFD program, six counselors reported the program was good, excellent, effective, important, or a combination of these responses. Two other counselors commented that the program may need to be updated.

I think it's interesting enough to keep the children's attention.

...kids have come back from middle school and told me, "Hey, the things you taught me, you know, with Carmen and Wagner and Tuggles," cause the kids love those puppets, and I ham it up a lot. They really work. So I am a proponent of the Too Good for Drugs program.

I think that it gives the kids the freedom to believe that they're not the only ones, that they have this big secret that they're hiding, and then if we talk about it openly it makes them realize that it is really out there and it's not just my mom or 
it's not just my dad or something like that.

I think it's effective and it will pay [off] in the long run.

Overall, the basics of [the activities] and the point they're trying to get across is very good. [But] I think that it probably needs to be updated a little...Somebody needs to go through and get some more hands on activities, get them up out of their seats a little bit more.

Three interconnected themes. Three other themes emerged as significant and interconnected among the guidance counselors when discussing the implementation of the substance use prevention program. These themes are: The Wheel, time, and scheduling. Due to the "interconnectedness" of the themes, some degree of overlap in the following text and excerpts will be evident.

The Wheel. The concept of The Wheel was mentioned during the first interview with a guidance counselor, and because of its potential role in delivering substance use prevention lessons to students, the author asked all guidance counselors about their experiences with The Wheel. As understood, The Wheel is a way for schools to structure the school day. Classes that are part of The Wheel are those known as the 'fine arts classes' and include: art, music, physical education, guidance, and media. In addition, The Wheel affects how often guidance counselors see students in a classroom setting. For instance, seven out of the nine counselors (78\%) were on The Wheel, and the amount of time that they saw the same group of students in the classroom ranged from every six days to every two and a half weeks. When asked what influences, and who decides, whether a school participates on The Wheel, the counselors responded: the principal, the number of students/the number of classes per grade level, and scheduling. 
Every school deals with their classroom set up in the wheel and their fine arts differently.

We are part of the fine arts team for teaching. And what happens is the schools get so big, so they need to justify how to split the kids to give the teachers a break...And what we do is, we have art, we have music, we have media, we have P.E., we have guidance, and we're doing science, science lab. So, we have 6, and so like in these 6 classes, we accommodate all the school.

So I will see three classes a day because guidance and media center split a slot so I'll take the morning classes and she'll take the afternoon classes.

Because we also take 3 classes a day, it does take longer to see everybody.

[The] Classroom Teachers Association, our union states that every single teacher that has a classroom has to have a 30-minute break. So, because of that, you have to have somebody on campus to take those kids for 30 minutes, that's how you have the wheel.

I don't think we're necessarily taken seriously when we are on the fine arts wheel...I feel like we're just overpaid babysitters sometimes.

Interviewer: What challenges have you come across when delivering the Too Good for Drugs program?

Counselor: Time constraints from the teachers in the classroom, it's all about time. They like it when I come, then they don't have to teach. I hate [the wheel].

Time. Time was a theme that emerged from six of the nine $(67 \%)$ counselor interviews. Time significantly affected the amount of the substance use prevention program that counselors delivered to students. The amount of time counselors had to implement each lesson ranged from 20 to 30 minutes. Several counselors reported this 
was not enough time to deliver the lessons, citing that the lessons took approximately 45 minutes to implement.

I don't teach it in, in full, because of time constraints due to everything else that needs to be taught.

These lessons are for 40 to 45 minutes, and I'm only getting 30 minutes. So, I have to either go a little bit faster or modify slightly.

...The classes are only 25 minutes long...so it's hard to get in one complete lesson.

Harder to get time [to deliver the program to older students] ...but see, they've already had it, kindergarten, $1^{\text {st }}$, and $2^{\text {nd }} . .$. that's the part that makes it okay for me.

Scheduling. Scheduling was another noteworthy theme among the interviews.

Many counselors cited scheduling as a challenge in delivering the substance use prevention program to students. Scheduling was closely linked to time, and both themes were tied to The Wheel.

I think for the first year, [teaching the program] was kind of difficult because of scheduling...It's just the scheduling of it.

I like the wheel and I don't, because I think that the wheel locks us into a very rigid schedule, where I literally...don't have time to go to the bathroom...so it's not what I envisioned...

Interviewer: What influences how many times you're able to see students a year?

Counselor: It's all on scheduling. If we have a certain number of classes in a grade level, if there are a lot of classes, we'll have more days between seeing [students] again, so that means I'll [teach] less lessons because I don't see them as much, as often. 
I don't go into [the lessons] probably as much as I should, because of time...schedule.

$\underline{\text { In what grades will program providers deliver more of the substance use }}$ prevention program to students?

Although it was not possible to answer this question with the quantitative data due its limitations, the qualitative data allowed this question to be addressed. It was hypothesized that program providers teaching in the lower elementary grades (i.e., K-2 ${ }^{\text {nd }}$ ) would report higher rates of program delivery compared to program providers in the upper elementary grades (i.e., $\left.3^{\text {rd }}-5^{\text {th }}\right)$. Five of the nine guidance counselors $(56 \%)$ taught a substance use prevention program to students in grades K-5; three counselors (33\%) delivered the program mostly to grades K-2; and one counselor (11\%) implemented the program in grades 3-5. Given that the majority of guidance counselors taught the program to all the grades, the hypothesis was not supported. Despite the hypothesis not being supported, it may be noteworthy to explore the reasons why three counselors implemented the program mostly to grades K-2.

One counselor disclosed that she taught some substance use prevention information to students in grades 3-5, but she didn't go into it as much as she should because of time constraints and scheduling. It is important to point out that testing for the Florida Comprehensive Assessment Test (FCAT) begins in third grade, and that may explain the time constraints faced by the guidance counselor. As will be seen below, a guidance counselor alludes to the FCAT as a reason why she did not teach the program to the older grades. 
The second counselor reported that it was easier to deliver the program to the younger grades, while it was more difficult to get time with students in grades 3-5. When asked if the older students did not receive as much of the program as the younger students, the counselor responded:

Yeah, but see they've already had it, Kindergarten, $1^{\text {st }}$, and $2^{\text {nd }}$. That's the part that makes it okay for me...

The same counselor suggested that the Florida Comprehensive Assessment Test (FCAT) was a major decision in the grades in which she delivered the prevention program.

The main [grades] that aren't doing FCAT are Kindergarten, $1^{\text {st }}$, and $2^{\text {nd }}$, and that's where we concentrate more. Because, actually, if you think about it, that's the foundation.

The day the students enter this class, enter this school in August, the teachers start with FCAT. FCAT, FCAT, FCAT...They're teaching to the test. So, it's easier to get in the lower grades with this program than the upper grades, because they're really focused on pushing every single minute they can.

The third counselor reported that she delivered the program to grades $\mathrm{K}-2$ because her co-worker - another guidance counselor - taught the program to the older grades.

\section{Chapter summary}

This chapter presented the quantitative and qualitative findings of the current study. To summarize, quantitative results showed that ease of program implementation was the factor that most frequently influenced program implementation, that is, both dosage and adherence. Interestingly, but perhaps not surprisingly, the flip side of this 
factor - difficulty of program implementation - emerged as an important theme from the interviews with guidance counselors. In addition, difficulty of program implementation was the most prevalent theme among the independent variables. Beliefs about the prevention program's effectiveness was the second most common factor influencing implementation, as shown by the quantitative data, although it was specific to adherence. An important theme among guidance counselors was curriculum modification. All guidance counselors modified the Too Good for Drugs program when delivering it to students by either changing the amount of the program lessons delivered to students or by changing how closely the program provider followed the curriculum guide. It is important to point out that these two activities represent both of the dependent variables of this study - dosage and adherence. Other noteworthy themes were difficulty of program implementation, justifications for modifying the curriculum, effectiveness of the program, as well as three interrelated themes, The Wheel, scheduling, and time. 


\section{CHAPTER 5}

\section{DISCUSSION}

The purpose of this study was to identify the factors that influence the implementation of substance use prevention programs in elementary schools. Researchers have called for more investigation into this area given the scarce literature concerning this topic (Durlak, 1998; Dusenbury et al., 2003). It is imperative to identify the factors that influence the implementation of these programs since researchers have found that program outcomes are tied to how well the program was implemented (Durlak \& DuPre, 2008; Wilson et al., 2003; Tobler, 1986). The importance of implementation led researchers to state that unless prevention programs are implemented as intended, the programs are not likely to yield the desired results (Botvin \& Griffin, 2003a; Mihalic et al., 2008). This is major problem because if substance use prevention programs are not implemented as intended by program developers, children and youth will likely begin and continue engaging in substance use. Johnston et al. (2012) report that children as young as elementary school age are already engaging in substance use. From there, it continues to rise throughout middle and high school (Johnston et al., 2012). These findings demonstrate the importance of delivering substance use prevention programs as intended by program developers.

Implementation is one of the four stages of Rogers' diffusion of innovations theory, and can be defined as the method by which organizations use a program (Rogers, 1995). Fidelity of implementation, or whether organizations used the program as program developers intended, has been measured in five ways: (1) exposure/dosage, (2) 
adherence, (3) quality of program delivery, (4) participant responsiveness, and (5)

program differentiation. Factors influencing implementation fall into five categories: (1)

provider characteristics, (2) program characteristics, (3) school characteristics, (4)

training and technical assistance characteristics, and (5) community-level characteristics.

Given the paucity of literature on this topic, and somewhat mixed finding among the very

few studies that have been conducted, a research model and questions were developed to guide the present research. In determining which variables to study, particular attention was placed on choosing factors that either received mixed results in the literature (e.g., beliefs about the program's effectiveness) or those not examined as often (e.g., program complexity). As such, two dependent (i.e., dosage and adherence) and five independent variables (beliefs about the program's effectiveness, beliefs in responsibility to teach substance use prevention concepts, self-efficacy, program complexity, and principal and district prevention coordinator encouragement) were selected. To test the proposed model, data was collected in the form of a survey which was completed by 65 guidance counselors and teachers in elementary schools in Palm Beach County, Florida. These individuals were identified as those who had taught a substance use prevention program to students. Because of the low statistical power resulting from the quantitative data collection, in-person interviews were subsequently conducted with nine participants who had completed a survey.

\section{Summary of factors influencing dosage}

For the dependent variable dosage, ease of program implementation, and less years working at their current school, significantly influenced the amount of the substance use prevention program that providers delivered to students. In other words, the 
easier that program providers believed the program was to implement, the greater the amount of the program they delivered to students. Thus, it appears that if a prevention program has clear goals and is straightforward, it will result in greater program delivery. In addition, the fewer years that program providers worked in the schools was also associated with delivering more of the program to students. The case may be that newer program providers believed they had to teach as much of the lessons as possible, whereas the providers who had worked at the school longer felt they had more leeway in the amount of the program they had to teach students. Another explanation may be that providers who worked longer at schools experienced more burnout, leading them to not be as motivated and compliant when implementing the substance use prevention program. Ease of program implementation represents the category of the prevention program, while years teaching at their school represented the category of the provider. When these variables underwent more stringent analyses using multiple regression, the regression model was not significant. However, ease of program implementation approached significance. Flannery and Torquati (1993) also found that ease of program implementation significantly influenced dosage. In addition, Rohrbach et al. (1993) found that less teaching experience was associated with amount of program delivery, which is partially similar to the findings from the current study. The current study examined two similar items to these researchers, that being "years teaching/working at your present school," and "years teaching/working in schools overall, including your present school." The current study found a significant relationship between less years that participants had worked in their school and the amount of the program they delivered to students. 
The nine in-person interviews with guidance counselors shed further light on the dependent variable, dosage. An important theme among the counselors was curriculum modification, which included modifying the amount of the program that counselors delivered to students (i.e., dosage) and the way in which the program was delivered (i.e., adherence). All nine of the counselors reported modifying the curriculum. Examples of changing the amount of the program implemented included not delivering the whole program, skipping, combining, and rearranging lessons, teaching additional substance use prevention material, and not teaching the entire lesson. The fact that all nine guidance counselors altered the curriculum is in line with what other researchers have observed that some degree of curriculum modification is inevitable (Ringwalt et al., 2003).

In addition, Young et al.'s (1986) findings that teachers delivered more of the prevention program if they perceived having freedom in deciding what to teach was reflected in seven of the nine (78\%) guidance counselor interviews in the current study. The majority of these counselors reported they were autonomous in their school concerning the implementation of the substance use prevention program. Specific comments from counselors included: "the interesting thing about being a guidance counselor is you get to pick what you want to talk about"; "there's no structured curriculum for guidance counselors"; “once the school year starts, you don't hear too much from the district about implementing this or how's it going"; "they pretty much let us do our thing"; "the principal never said to do it"; and "they don't tell me what to teach, I tell them."

A second important theme in the interviews, difficulty of program implementation, offers a glimpse into the reasons why it was challenging for counselors 
to deliver the entire program to students. It is important to point out that difficulty of program implementation is the flip side of ease of program implementation. Both of these variables were found to significantly influence the amount of the prevention program that was delivered to students. As to the reasons why it was difficult to implement the entire program, counselors cited time constraints, issues with scheduling, determining how to address personal stories about substance use shared by students, and differences in students' maturity levels and developmental learning abilities. These reasons represent the categories of factors that influence implementation of the school, the student, and the provider. This is important to bring attention to because while the findings yielded from the quantitative data mainly resulted in the three prescribed categories of program implementation - provider, program, and school, - and are subject to the specific questions asked, findings from the qualitative data produced additional important information that was not part of a prescribed questionnaire. For instance, during the interviews with guidance counselors, the issue of student characteristics emerged several times as a factor that influenced counselors' delivery of the substance use prevention program. However, since this factor was not assessed in the survey, it was impossible to learn of its importance without the qualitative data.

A third theme in the interviews was counselors' justifications as to why they modified the curriculum. Reasons included: it depended on students' needs, demographics, and maturity level; whether the lesson was appropriate; time constraints; scheduling; bad neighborhood surrounding school; and counselors' beliefs that they had latitude when delivering the program. These factors represent the categories of student, program, school, and provider. Given counselors' justifications as to why the program 
was modified, these individuals may be under the impression that they have to alter the program in some way to address the issues they raised. For instance, counselors may believe that the substance use prevention program they are implementing does not meet the needs of their population and, therefore, either skip some of the lessons or use another program they believe more accurately meets their students' needs. Those reasons, in addition to counselors' beliefs they have leeway in what to teach in the program, can be addressed through training. Trainers can inform and provide evidence to counselors that the lessons are appropriate for their students, despite and in spite of students' neighborhoods, and that adhering to the curriculum guide is of paramount importance. Concerning time constraints and scheduling, this is a factor that was common across most interviews, which points to its significance in implementing programs to students. Counselors appeared frustrated at having less time than needed to teach the prevention program. This caused them to either skip or combine lessons or skip activities that are part of the program. Granting these program providers more time, even several minutes, may make a key difference in the amount of the program they can deliver to students.

\section{Summary of factors influencing adherence}

For the other dependent variable, adherence, three items were used to assess this variable. How closely counselors followed the curriculum guide was influenced by ease of program implementation, as well as their beliefs that the program was effective. In addition, counselors who were not White were marginally more likely to adhere to the curriculum guide. In other words, counselors who believed that the program was easier to implement, who thought the program was effective, and who were not White were more likely to follow the curriculum guide closely. These factors represent the categories of the 
program and the provider. When these variables went through more rigorous analyses using multiple regression, the model was found to be significant. In addition, ease of program implementation remained a significant factor in predicting how closely guidance counselors followed the curriculum guide. Beliefs in the program's effectiveness also emerged as an important factor in the interviews in relation to how closely counselors followed the curriculum guide. Six counselors reported that the substance use prevention program was either excellent, good, important, or a combination of these responses. Two counselors mentioned that the program needs to be updated.

How often counselors used the interactive components of the prevention program - the second item measuring adherence - was influenced by ease of program implementation, beliefs about the program's effectiveness, and self-efficacy. In addition, being non-White approached significance, while receiving less encouragement from the district prevention coordinator was marginally significant. In other words, guidance counselors used the interactive components of the program more often if they reported the program was easy to implement, believed the program was effective, had higher rates of confidence, were not White, and received less encouragement from the district prevention coordinator. Qualitative data also supported the findings that ease of program implementation and beliefs about the program's effectiveness were important in how often providers used interactive components. These factors represent the categories of the program, the provider, and the school.

A possible reason why respondents reported using the interactive components more frequently when they received less encouragement from the district prevention coordinator may be that the coordinator did not offer encouragement to these program 
providers to specifically teach the interactive components of the program. Instead, perhaps the support from the coordinator was focused on other areas, such as encouragement to teach the program in general or checking in with providers to determine whether they needed more program materials, rather than on encouraging them to teach particular aspects of the program. In addition, since only one item measured encouragement from the district prevention coordinator, perhaps additional questions are needed to assess this variable to more accurately reflect the range of activities that can represent encouragement. While the current study found that less encouragement from the district prevention coordinator was associated with using interactive components more often, Gingiss et al. (1994) found the opposite; that inter-personal support predicted use of tobacco prevention materials. Unfortunately, since the authors did not operationally define the dependent variable, "use of tobacco prevention materials" can signify either dosage or adherence. The failure of these authors to define the variable is likely a result of the absence of correct terminology at the time their study was conducted and published, given that one of the first documented accounts of consistent verbiage concerning the aspects of fidelity (i.e., the dependent variables) came several years later (Dane \& Schneider, 1998).

Furthermore, if the finding from Gingiss et al. (1994) is associated to adherence, rather than dosage, it is unknown which of the three adherence questions from the current study it may be tied to. The author of the current study made the decision to compare the finding from Gingiss et al. (1994) to the adherence question concerning frequency of using interactive components. Future research on the two factors - frequency using interactive components and support from the district prevention coordinator - may shed 
more light into the relationship and perhaps clarify the issue. When all the variables for this item were subjected to stricter analyses using multiple regression, the regression model was found to be significant. In addition, ease of program implementation, selfefficacy, and being non-White remained marginally significant in the regression model. For the third and last item measuring adherence - "when delivering a substance use prevention program, I think it is more important to (a) follow the curriculum guide closely, or (b) modify the program according to the needs of my students, time, or other considerations" $-86 \%$ of program providers reported it was more important to modify the program. In the current study, providers modified the program by skipping, combining, and rearranging lessons; not teaching the entire lesson; not using the interactive components (e.g., puppets); not adhering to the curriculum manual; and adding material other than the TGFD program to the lessons. For example, $66 \%$ of program providers did not deliver all the lessons, $73 \%$ either did not follow the curriculum guide very closely or use a guide at all, and $67 \%$ did not always use the interactive components of the program.

The longer that program providers worked at their schools overall, including their current school, was associated with reporting it was more important to modify the curriculum than to follow it closely. In addition, age and ease of program implementation were marginally significant. In other words, program providers believed it was more important to modify the curriculum than to follow the manual closely if they reported working more years at their schools, were older, and if they found the program easy to implement. 
Ease of program implementation was also found to be a significant factor in the qualitative interviews. These factors represent the categories of the provider and the program. When more stringent analyses were conducted, the model was not significant. Despite the nonsignificance of the model, more years working in schools overall, including their current school, approached significance in counselors' reporting it was more important to modify the curriculum than to follow the program manual closely. The findings that counselors believe it is more important to modify the prevention program rather than adhere to the manual, is in line with one of the themes that emerged from the qualitative data, that being curriculum modification. All nine counselors reported changing the curriculum in some way. This finding also reflects the same observation arrived at by Ringwalt et al. (2003) when they concluded that some degree of curriculum modification is unavoidable.

\section{Additional factors influencing implementation}

Another topic of discussion concerning the current study's findings is the relationship between three themes that emerged as important among guidance counselors in the in-person interviews: The Wheel, time, and scheduling. The topic of The Wheel was brought up by the first guidance counselor the author met with. Also mentioned by the counselor were the issues of scheduling and time. Considering the potential role these factors may play in implementing substance use prevention programs, the author asked the other eight counselors whether they taught on The Wheel and what their experiences were teaching on it. From these nine interviews, the association among The Wheel, scheduling, and time became apparent. Most guidance counselors (78\%) taught on The Wheel. As understood, The Wheel is a way that Palm Beach County elementary schools 
structure their school day. Schools that participate in The Wheel have the students attend a mix of fine arts classes (e.g., guidance, media, art) for approximately thirty minutes in addition to their core academic courses. The Wheel affects how often counselors see students in the classroom. For example, the amount of time that counselors saw the same group of students in the current study ranged from every six days to every two and a half weeks. If the higher end of this finding is considered, that translates to the counselor delivering the substance use prevention program to students approximately twice per month.

Time also emerged as an important theme. Of the guidance counselors interviewed, $67 \%$ brought up time as an issue in delivering substance use prevention programs to students. In fact, when counselors were asked in the survey about the most challenging aspect of implementing a substance use prevention program, $47 \%$ of those who responded reported 'time.' Counselors stated they have between 20 and 30 minutes to teach a lesson, yet they pointed out that lessons take about 45 minutes to deliver. At least one counselor admitted to either teaching the lesson faster than she normally would or modifying it some way to get the whole lesson in. Similar findings were shown by Flannery and Torquati (1993) who discovered that over half (58\%) of teachers in their sample reported they needed more time to teach prevention lessons. Some of the counselors in the current study commented that they focused on teaching the lessons to the earlier grades since it was easier to get time with them, given that it was more difficult to have time with the older grades. Counselors indicated that the reason for that was because more time is spent preparing older elementary students for the FCAT. 
Scheduling was the third and last theme that emerged as related to The Wheel and time. Scheduling also affected how often counselors delivered substance use prevention lessons to the same group of students. To the author's understanding, scheduling is influenced by how many students are in the school, which in turn affects the number of classes in a grade level. For instance, one elementary school may have four third grade classes, while another school may have eight. If these two schools were on The Wheel, then the former school would see the guidance counselor more often than the latter school. Furthermore, this also translates to the probability that counselors would deliver fewer lessons to the latter school.

These three interrelated themes that emerged from the interviews with counselors - The Wheel, time, and scheduling - represent areas that can benefit from further research. In particular, how often should program providers deliver substance use prevention lessons to elementary students? Should it be every day, once per week, once per month? Also, how many lessons can providers deliver each time they see students while maintaining a good level of implementation? Is one sufficient? Is three too many? In addition, how long should the lessons take to deliver? Twenty minutes? Thirty? Lastly, in what time period should the entire substance use prevention program be taught? Does the program need to be delivered over a consecutive number of days or weeks, or can it be taught randomly throughout the year? These questions bring to light an important issue that may currently not be adequately addressed concerning the fidelity of implementation. For instance, answers to the previous questions are arguably critical in program implementation and program outcomes. Yet, of the five ways to measure fidelity of implementation - adherence, exposure/dosage, quality of program delivery, participant 
responsiveness, and program differentiation - none represent how often programs should be delivered to students and for how long. If the answers to the previous questions are important in implementation and program outcomes, perhaps this would warrant the inclusion of an additional criteria to measure fidelity of implementation.

Answers to the immediately preceding questions will likely affect the outcomes of the prevention program. Furthermore, the answers can potentially influence the implementation of these programs. For example, the answers to these questions can be shared with program developers, administrators, and providers to raise their awareness about how frequently prevention programs should be delivered in order to ensure programs are well-implemented and achieve their goals, that is, the prevention of substance use among elementary students. Once these questions are addressed, they can inform the three important and interconnected issues that emerged from the counselor interviews: The Wheel, scheduling, and time. In the meantime, administrators need to be made aware of the challenges faced by program providers when implementing substance use prevention programs. Perhaps more time can be allotted to teach these programs; even ten or fifteen minutes may make a key difference. The importance of the role of school administrators was underscored by Beets et al. who suggested that these individuals should develop a shared vision and be supportive of prevention programs (Beets et al., 2008).

Another approach that can be implemented while the answers to the previous questions are addressed is to create an online listserv, or discussion group. This can act as a place where program providers who teach substance use prevention can come together to post challenges they are experiencing, as well as become aware of lessons learned 
from other providers who may have gone through similar issues. A third suggestion, albeit long-term, represents a potentially ideal scenario - to require that substance use prevention be taught, perhaps in addition to other prevention classes, if deemed appropriate. Presently, substance use prevention is not mandated in Palm Beach County elementary schools, unlike character education, which is required. In fact, one of the guidance counselors pointed out that substance use prevention programs should be required for students. Rohrbach et al. also recommended this option after their study found that while $78 \%$ of teachers implemented one or more of the prevention program's lessons in year one, in year two, only $25 \%$ of teachers reported delivering the lessons (Rohrbach et al.,1993). However, these researchers also point out that teachers are generally held less accountable for non-academic classes and activities. This line of thinking likely extends to guidance counselors and other instructional staff as well. If the prevention of substance use among elementary students is truly a priority for schools, families, and communities, a shift in perspective may be warranted from attaining success solely in academics to placing at least an equal importance in achieving success in the areas of mental and social health (Kelly et al., 2010).

\section{Implementation differences between providers}

No significant findings appeared for which group of program providers (i.e., teachers or counselors) delivered more of the curriculum to students or adhered more often to the curriculum guide. Even though more teachers than guidance counselors reported delivering a greater amount of the program, following the curriculum guide closely, using the interactive components more frequently, and believing it was more important to follow the curriculum guide rather than to modify the program, these 
findings were not statistically significant. The sample size of teachers $(n=13)$ compared to guidance counselors ( $n=44-46)$ may not have been large enough to yield significant results. Using a larger sample, future research can further examine which groups are more likely to deliver a greater amount of the program and adhere more closely to the curriculum guide. On one hand, teachers may be more likely than counselors to deliver a greater amount of the program and adhere to the curriculum guide if the program is interwoven into their classes, and since they may better understand the importance of delivering lessons in full. On the other hand, counselors may be more appropriate program providers given their education and training on assisting students not only academically, but also emotionally and socially.

While the quantitative data did not allow analysis of the grades in which program providers delivered more of the substance use prevention program, the qualitative data showed that five out of nine counselors (56\%) implemented the program to grades K-5, three $(33 \%)$ to grades $\mathrm{K}-2$, and one (11\%) to grades $3-5$. Reasons why counselors did not deliver the program to all grades included time constraints and scheduling. The Florida Comprehensive Assessment Test (FCAT) was cited by some counselors as a reason why they did not implement the program to the older grades (i.e., 3-5), pointing out it was easier to get time with the younger grades (i.e., K-2). Program providers may not be aware that delivering prevention programs across the grades may be warranted (Botvin \& Griffin, 2003a; Tobler et al., 2000). This information can be shared with providers via the school's prevention center, school administrators, and program developers. Future research can investigate this issue, with a larger sample size, to determine whether the grade the students are in influences the amount of the substance use prevention program 
delivered to them. In addition, the factors that affect the varied amounts of program delivery by grade (e.g., standardized testing) should also be explored.

\section{Relationship between dependent and independent variables}

The association between the dependent variables (i.e., dosage and adherence) was also examined in the current study. Dosage was significantly associated with following the curriculum guide closely and frequency using interactive components. That is, program providers who delivered a greater amount of the program to students also followed the curriculum guide closely and used the interactive components more often. This may not be surprising considering that all three outcomes go hand in hand. When program providers follow the curriculum guide, it explicitly shows the beginning and the end of each lesson, in addition to clearly pointing out when to utilize interactive activities as part of the lesson. Also, it stands to reason that the more often providers used interactive activities is a product of teaching a greater amount of the program since providers used the activities as they came across them in the curriculum guide. Of the seven studies reviewed, only one other (Beets et al., 2008) explored the relationship between dosage and adherence. Beets et al. (2008) also found that greater rates of program delivery were associated with higher rates of adherence.

Following the curriculum guide closely was significantly related to using the interactive components more frequently, and paradoxically, to believing it was more important to modify the program than to follow the curriculum guide closely. In regard to frequency, it makes sense that program providers who followed the curriculum guide closely also used the interactive components more frequently, given that providers who adhered to the program manual were informed when it was time to utilize the interactive 
components of the program. An unexpected finding was that program providers who reported following the curriculum guide closely also stated they believed it was more important to modify the curriculum than to follow it closely. Of respondents, $27 \%$ reported they followed the curriculum guide very closely, which translated to "I taught the material as specified." Yet $86 \%$ of providers admitted they modified the program when delivering it to students. The majority of providers (61\%) reported following the curriculum guide somewhat closely (i.e., "I sometimes adapted the material as appropriate.”). This begs the question: how can providers simultaneously report that they adhered to the curriculum guide and believe it is more important to modify the program according to the needs of students, time, or other considerations?

A couple of potential explanations may address this issue. First, it is important to point out that this touches on a core subject that was significant in both the quantitative and qualitative data, that being curriculum modification. This was an important theme in the interviews among guidance counselors. It was also significant in the survey results as demonstrated by the previous findings concerning how the majority of program providers modified the prevention program in some way. Providers who delivered the program may believe that following the curriculum "somewhat closely" is good enough and close enough to "very closely." In believing this, modifying the curriculum even slightly which the data shows providers do - could be sufficient to account for the puzzling finding. Second, perhaps the issue with the inconsistency lies in the instrument. The case may be that the questions assessing these two adherence concepts (i.e., [1] how closely was the curriculum guide followed?, and [2] is it more important to follow the curriculum guide closely or modify it according to the needs of students, time, or other 
considerations?) may not have been sufficient and/or did not accurately tap these two concepts. Future research can use questions that assesses more precisely these two concepts, as well as including a greater number of questions to increase the likelihood of minimizing paradoxical results.

Relationship among independent variables

Several associations were found for the independent variables. Program providers who believed the prevention program was effective were more likely to report higher rates of ease of program implementation, and to a marginal degree, self-efficacy and principal and district prevention coordinator encouragement. In addition, providers who reported that the program was easier to implement also had higher self-efficacy.

\section{Relationship between independent and demographic variables}

Relationships between the independent and demographic variables were also demonstrated. Older participants reported that the prevention program was easier to implement. In addition, the longer that program providers had taught substance use prevention overall, including in their current school, the greater rates of self-efficacy and principal encouragement they reported. Lastly, the more years that implementers had worked in their current school, the higher the rates of their self-efficacy, though this was marginally significant.

\section{Training and implementation}

Another aspect of implementation that was examined was training. Of participants, $73 \%$ reported they received training to deliver the substance use prevention program, while $27 \%$ said they never attended a training session. While it may seem impressive that almost three quarters of program providers received training to deliver the 
prevention program, it is worthwhile to explore these findings further. For instance, a closer look shows that only $15 \%$ of providers attended training during the year in which data was collected and $16 \%$ during the previous year. Most participants $(42 \%)$ reported they received training two or more years before data was collected.

These findings are a cause for concern for several reasons. First, although most respondents reported they received training to deliver the program, the majority had not attended a training session for two or more years since data was collected. That could easily translate to as little as two years before or ten years or more. Attending training often may be important in order to stay current with any changes the program developer may have made to the prevention program. The case may be that the program developer removed or modified certain lessons or added new activities to increase the effectiveness of the program. Second, attending training may influence the amount of the program that providers deliver to students, as well as their level of adherence to the curriculum guide. By taking part in training sessions, trainers can emphasize to program providers the importance of delivering all the lessons in the program and of making sure the curriculum manual is followed as closely as possible. Showing providers the link between wellimplemented programs and program outcomes (e.g., prevention of substance use) may also be warranted at this stage. In fact, the current study found that providers who believed the prevention program was effective followed the curriculum guide closely and used the interactive components of the program more frequently. Third, attending training may increase the camaraderie among program providers which may, in turn, affect the level of program implementation. Inevitably, participating in training will bring program providers together. Here, they can share their concerns about implementing the 
prevention program, in addition to obstacles they faced, as well as convey the lessons they have learned. These experiences have the potential to build a sense of cohesion and a can-do attitude that may translate into a greater level of implementation by program providers. Future research can explore whether, and to what degree, training is important to program outcomes, specifically focusing on substance use prevention programs and elementary schools. Subsequently, program developers and trainers can include in their materials and presentations the results of the findings and share it with program providers and school administrators to increase attendance in training sessions.

In the current study, $28 \%$ of respondents who attended training to implement the program taught all of the lessons, compared to $60 \%$ who did not receive training. This may seem counter-intuitive, but delving deeper into the findings points to several possible explanations. First, the problem may lie with issues related to the training itself, such as insufficient number of training sessions attended or having an ineffective trainer. A second reason needs to be mentioned, despite its potential unpopularity. Perhaps training is not an important factor in the implementation of prevention programs, or at least not a significant factor in delivering the Too Good for Drugs ${ }^{6}$ program to elementary students. For instance, neither the brief or intensive training conditions that teachers participated in for Rohrbach et al.'s study were associated with dosage, although the one-on-one meeting between the first author and principals was related to dosage (Rohrbach et al., 1993). Similar findings were demonstrated by Flannery and Torquati (1993) who found that training was unrelated to the amount of the program teachers taught students. Yet, when these same researchers asked teachers ways in which the

\footnotetext{
${ }^{6}$ Too Good for Drugs was the program that $90 \%$ of providers delivered to students in the current study.
} 
prevention program activities could be better incorporated into their curriculum, one of the recommendations from teachers was to offer updated and continued training (Flannery \& Torquati, 1993).

To address this unresolved issue, Rohrbach et al. (1993) point out that "more research is needed to determine how teacher training affects implementation of psychosocial based substance use prevention programs. The optimal instructional approach to, and amount of, training required to prepare teachers for effective implementation has yet to be determined" (Rohrbach et al., 1993, p. 250). Despite the lack of positive findings linking training to implementation in the seven studies reviewed in the current study, all of these studies recommended that providers attend training prior to implementing a program (Beets et al., 2008; Flannery \& Torquati, 1993; Gingiss et al., 1994; Klimes-Dougan et al., 2009; Lochman et al., 2009; Rohrbach et al., 1993; Young et al., 1986).

Future research can examine whether, and to what degree, training is important to program outcomes. This can be achieved by having one intervention condition in which program providers attend training and another condition in which they do not. Program outcomes would be assessed and all other variables except training would be controlled. If research finds that training is, in fact, important to program outcomes, perhaps the next step would be to investigate how often program providers should attend training. In addition, program developers and school administrators should choose trainers who believe in the effectiveness of the prevention program and are enthusiastic about teaching it. 


\section{Time spent by guidance counselors on responsibilities}

The current study also explored the activities that comprise a guidance counselor's day. This was done for two reasons. First, it is useful to be aware of the responsibilities that take up a guidance counselor's time because this informs the literature on how much time counselors spend on universal, selective, or indicated activities. Second, these findings were compared to those of Kelly et al. concerning the activities that comprise a school social worker's work day (Kelly et al., 2010). It should be pointed out that in the current study, guidance counselors - and not school social workers - answered this question. Only three individuals in the sample possessed a degree in social work; two guidance counselors and one teacher held an MSW. To assess this information, counselors were asked to report how much of their time is spent on certain activities. Counselors reported spending their time on the following responsibilities: $41 \%$ classroom activities, 36\% individual counseling, 20\% administrative tasks, 14\% group activities, $8 \%$ family-based programs, and 19\% other activities, which included meetings, teaching character education classes, lunch duty, and tutoring students.

The most notable finding between these results and those of Kelly et al. (2010) is the difference in the amount of time practitioners spent on the activity taking up most of their time. For example, while Kelly et al. (2010) found that over $60 \%$ of school social workers spent all or most of their time conducting individual counseling, the current study showed that guidance counselors spend, on average, $41 \%$ of their time engaged in classroom activities. Kelly et al.'s (2010) findings did not demonstrate that school social workers spend most of their time working in the area of prevention. Therefore, their 
findings do not reflect the shift in changes in school-based mental health-related practice, research, and policy that has moved from a predominately clinical casework perspective to an orientation that focuses at least equally on prevention. In contrast, the results from the current study are in line with the shift in perspective towards a prevention orientation as documented by the findings that guidance counselors spend an average of $41 \%$ of their time conducting classroom activities. This means that counselors are working in the area of universal prevention as opposed to the two other types of interventions that involve either individuals demonstrating at least some risk factors (i.e., selective interventions) or the problem behavior (i.e., indicated interventions) before they are exposed to a prevention program. When comparing these findings, it is important to remember that while Kelly et al. (2010) surveyed school social workers, the current study assessed guidance counselors ${ }^{7}$. The rationale behind this was that the author was informed that guidance counselors and teachers were the primary individuals responsible for delivering substance use prevention programs in Palm Beach County elementary schools. Findings in light of the theoretical framework

The current study, and the review of the seven studies presented earlier, was guided by Durlak and DuPre's (2008) Ecological Model for Effective Implementation (Figure 1). In their model, factors influencing implementation are organized into five categories. The framework posits that the categories located closer to the center of the model (e.g., innovation characteristics) influence implementation more than categories further away from the center (e.g., community characteristics). It is important to remember that this model is not specific to schools or to substance use prevention

\footnotetext{
${ }^{7}$ Two guidance counselors in the current sample had an MSW degree.
} 
programs. Nonetheless, Table 1 represents the most extensive list that is currently available on factors related to the implementation process. The five categories representing the factors (in order from the center of the model moving outwards) are: (1) Level 1/Center of the Model: (a) the innovation (e.g., prevention program); (b) the prevention delivery system (e.g., school leadership); (c) the prevention support system (e.g., teacher training); (2) Level 2 of the Model: (a) the provider (e.g., teachers or counselors); and (3) Level 3 of the Model: (a) community level (e.g., funding availability).

To determine how closely the results reflect the model, a comparison will be made between the categories represented in the seven reviewed studies, as well as the findings from the current study. Across the seven studies, the category that most characterized the factors influencing implementation was provider characteristics (see Table 2). The category that came in close second was the school. However, in the current study, the most significant category was the program. The two factors that reflect this category are ease of program implementation and beliefs about the program's effectiveness. These findings represent the quantitative data. When results from the qualitative data were taken into account, two other categories were represented the most, those being the school and the students. As may be noted, the category of 'students' is not one of the five categories identified in Durlak and DuPre's (2008) Ecological Model for Effective Implementation. The implications of this finding will be discussed shortly. Examples of factors representing the school included time constraints and scheduling, while factors representing students included how to address personal stories concerning 
substance use that students brought up during the lessons and differences in the maturity and developmental learning abilities of students.

Findings from the current study offers support for Durlak and DuPre's (2008) Ecological Model for Effective Implementation. In terms of the quantitative data, the category of the innovation, or program, was most significant (the innovation is located in the center of the model). The category of the provider was also significant (the provider is located one level away from center of model). In addition, the qualitative data found that the school was the most important category affecting implementation (the school is located in the center of the model), followed by the category of students (the category of students is not explicitly reflected in the model).

\section{Intercoder reliability}

In an effort to increase the credibility of the qualitative findings, intercoder reliability was assessed. Results indicated a "substantial" agreement between the two coders (Landis and Koch, 1977; Hruschka et al., 2004). This signifies that the findings can be considered trustworthy, more so than if intercoder reliability had not been measured. Factors that could have led to a higher agreement between the two coders may be: (a) a clearer definition of the codes; (b) a narrower definition of the codes; and (c) a more specific explanation of the coding rules (Burla et al., 2008). Future research should seriously consider employing a method to increase the validity of their studies. Intercoder reliability is one such method. As Singletary (1993) states, intercoder reliability is "near the heart of content analysis; if the coding is not reliable, the analysis cannot be trusted" (p. 294). 


\section{Summary and Conclusion}

The following briefly highlights the findings of the current study. The category of factors most influencing implementation represented the program provider, closely followed by factors characterizing the prevention program. The qualitative data identified the factors representing the school and students as primary. These findings partially supported Durlak and DuPre's (2008) Ecological Model for Effective Implementation, the theoretical framework guiding the current study. Ease of program implementation was the most cited factor affecting dosage and adherence. In the qualitative data, curriculum modification was an important theme that emerged. All guidance counselors reported modifying the substance use prevention program. Reasons for altering the curriculum and its delivery included time constraints, issues with scheduling, differences in students' needs, demographics, and maturity levels, appropriateness of the lessons, "bad neighborhood" surrounding school, and believing they had latitude in deciding what to teach. Beliefs in the program's effectiveness and self-efficacy were significant in affecting adherence. Most counselors delivered the prevention program in all grades, although one third only implemented the program to students in grades K-2, citing issues with time, scheduling, and the FCAT. Providers who delivered a greater amount of the program also followed the curriculum guide more closely and used interactive components more frequently. A large percentage (42\%) of respondents had not received training to deliver the program for two or more years before data was collected.

\section{Limitations}

There are several limitations to this study. First, because a cross-sectional research design was used, it was not possible to determine the causal direction of 
significant relationships. Second, only public elementary schools in Palm Beach County, Florida were included in the sample. This may limit the generalizability of the findings. Third, since guidance counselors were the only participants in the in-person interviews, the findings are limited to guidance counselors. Fourth, given that respondents primarily taught the Too Good for Drugs program, the findings are specific to that program. Fifth, the study was comprised of a small sample size $(N=65)$, which may also limit the generalizability of the results. Sixth, two indicators of program implementation were measured (i.e., dosage and adherence). Dane and Schneider (1998) cite three other indicators that may influence implementation (i.e., quality of program delivery, participant responsiveness, and program differentiation). These other aspects are important to consider, as they are just as likely to affect implementation fidelity (Payne et al., 2006). However, as Durlak and DuPre (2008) point out, investigators generally focus on only a few variables at a time, since researchers cannot study everything at once. This issue is further illustrated as these researchers indicated that of the 59 studies they evaluated concerning implementation issues, $69 \%$ assessed one aspect of implementation while $31 \%$ assessed at least two aspects. Seventh, this study used self-report data from program providers. Researchers have stated that self-reports may be more thorough than observer data, yet the latter appears to be more valid since it is more objective compared to self-reports (Dane \& Schneider, 1998; Durlak \& DuPre, 2008; Dusenbury et al., 2003). Lastly, the study may have been exposed to selection bias. Participants who took part in the study may have had more favorable views of the prevention program than those who did not participate. In addition, the incentive offered may have influenced certain individuals to respond to the request for an in-person interview. 
Despite these limitations, this study has numerous strengths. First, original data collection was conducted. Gathering primary data permitted the author to hone in on a specific area of the literature which was lacking, and utilize the most appropriate methods for analysis of the data, instead of allowing existing data to drive the research focus and methodology. Second, the survey instrument was pre-tested. This identified areas that needed to be modified in order to increase the user-friendliness of the measure. Third, intercoder reliability was assessed as a method to increase the credibility of the qualitative findings. "Substantial" agreement between the two coders was demonstrated. Fourth, a mixed methods approach was used which allowed for a deeper exploration of the qualitative data. Fifth, this study assessed - and controlled for - social desirability among participants. By doing so, importance was placed on this potential bias, and findings can be interpreted with this information in mind. Lastly, the relationship between adherence and dosage was assessed. Only one other study in this review (Beets et al., 2008) measured the relationship between these two variables.

\section{Implications for research}

More research is needed on the effect of training on the implementation of substance use prevention programs in elementary schools. For instance, the current study found that while $28 \%$ of respondents who attended training to implement the program taught all program lessons, $60 \%$ who did not receive training also implemented all the lessons. This finding warrants further exploration into the importance of training in relation to program implementation and outcomes. Specific questions that this finding brings to light are: Whether and to what degree does training influence the quality of implementation? Whether and to what degree does training affect program outcomes? 
How often should program providers attend training? Which group of program providers (e.g., teachers, counselors, individuals who hold an MSW degree) are more suitable to deliver the program?

Additional research is needed to identify the appropriate amount of time to deliver the substance use prevention program. For instance, how often should program providers deliver lessons to elementary students? Should it be every day, once per week, or once per month? Also, how many lessons can providers deliver each time they see students while maintaining a good level of implementation? Is one sufficient? Is three too many? In addition, how long should the lessons take to deliver? Twenty minutes? Thirty? Lastly, in what time period should the entire substance use prevention program be taught? Does the program need to be delivered over a consecutive number of days or weeks, or can it be taught randomly throughout the year? The answers to these questions are barely, if at all, prominent in the implementation literature, yet they likely affect the outcomes of the prevention program. Perhaps results from future research will call for an additional method to measure implementation fidelity - that being the timing of delivering substance use prevention programs. This information can subsequently be added to the existing five methods of measuring fidelity - exposure/dosage, adherence, quality of program delivery, participant responsiveness, and program differentiation.

Another area that will benefit from research in increasing the implementation of substance use prevention programs is how to address differences in: students' needs, demographics, developmental learning abilities, and maturity levels. These factors were repeatedly mentioned by providers as reasons they modified the program. The factors also represent the category of 'student,' which is one of the two most prevalent categories 
that influenced the implementation of substance use prevention programs that emerged from the qualitative data. Ways to address the differences in the previously mentioned factors would be a welcome resource for program providers.

The category of 'student' emerged as important in the current study, as evidenced by providers' stating that several factors in that category influenced whether and to what degree they modified the program. However, the category of 'student' is not one of the five categories (i.e., provider characteristics, program characteristics, school characteristics, training and technical assistance characteristics, and community-level characteristics) reflected in the theoretical framework that guided this study. Given its importance among program providers, research should explore how student characteristics affect the level of implementation, and if warranted, include it as an additional category that influences the delivery of substance use prevention programs in elementary schools.

Lastly, considering the importance of providers' beliefs in the effectiveness of the prevention program when implementing substance use prevention programs, research should continue to study the efficacy of these programs. Findings should be shared with program developers, school administrators, and program providers.

\section{Implications for policy}

Substance use prevention programs are not mandated in Palm Beach County elementary schools. Perhaps this explains why program providers did not teach the program to all grades or modified the program in some way. The fact that children in elementary school engage in, or are surrounded by, substance use has been documented 
by Johnston et al. (2012). The current study also found similar evidence as guidance counselors stated that students bring up personal stories of substance use during delivery of the prevention program. Given the reality that children are exposed to these substances, schools and school districts should consider requiring schools to teach substance use prevention programs. If these programs are not mandated, providers will likely continue to either modify them or not teach them, especially since they are not part of the academic core classes for which teachers and staff are held accountable (Rohrbach et al., 1993). A good first step to moving in this direction may be conducting a prevalence assessment to determine how many children are engaged in, exposed to, and have attitudes and intentions towards substance use. These findings may provide the justification for requiring schools to mandate substance use prevention programs.

The association between well-implemented programs and program outcomes has been documented in the literature (Durlak \& DuPre, 2008; Wilson et al., 2003). National and state education departments should consider setting a policy that schools which receive grants for prevention programs should assess its implementation. Perhaps school districts can partner with universities - such as schools of social work - or other entities, who can assess the implementation of these programs. Funding for program implementation should be provided by agencies who award grants to school districts and schools. 


\section{Implications for practice}

Most (67\%) guidance counselors brought up time as an issue in delivering substance use prevention programs to students. Counselors stated they have between 20 and 30 minutes to teach a lesson, yet they pointed out that lessons take about 45 minutes to deliver. At least one counselor admitted to either teaching the lesson faster than she normally would or modifying it some way to teach the whole lesson. These are ingredients for a poorly-implemented program. As previously discussed, wellimplemented programs generally yield better program outcomes (Durlak \& DuPre, 2008; Wilson et al., 2003). School administrators and prevention staff should be made aware of this issue expressed by providers and offer them more time to deliver the substance use prevention program. The following are potential methods of increasing the likelihood that school administrators will oblige with providers' request: (a) share with them the effects substance use has on student academic achievement, and (b) conduct a prevalence assessment of substance use among students, including their attitudes and intentions towards drug use, and present this information to school administrators. These data may likely bring to light facts that school officials may be unaware of and could be the deciding factors in whether more time is granted to providers to implement substance use prevention programs. Additional time to teach the program has the probability of increasing the program's effectiveness, and hence, result in greater positive outcomes among children.

Some guidance counselors reported not delivering the substance use prevention program to all grades. School officials, prevention staff, program developers, and trainers should inform providers that all grades need to receive the substance use prevention 
program for maximum effectiveness. They may not be aware of the research stating that prevention across all grades may be warranted (Tobler, 1986).

Many participants reported modifying the substance use prevention program to fit their needs. Reasons often cited by program providers concerning why they had modified the prevention program were differences in students' needs, demographics, developmental learning abilities, and maturity levels. Prevention staff, program developers, and trainers should be aware of this challenge that providers face and take appropriate steps to assist them in addressing those concerns.

Since all program providers modified the substance use prevention program in some way, and given Ringwalt et al.'s similar finding that some degree of program modification is inevitable (Ringwalt et al., 2003), program developers should accept that prevention programs will be changed by program providers. Next, developers should consider following the recommendation summarized by Dusenbury et al. (2003) which suggests that program developers clearly state the components of the prevention program that may and may not be modified. This will inform program providers which parts of the program they must deliver and which ones they can modify if they need to. Over time, perhaps program developers or researchers can discover which parts of the program are most likely to be modified. With this information in hand, they can offer tips to providers on how to modify and/or replace those sections in the curriculum to maintain a high level of implementation.

Considering that ease of program implementation was the most often cited factor affecting dosage and adherence, program developers should continue to develop easy to implement programs. This can entail ensuring that the program is user-friendly, has clear 
goals and objectives, is sensitive to time, and offers an easy to follow curriculum guide where the entire program is spelled out for the provider. Two other factors that program developers, and prevention staff, and trainers, need to be aware of - given their influence in implementing prevention programs - are providers' beliefs of the program's effectiveness and their self-efficacy. These three groups of individuals should communicate to providers information about the effectiveness of substance use prevention programs since providers have identified it as a major factor in implementing the program. Attention should also be placed to bolstering the self-efficacy of providers before they implement the program. This can be addressed through trainings.

If research finds that training is a significant factor in well-implemented programs, as well as program outcomes, program developers and trainers should communicate these findings to program providers. This can be done via Web, email, print, and in-person communication. This information may increase the likelihood that program providers will attend training sessions.

Another piece of information that can be shared with providers during training, or via other forms of communication, is how often the substance use prevention program should be offered to students. Specific questions that may benefit from answers are: How often should programs be delivered? How many lessons can be implemented during one class? For how long should the program be delivered? Over how much time should the entire program be implemented? Answers to these questions will likely affect program outcomes, and will specifically address how well programs are implemented.

In conclusion, this study's findings add to the current and scarce knowledge-base concerning factors influencing the implementation of substance use prevention programs 
in elementary schools. Factors identified as important represented the categories of the program provider, the prevention program, schools, students, and the community. While ease of program implementation was the most significant factor affecting both dosage and adherence in the quantitative results, time, scheduling, and differences among students emerged as important in the qualitative findings. Despite the relationship between well-implemented programs and program outcomes, the majority of respondents, and all nine interviewed guidance counselors, admitted to modifying the prevention program in some way. This underscores the importance of continuing to assess and address issues related program implementation. It is by researchers, program developers, school officials, and program providers coming together that effective substance use prevention programs and their implementation will lead to the prevention of substance use among one of the most vulnerable groups of individuals already engaging in this behavior - elementary school-age children. 


\section{References}

Ballard, R. (1992). Short forms of the Marlowe-Crowne Social Desirability Scale. Psychological Reports, 71, 1155-1160.

Basch, C. E. (1984). Research on disseminating and implementing health education programs in schools. Journal of School Health, 54(6), 57-66.

Beets, M. W., Flay, B. R., Vuchinich, S., Acock, A. C., Li, K. K., \& Allred, C. (2008). School climate and teachers' beliefs and attitudes associated with implementation of the Positive Action Program: A diffusion of innovations model. Prevention Science, 9, 264275.

Berman, P., \& McLaughlin, M. W. (1976). Implementation of educational innovation. The Educational Forum, 40, 345-370.

Bernard, R. H. (2011). Research methods in anthropology: Qualitative and quantitative approaches. Lanham, MD: AltaMira Press.

Biglan, A., Brennan, P. A., Foster, S. L., \& Holder, H. D. (2005). Helping adolescents at risk: Prevention of multiple problem behaviors. New York: Guildford Press.

Blakely, C. H., Mayer, J. P., Gottschalk, R. G., Schmitt, N., Davidson, W., Roitman, D. B., \& Emshoff, J. G. (1987). The fidelity-adaptation debate: Implications for the implementation of public sector social programs. American Journal of Community Psychology, 15, 253-268.

Botvin, G. J., \& Griffin, K. W. (2004). Life Skills Training: Empirical findings and future directions. Journal of Primary Prevention, 25(2), 211-232.

Botvin, G. J., \& Griffin, K.W. (2003a). Drug abuse prevention curricula in schools. In Z. Sloboda \& W. J. Bukoski (Eds.), Handbook of drug abuse prevention: Theory, science, and practice (pp. 45-74). New York: Kluwer Academic Publishers.

Botvin, G. J., Griffin, K. W., Paul, E., \& Macaulay, A. P. (2003b). Preventing tobacco and alcohol use among elementary school students through life skills training. Journal of Child \& Adolescent Substance Abuse, 12(4), 1-17.

Botvin, G. J., Baker, E., Dusenbury, L., Tortu, S., \& Botvin, E. M. (1990). Preventing adolescent drug abuse through a multimodal cognitive-behavioral approach: Results of a 3-yr study. Journal of Consulting and Clinical Psychology, 58(4), 437-446.

Burla, L., Knierim, B., Barth, J., Liewald, K., Duetz, M., \& Abel, T. (2008). From text to codings: Intercoder reliability assessment in qualitative content analysis. Nursing Research, 57(2), 113-117. 
Center for Substance Abuse Prevention. (2002). Center for Substance Abuse Prevention's Prevention Portal: Model Programs. Available:

http://modelprograms.samhsa.gov/model.htm; retrieved: 2 February 2009.

Coie, J. D., Watt, N. F., West, S. G., Hawkins, J. D., Asarnow, J. R., Markman, H. J., Ramey, S. L., Shure, M. B., \& Long, B. (1993). The science of prevention: A conceptual framework and some directions for a national research program. American Psychologist, 48(10), 1013-1022.

Crowne, D. P., \& Marlowe, D. (1960). A new scale of social desirability independent of psychopathology. Journal of Consulting Psychology, 24(4), 349-354.

Dane, A. V., \& Schneider, B. H. (1998). Program integrity in primary and early secondary prevention: Are implementation effects out of control. Clinical Psychology Review, 18, 23-45.

Dent, C. W., Sussman, S., Hennesy, M., Galaif, E. R., Stacy, A. W., Moss, M., Craig, S. (1998). Implementation and process evaluation of a school-based drug abuse prevention program: Project Towards No Drug Abuse. Journal of Drug Education, 28(4), 361-375.

Drug Strategies. (1999). Making the grade: A guide to school drug prevention programs. Washington, DC: Author.

Dryfoos, J. G. (1990). Adolescents at risk: Prevalence and prevention. New York: Oxford University Press.

Dunlap, G., Sailor, W., Horner, R. H., \& Sugai, G. (2008). Overview and history of positive behavior support. In W. Sailor, G. Dunlap, G. Sugai, \& R. Horner (Eds.), Handbook of positive behavior support: Issues in clinical child psychology (pp. 3-16). New York, NY: Springer.

Durlak, J. A. (1998). Why program implementation is important. Journal of Prevention \& Intervention in the Community, 17, 5-18.

Durlak, J. A., \& DuPre, E. P. (2008). Implementation matters: A review of research on the influence of implementation on program outcomes and the factors affecting the implementation. American Journal of Community Psychology, 41, 327-350.

Dusenbury, L., Brannigan, R., Falco, F., \& Hansen, W. B. (2003). A review of research on fidelity of implementation: Implications for drug abuse prevention in school settings. Health Education Research, 18, 237-256.

Dusenbury, L., \& Falco, M. (1995). Eleven components of effective drug abuse prevention curricula. Journal of School Health, 65(10), 420-425. 
Ennett, S. T., Ringwalt, C. L., Thorne, J., Rohrbach, L. A., Vincus, A., Simons-Rudolph, A., \& Jones, S. (2003). A comparison of current practice in school-based substance use prevention programs with meta-analysis findings. Prevention Science, 4(1), 1-14.

Fixsen, D. L. \& Blase, K. A. (2009). Implementation: The missing link between research and practice. NIRN Implementation Brief \#1. Chapel Hill: The University of North Carolina, FPG, NIRN. Retrieved May 25, 2009, from http://www.fpg.unc.edu/ nirn/resources/publications/NIRN_brief_1_2009.pdf.

Flannery, D. J., \& Torquati, J. (1993). An elementary school substance abuse prevention program: Teacher and administrator perspectives. Journal of Drug Education, 23(4), 387397.

Gingiss, P. L., Gottlieb, N. H., \& Brink, S. G. (1994). Increasing teacher receptivity toward use of tobacco prevention education programs. Journal of Drug Education, 24(2), 163-176).

Glaser, B., \& Strauss, A. (1967). The discovery of grounded theory: Strategies for qualitative research. New York: Aldine Publishing Company.

Hahn, E. J., Noland, M. P., Rayens, M. K., \& Christie, D. M. (2002). Efficacy of training and fidelity of implementation of the life skills training program. Journal of School Health, 72, 282-287.

Hallfors, D. \& Godette, D. (2002). Will the "Principles of Effectiveness" improve prevention practice? Early findings from a diffusion study. Health Education Review, 17, $461-470$

Hanley, S. M., Ringwalt, C., Ennett, S. T., Vincus, A. A., Bowling, J. M., Haws, S. W., \& Rohrbach, L. A. (2010). The prevalence of evidence-based substance use prevention curricula in the nation's elementary schools. Journal of Drug Education, 40(1), 51-60.

Havelock, R. G. (1969). Planning for innovation through dissemination and utilization of knowledge. Ann Arbor, MI: Institute for Social Research.

Hawkins, J. D., Catalano, R. F., \& Miller, J. Y. (1992). Risk and protective factors for alcohol and other drug problems in adolescence and early adulthood: Implications for substance abuse prevention. Psychological Bulletin, 112(1), 64-105.

Hill, L. G., Maucione, K., \& Hood, B. K. (2007). A focused approach to assessing program fidelity. Prevention Science, 8(1), 25-34.

Hruschka, D. J., Schwartz, D., St. John, D. C., Picone-Decaro, E., Jenkins, R. A., \& Carey, J. W. (2004). Reliability in coding open-ended data: Lessons learned from HIV behavioral research. Field Methods, 16(3), 307-331. 
Huberman, A. M., \& Miles, M.B. (1984). Innovation up close: How school improvement works. Plenum Press: NY.

Johnston, L. D., O'Malley, P. M., Bachman, J. G., \& Schulenberg, J. E. (2012). Monitoring the Future national survey results on drug use, 1975-2011: Volume I: Secondary school students. Ann Arbor: Institute for Social Research, The University of Michigan.

Kelly, M., Berzin, S., Frey, A., Alvarez, M., Shaffer, G., \& O’Brien, K. (2010). The state of school social work: Findings from the national school social work survey. School Mental Health, 2, 132-141.

Klimes-Dougan, B., August, G. J., Lee, C, S., Realmuto, G. M., Bloomquist, M. L., Horowitz, J. L., \& Eisenberg, T. L. (2009). Practitioner and site characteristics that relate to fidelity of implementation: The Early Risers prevention program in a going-to-scale intervention trial. Professional Psychology: Research and Practice, 40(5), 467-475.

Landis, J. R., \& Koch, G. G. (1977). The measurement of observer agreement for categorical data. Biometrics, 33, 159-174.

Lochman, J. E., Powell, N. P., Boxmeyer, C. L., Qu, L., Wells, K. C., \& Windle, M. (2009). Implementation of a school-based prevention program: Effects of counselor and school characteristics. Professional Psychology: Research and Practice, 40(5), 476-482.

Lombard, M., Snyder-Duch, J., \& Bracken, C. C. (2002). Assessment and reporting of intercoder reliability. Communication Research, 28(4), 587-604.

Loo, R., \& Loewen, P. (2004). Confirmatory factor analyses of scores from full and short versions of the Marlowe-Crowne Social Desirability Scale. Journal of Applied Social Psychology, 34(11), 2343-2352.

Mihalic, S. F., Fagan, A. A., \& Argamaso, S. (2008). Implementing the Life Skills Training drug prevention program: Factors related to implementation fidelity. Implementation Science, 3(5), doi:10.1186/1748-5908-3-5.

National Institute on Drug Abuse. (1997). Preventing Drug Use Among Children and Adolescents: A Research-Based Guide. National Institute on Drug Abuse, Rockville, MD.

Nelson, J. L., Palonsky, S. B., \& McCarthy, M. R. (2004). Critical issues in education: Dialogues and dialectics (5th ed.). Boston, MA: McGraw Hill.

Pankratz, M. M., Jackson-Newson, J., Giles, S. M., Ringwalt, C. L., Bliss, K., \& Bell, M. L. (2006). Implementation fidelity in a teacher-led alcohol use prevention curriculum. Journal of Drug Education, 36(4), 317-333. 
Payne, A. A., Gottfredson, D. C., \& Gottfredson, G. D. (2006). School predictors of the intensity of implementation of school-based prevention programs: Results from a national study. Prevention Science, 7, 225-237.

Pentz, M. A., Trebow, E. A., Hansen, W. B., MacKinnon, D. P., Dwyer, J. H., Johnson, C. A., Flay, B. R., Daniels, S., \& Cormack, C. (1990). Effects of program implementation on adolescent drug use behavior: The Midwestern Prevention Project (MPP). Evaluation Review, 14, 264-289.

Resnicow, K., Davis, M., Smith, M., Lazarus-Yaroch, A., Baranowski, T., Baranowski, J., Doyle, C., \& Wang, D. T. (1998). How best to measure implementation of school health curricula: A comparison of three measures. Health Education Research, 13(2), 239-250.

Reynolds, W. M. (1982). Development of reliable and valid short forms of the MarloweCrowne Social Desirability Scale. Journal of Clinical Psychology, 38(1), 119-125.

Ringwalt, C. L., Pankratz, M.M., Hansen, W. B., Dusenbury, L., Jackson-Newsom, J., Giles, S. M., \& Brodish, P. H. (2009). The potential of coaching as a strategy to improve the effectiveness of school-based substance use prevention curricula. Health Education \& Behavior, 36(4), 696-710.

Ringwalt, C. L., Ennett, S., Johnson, R., Rohrbach, L. A., Simons-Rudolph, A., Vincus, A., \& Thorne, J. (2003). Factors associated with fidelity to substance use prevention curriculum guides in the nation's middle schools. Health Education \& Behavior, 30, 375-391.

Ringwalt, C. L., Ennett, S.T., Vincus, A.A., Thorne, J., Rohrbach, L.A., \& SimonsRudolph, A. (2002). The prevalence of effective substance use prevention curricula in U.S. middle schools. Prevention Science, 3(4), 257-265.

Rogers, E. M. (1995). Diffusion of innovations. New York: The Free Press.

Rogers, E. M., Eveland, J. D. and Klepper, C. (1977). The Innovation Process in Organizations. Department of Journalism, University of Michigan, Ann Arbor, MI.

Rohrbach, L.A., Ringwalt, C.L., Ennett, S.T., \& Vincus, A.A. (2005). Factors associated with adoption of evidence-based substance use prevention curricula in U.S. school districts. Health Education Research 20(5), 514-526.

Rohrbach, L. A., D’Onofrio, C. N., Backer, T. E., \& Montgomery, S. B. (1996). Diffusion of school-based substance abuse prevention programs. American Behavioral Scientist, 39(7), 919-934. 
Rohrbach, L. A., Graham, J. W., \&Hansen, W. B. (1993). Diffusion of a school-based substance abuse prevention program: Predictors of program implementation. Preventive Medicine, 22, 237-260.

Rothenbach Research and Consulting, Florida Department of Children and Families, \& Families Substance Abuse Program. (2008). 2008 Florida Youth Substance Abuse Survey. Retrieved November 1, 2010, from http://www.dcf.state.fl.us/programs/samh/publications/fysas/08Survey/2008FYSASState wideTablesFinal.pdf

Rubin, A., \& Babbie, E. R. (2005). Research methods for social work (5 ${ }^{\text {th }}$ ed.). Belmont, CA: Brooks/Cole-Thompson Learning.

Scott, T. M., Anderson, C., Mancil, R., \& Alter, P. (2008). Function-based supports for individual students in school settings. In W. Sailor, G. Dunlap, G. Sugai, \& R. Horner (Eds.), Handbook of positive behavior support: Issues in clinical child psychology (pp. 421-441). New York, NY: Springer.

Singletary, M. W. (1993). Mass communication research: Contemporary methods and applications. Boston: Addison-Wesley.

Smith, J. D., Schneider, B. H., Smith, P. K., \& Ananiadou, K. (2004). The effectiveness of whole-school anti-bullying programs: A synthesis of evaluation research. School Psychology Review, 33, 547-560.

Sobeck, J. L., Abbey, A., \& Agius, E. (2006). Lessons learned from implementing school-based substance abuse prevention curriculums. Children \& Schools, 28(2), 77-85.

Soper, D. (nd). Hierarchical multiple regression power calculator [computer software]. Available from http://www.danielsoper.com/statcalc/calc09.aspx.

St. Pierre, T. L., \& Kaltreider, D. L. (2004). Tales of refusal, adoption, and maintenance: Evidence-based substance abuse prevention via school-extension collaborations. American Journal of Evaluation, 25(4), 479-491.

Thaker, S., Steckler, A., Sanchez, V., Khatapoush, S., Rose, J., \& Hallfors, D. D. (2008). Program characteristics and organizational factors affecting the implementation of a school-based indicated prevention program. Health Education Research, 23(2), 238-248.

Tobler, N. S. (1986). Meta-analysis of 143 adolescent drug prevention programs: Quantitative outcome results of program participants compared to a control or comparison group. Journal of Drug Issues, 16, 537-567. 
Tobler, N. S., Roona, M. R., Ochshorn, P., Marshall, D. G., Streke, A. V., \& Stackpole, K. M. (2000). School-based adolescent drug prevention programs: 1998 meta-analysis. Journal of Primary Prevention, 20, 275-337.

Tricker, R., \& Davis, L. G. (1988). Implementing drug education in schools: An analysis of the costs and teacher perceptions. Journal of School Health, 58(5), 181-185.

U.S. Department of Education, Office of Special Educational Research and Improvement, Office of Reform Assistance and Dissemination, Safe, Disciplined, and Drug-Free Schools Programs, Washington, D.C., 2001, http://www.ed.gov/admins/lead/safety/exemplary01/exemplary01.pdf; retrieved: 2 February 2009.

U.S. Department of Health and Human Services. (2004). The health consequences of smoking: A report of the Surgeon General. Atlanta, GA: U.S. Department of Health and Human Services, Centers for Disease Control and Prevention, National Center for Chronic Disease Prevention and Health Promotion, Office on Smoking and Health.

Wagner, E. F., Tubman, J. G., \& Gil, A. G. (2004). Implementing school-based substance abuse interventions: Methodological dilemmas and recommended solutions. Addiction, 99(2), 106-119.

Walker, H. M., Horner, R. H., Sugai, G., Bullis, M., Sprague, J. R., Bricker, D., et al. (1996). Integrated approaches to preventing antisocial behavior patterns among schoolage children and youth. Journal of Emotional \& Behavioral Disorders, 4(4), 194-209.

Webster-Stratton, C., \& Taylor, T. (2001). Nipping early risk factors in the bud: Preventing substance abuse, delinquency, and violence in adolescence through interventions targeted at young children (0-8 years). Prevention Science, 2(3), 165-192.

Wilson, S. J., Lipsey, M. W., \& Derzon, J. H. (2003). The effects of school-based intervention programs on aggressive behavior: A meta-analysis. Journal of Consulting and Clinical Psychology, 71, 136-149.

Young, M., Hendricks, C., \& Hubbard, B. (1986). Teacher training workshops in drug education: Correlates of curriculum implementation. (ERIC Document Reproduction Service No. ED277673). 


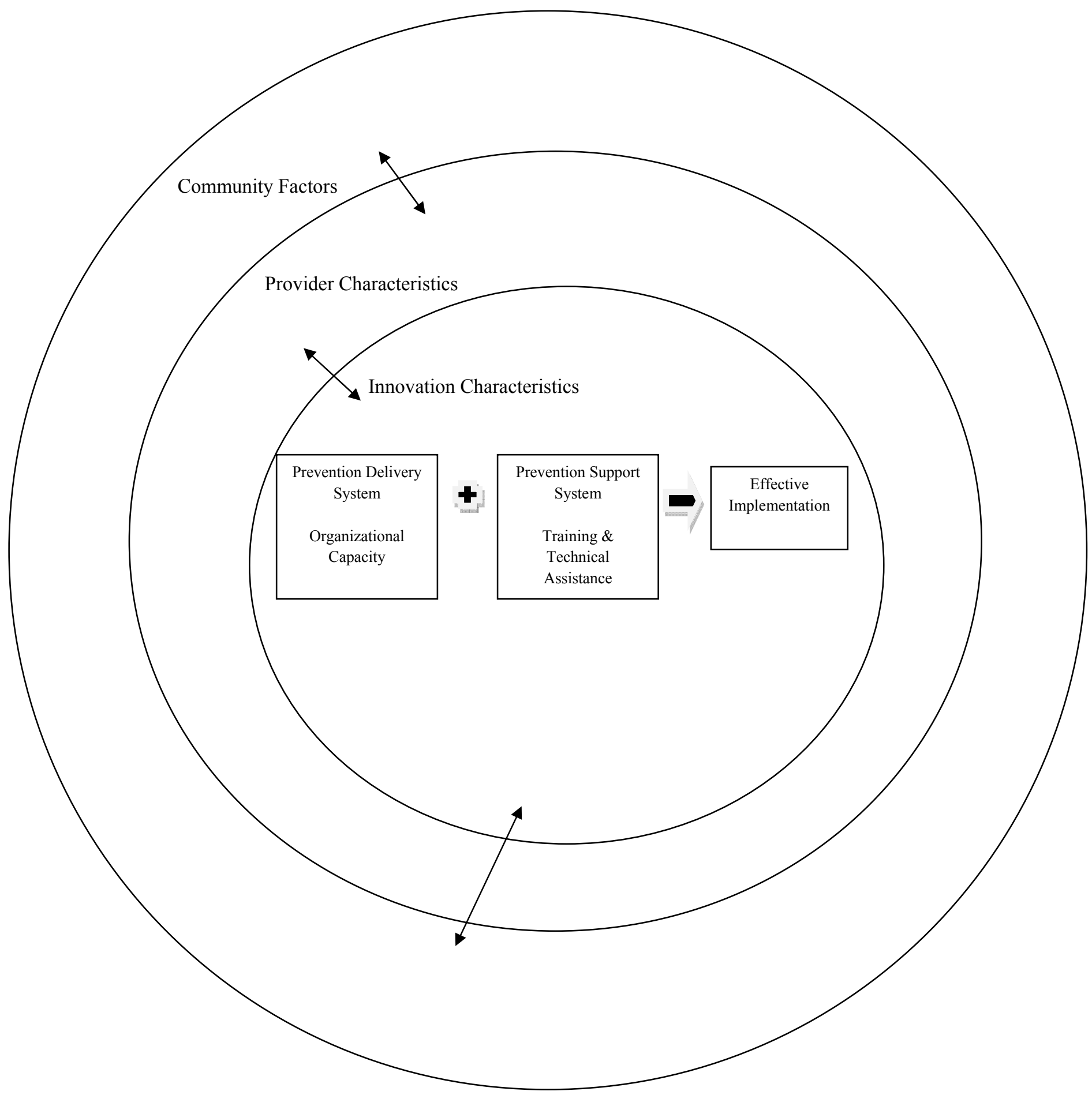

Figure 1. Ecological framework for understanding effective implementation

Note. From "Implementation Matters: A Review of Research on the Influence of Implementation on Program Outcomes and the Factors Affecting Implementation," by J. A. Durlak \& E. P. DuPre, 2008, American Journal of Community Psychology, 41, pp. 337-338. 
Table 1. Factors Affecting Program Implementation

I. Community Level Factors

A. Prevention Theory and Research

B. Politics

C. Funding

D. Policy

II. Provider Characteristics

A. Perceived Need for Innovation

Extent to which the proposed innovation is relevant to local needs

B. Perceived Benefits of Innovation

Extent to which the innovation will achieve benefits desired at the local level

C. Self-efficacy

Extent to which providers feel they will be able to do what is expected

D. Skill Proficiency

Possession of the skills necessary for implementation

III. Characteristics of the Innovation

A. Compatibility (contextual appropriateness, fit, congruence, match)

Extent to which the intervention fits with an organization's mission, priorities, and values.

B. Adaptability (program modification, reinvention)

The extent to which the proposed program can be modified to fit provider preferences, organizational practices, and community needs, values, and cultural norms

IV. Factors Relevant to the Prevention Delivery System: Organizational Capacity

\section{A. General Organizational Factors}

1. Positive Work Climate

Climate may be assessed by sampling employees' views about morale, trust, collegiality, and methods of resolving disagreements

2. Organizational norms regarding change (e.g., openness to change, innovativeness, risk-taking)

This refers to the collective reputation and norms held by an organization in relation to its willingness to try new approaches as opposed to maintaining the status quo

3. Integration of new programming

This refers to the extent to which an organization can incorporate an innovation into its existing practices and routines

4. Shared vision (shared mission, consensus, commitment, staff buy-in)

This refers to the extent to which organizational members are united regarding the value and purpose of the innovation 


\section{B. Specific Practices and Processes}

1. Shared decision-making (local input, community participation or involvement, local ownership, collaboration)

The extent to which relevant parties (e.g., providers, administrators, researchers, and community members) collaborate in determining what will be implemented and how

2. Coordination with other agencies (partnerships, networking, intersector alliances, multidisciplinary linkages)

The extent to which there is cooperation and collaboration among local agencies that can bring different perspectives, skills, and resources to bear on program implementation

3. Communication

Effective mechanisms encouraging frequent and open communication

4. Formulation of tasks (workgroups, teams, formalization, internal functioning, effective human resource management)

Procedures that enhance strategic planning and contain clear roles and responsibilities relative to task accomplishments

C. Specific Staffing Considerations

\section{Leadership}

Leadership is important in many respects, for example, in terms of setting priorities, establishing consensus, offering incentives, and managing the overall process of implementation

2. Program champion (internal advocate)

An individual who is trusted and respected by staff and administrators, and who can rally and maintain support for the innovation, and negotiate solutions to problems that develop

3. Managerial/supervisory/administrative support

Extent to which top management and immediate supervisors clearly support and encourage providers during implementation

\section{Factors Related to the Prevention Support System}

\section{A. Training}

Approaches to insure provider proficiencies in the skills necessary to conduct the intervention and to enhance providers' sense of self-efficacy

\section{B. Technical Assistance}

This refers to the combination of resources offered to providers once implementation begins, and may include retraining in certain skills, training of new staff, emotional support, and mechanisms to promote local problem solving efforts

\footnotetext{
Note. From "Implementation Matters: A Review of Research on the Influence of Implementation on Program Outcomes and the Factors Affecting Implementation," by J. A. Durlak \& E. P. DuPre, 2008, American Journal of Community Psychology, 41, pp. 337-338.
} 
Table 2. Factors Influencing Implementation of School-Based Substance Use Prevention Programs in Elementary Schools

\begin{tabular}{|c|c|c|c|c|c|}
\hline Study & Provider Characteristics & Program Characteristics & School Characteristics & $\begin{array}{c}\text { Training / Technical } \\
\text { Assistance Characteristics }\end{array}$ & $\begin{array}{c}\text { Community-Level } \\
\text { Characteristics } \\
\end{array}$ \\
\hline $\begin{array}{l}\text { 1. } \begin{array}{l}\text { Beets et al. } \\
(2008)\end{array}\end{array}$ & $\mathrm{N} / \mathrm{F}$ & $\begin{array}{l}\text { - Attitudes towards the } \\
\text { program }^{\text {a }}\end{array}$ & $\begin{array}{l}\text { - Perceptions of school } \\
\text { climate }^{\mathrm{a}}\end{array}$ & $\mathrm{N} / \mathrm{F}$ & $\mathrm{N} / \mathrm{F}$ \\
\hline $\begin{array}{l}\text { 2. Flannery \& } \\
\text { Torquati } \\
\text { (1993) }\end{array}$ & $\mathrm{N} / \mathrm{F}$ & 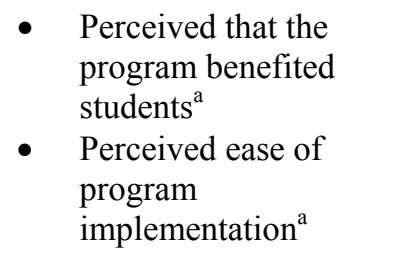 & $\mathrm{N} / \mathrm{F}$ & $\mathrm{N} / \mathrm{F}$ & $\mathrm{N} / \mathrm{F}$ \\
\hline $\begin{array}{l}\text { 3. Gingiss et al. } \\
\text { (1994) }\end{array}$ & $\begin{array}{l}\text { - Personal involvement in } \\
\text { teaching tobacco prevention } \\
\text { education }^{\text {a }}\end{array}$ & $\mathrm{N} / \mathrm{F}$ & $\begin{array}{l}\text { - Perceptions of intra- } \\
\text { and inter-personal } \\
\text { support for teaching } \\
\text { tobacco prevention } \\
\text { education }{ }^{\mathrm{a}} \\
\text { - } \quad \text { School involvement } \\
\text { in tobacco } \\
\text { prevention }^{\mathrm{a}}\end{array}$ & $\mathrm{N} / \mathrm{F}$ & $\mathrm{N} / \mathrm{F}$ \\
\hline $\begin{array}{l}\text { 4. Klimes- } \\
\text { Dougan et } \\
\text { al. }(2009)\end{array}$ & $\begin{array}{ll}\text { - } & \text { Age }^{\mathrm{b}} \\
\text { - } & \text { Neuroticism (negative } \\
\text { - } & \text { Exlationship) }^{\mathrm{b}} \\
\text { - } & \text { Optroversion }^{\mathrm{b}} \\
\text { - } & \text { Conscientiousness }^{\mathrm{b}} \\
\text { - } & \text { Reappraisal coping } \\
\text { - } & \text { Avoidant coping } \\
\text { - } & \text { Job satisfaction (negative } \\
\text { - } & \text { relationship) } \\
& \text { Pre-implementation expectancies } \\
& \text { (e.g., self-efficacy and program } \\
& \text { acceptance) about the expected } \\
\text { - } & \text { success of the program }{ }^{\mathrm{b}, \mathrm{c}} \\
& \text { Post-implementation attitudes, } \\
& \text { such as self-efficacy and }\end{array}$ & $\mathrm{N} / \mathrm{F}$ & 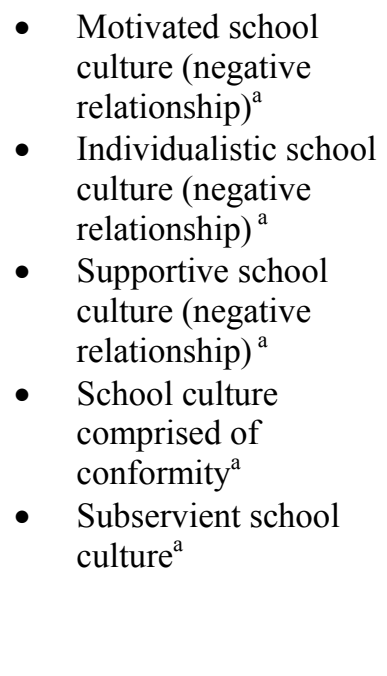 & $\begin{array}{l}\text { - Support from } \\
\text { prevention program } \\
\text { supervisor }{ }^{b}\end{array}$ & $\mathrm{~N} / \mathrm{F}$ \\
\hline
\end{tabular}


program acceptance $e^{b, c}$

5. Lochman et $\bullet$ Agreeableness $^{\mathrm{d}} \mathrm{N} / \mathrm{F}$ al. (2009)

- Conscientiousness ${ }^{\mathrm{d}}$

6. Rohrbach et - Teaching experience (negative al. (1993) relationship for dosage and adherence) $^{\mathrm{a}}$

- $\quad$ Experience with teaching methods compatible with psychosocial-based programs $^{\mathrm{a}}$

- Enthusiastic about the program ${ }^{\mathrm{a}}$

- Implementation self-efficacy ${ }^{a}$

- Overall teaching skills ${ }^{\mathrm{e}}$

- Program acceptance ${ }^{a}$

7. Young et al. - Gender of the respondent $\mathrm{t}^{\mathrm{a}}$ (1986)

- Perceived freedom in deciding what to teach ${ }^{\mathrm{a}}$
- High level of school managerial control

- Encouragement from

- Active participation in teacher training ${ }^{\mathrm{f}}$

principal $^{\mathrm{a}}$

- Felt better prepared to teach the program ${ }^{\mathrm{a}}$

$\mathrm{a}=$ reported by teachers. $\mathrm{b}=$ reported by family advocates. $\mathrm{c}=$ this factor should also be represented in the provider characteristics column. $\mathrm{d}=$ reported by counselors.

$\mathrm{e}=$ reported by principals. $\mathrm{f}=$ reported by health educators who conducted trainings. $\mathrm{N} / \mathrm{F}=$ no findings. 
Table 3. Review of Study Methodology

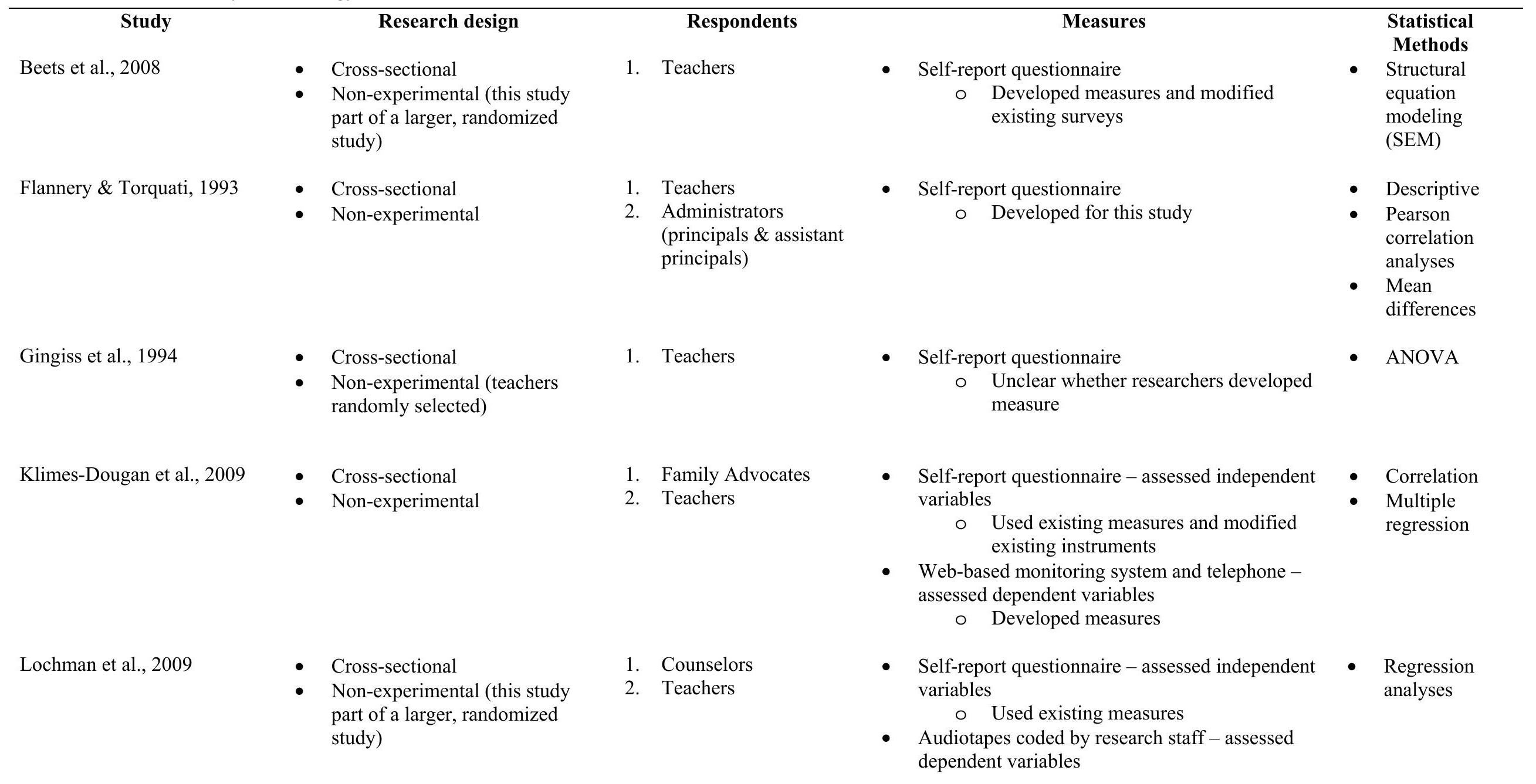


Rohrbach et al., 1993

Young et al., 1986
- Cross-sectional

- Non-experimental (this study part of a larger, randomized study)

- Cross-sectional

- Non-experimental
1. Teachers

2. Principals

3. Students

1. Teachers
- Self-report questionnaire and observations assessed dependent variables

○ Developed for this study

- Self-report questionnaire - assessed independent variables

- Developed for this study

- Self-report questionnaire

○ Developed for this study
Univariate tests

- Pearson correlation analyses

- Logistical regression 
Table 4. Self-Report Data Collection Method and Corresponding Response Rates

\section{Study}

Beets et al., 2008

Flannery \& Torquati, 1993

Gingiss et al., 1994

Klimes-Dougan et al., 2009

Lochman et al., 2009

Rohrbach et al., 1993

Young et al., 1986
Data Collection Method

NR

Distributed by \& returned to administrative personnel at schools

Mail

Mail

NR

NR

Mail
Response Rate

$60 \%$

$31 \%$

$79 \%$

NR - Family Advocates $85 \%$ - Teachers

NR

NR

$60 \%$ 
Figure 2. Proposed Model

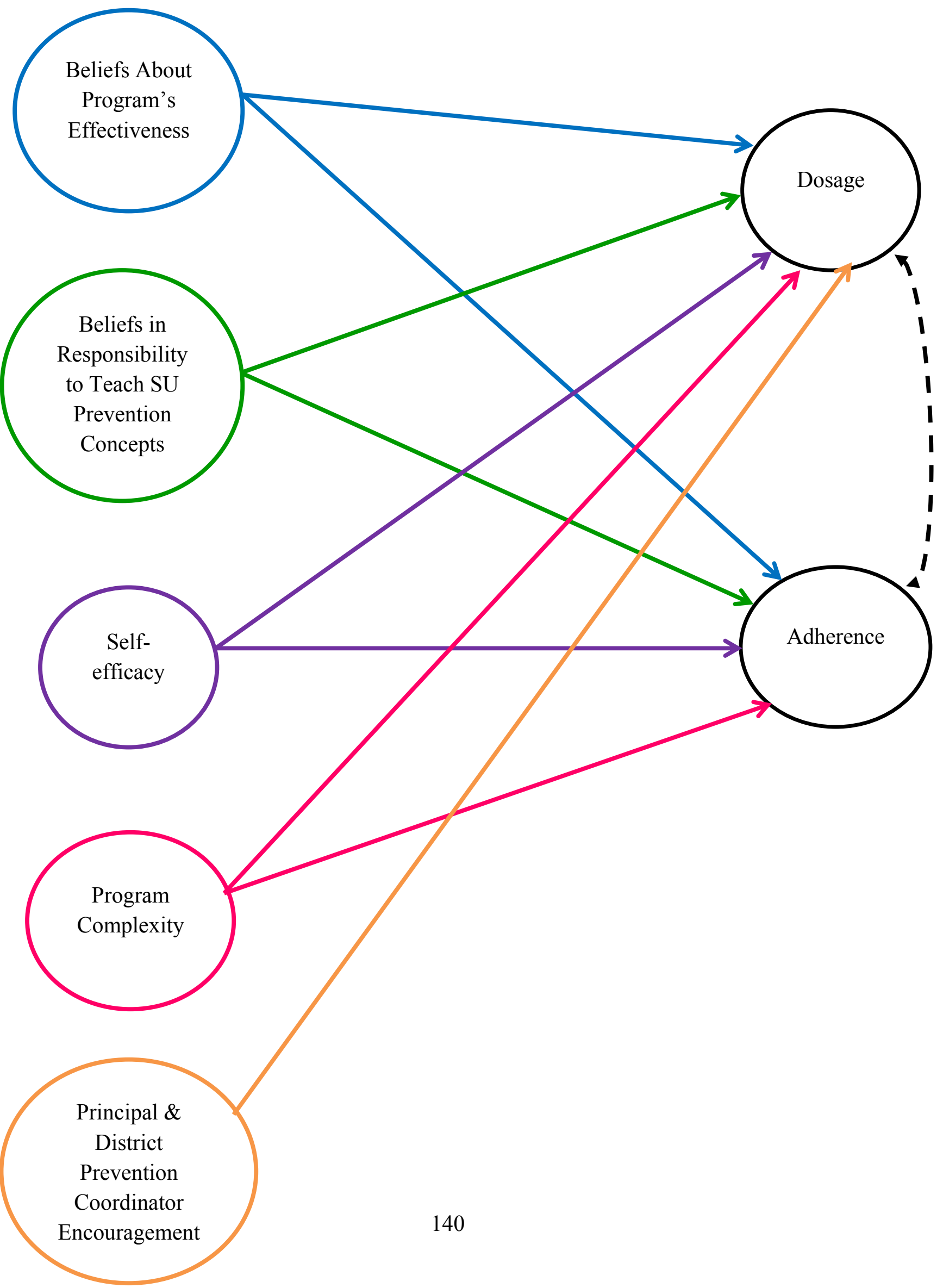


Table 5. Demographic Characteristics of Respondents

\begin{tabular}{|c|c|c|}
\hline & $\%$ & $\mathrm{~N}$ \\
\hline Total Respondents & $100 \%$ & 65 \\
\hline \multicolumn{3}{|l|}{ Gender } \\
\hline Female & $91 \%$ & 59 \\
\hline Male & $9 \%$ & 6 \\
\hline \multicolumn{3}{|l|}{ Race } \\
\hline White & $85 \%$ & 55 \\
\hline Black & $8 \%$ & 5 \\
\hline Asian & $5 \%$ & 3 \\
\hline Other & $3 \%$ & 2 \\
\hline \multicolumn{3}{|l|}{ Hispanic } \\
\hline Yes & $16 \%$ & 10 \\
\hline No & $84 \%$ & 54 \\
\hline \multicolumn{3}{|c|}{ Age (years) $[\mathrm{M}=47.34(11.50)]$} \\
\hline $25-34$ & $18 \%$ & 10 \\
\hline $35-44$ & $25 \%$ & 15 \\
\hline $45-54$ & $18 \%$ & 13 \\
\hline $55+$ & $29 \%$ & 19 \\
\hline \multicolumn{3}{|l|}{$\underline{\text { Job Title }}$} \\
\hline Guidance Counselor & $77 \%$ & 49 \\
\hline Teacher & $23 \%$ & 15 \\
\hline \multicolumn{3}{|l|}{ Highest Degree } \\
\hline Bachelors & $19 \%$ & 12 \\
\hline Masters & $76 \%$ & 47 \\
\hline $\mathrm{PhD} / \mathrm{EdD}$ & $5 \%$ & 3 \\
\hline \multicolumn{3}{|c|}{$\begin{array}{l}\text { Years Working at Current School } \\
{[\mathrm{M}=8.60(5.94)]}\end{array}$} \\
\hline$\leq 5$ years & $32 \%$ & 20 \\
\hline $6-15$ years & $56 \%$ & 35 \\
\hline $16+$ years & $13 \%$ & 8 \\
\hline \multicolumn{3}{|c|}{$\frac{\text { Years Working at Schools Overall }}{[\text { Mean }=17.45(9.84)]}$} \\
\hline$\leq 5$ years & $9.5 \%$ & 6 \\
\hline $6-15$ years & $35.9 \%$ & 23 \\
\hline $16+$ years & $54.9 \%$ & 35 \\
\hline
\end{tabular}




\begin{tabular}{lcc}
\hline $\begin{array}{l}\text { Years Teaching Substance Use } \\
\text { Prevention at Current School }\end{array}$ & & \\
[Mean=7.24 (5.53)] & & \\
$\leq 5$ years & $36 \%$ & 23 \\
6-15 years & $49 \%$ & 31 \\
16+ years & $10 \%$ & 6 \\
& & \\
Years Teaching Substance Use & & \\
Prevention Overall [Mean=11.44 & & \\
(8.28)] & $19 \%$ & 12 \\
$\leq 5$ years & $50 \%$ & 33 \\
6-15 years & $24 \%$ & 15 \\
\hline 6+ years & \\
\hline
\end{tabular}


Table 6. Means and Reliabilities of Independent Variables

\begin{tabular}{|c|c|c|c|c|}
\hline & $\mathrm{N}$ & Mean (SD) & $\begin{array}{c}\text { Cronbach's } \\
\text { Alpha }\end{array}$ & $\begin{array}{c}\text { Number of } \\
\text { items }\end{array}$ \\
\hline $\begin{array}{l}\text { Beliefs About Program Effectiveness } \\
1=\text { strongly disagree } \\
5=\text { strongly agree }\end{array}$ & 56 & $4.10(.51)$ & .89 & 10 \\
\hline $\begin{array}{l}\text { Beliefs About Responsibility to Teach } \\
\text { Substance Use Prevention } \\
1=\text { none } \\
3=\mathrm{a} \text { lot }\end{array}$ & 60 & $2.75(.38)$ & .94 & 7 \\
\hline $\begin{array}{l}\text { Self-efficacy } \\
1=\text { not at all confident } \\
4=\text { very confident }\end{array}$ & 56 & $3.65(.49)$ & .84 & 3 \\
\hline $\begin{array}{l}\text { Ease of Program Implementation } \\
1=\text { strongly disagree } \\
5=\text { strongly agree }\end{array}$ & 57 & $4.37(.59)$ & .86 & 6 \\
\hline $\begin{array}{l}\text { Principal Encouragement } \\
1=\text { strongly disagree } \\
5=\text { strongly agree }\end{array}$ & 56 & $3.89(.79)$ & .77 & 2 \\
\hline
\end{tabular}


Figure 3. Beliefs About Program's Effectiveness

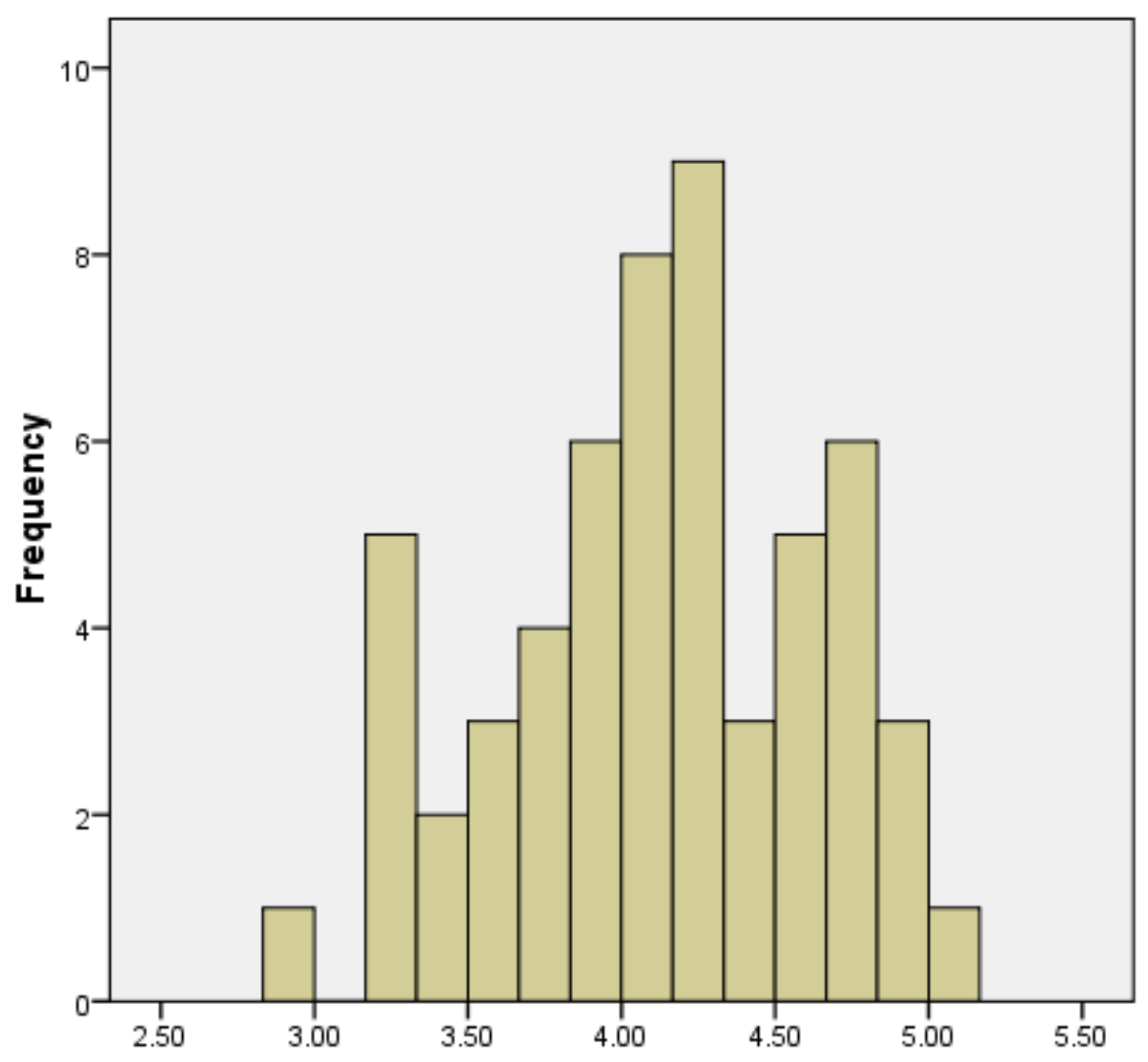

Mean $=4.10$ Stc. Dev. $=0.505$

$\mathrm{N}=56$

Note. $1=$ strongly disagree; $5=$ strongly agree 
Figure 4. Beliefs About School's Responsibility to Teach Substance Use Prevention Lessons

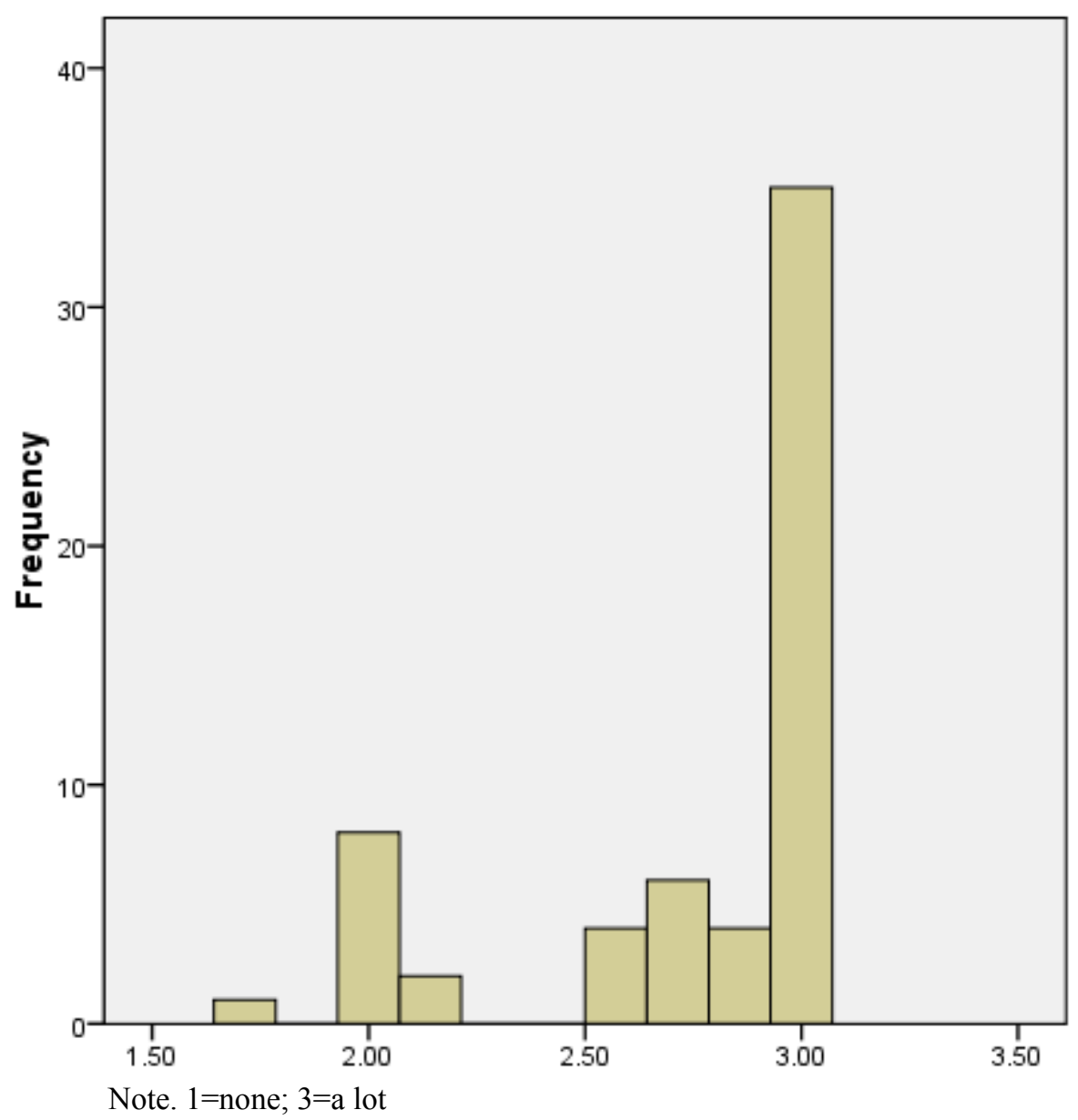

Mean $=2.75$ Std. Dev. $=0.384$

$\mathrm{N}=60$

Note. $1=$ none; $3=\mathrm{a}$ lot 
Figure 5. Self-efficacy

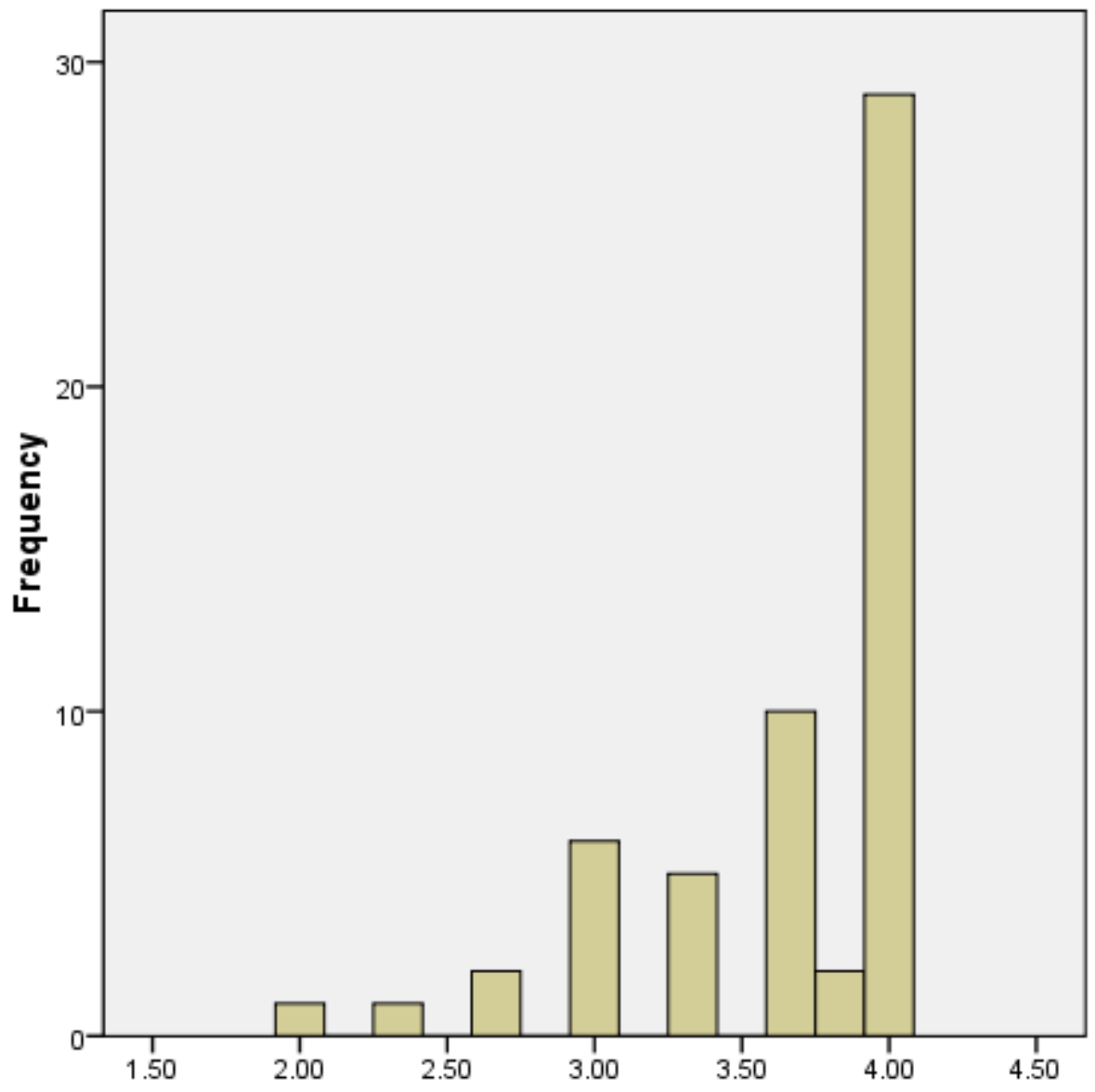

Mean $=3.65$

Std. Dev. $=0.487$ $\mathrm{N}=56$

Note. $1=$ not at all confident; $4=$ very confident 
Figure 6. Ease of Program Implementation (Program Complexity)

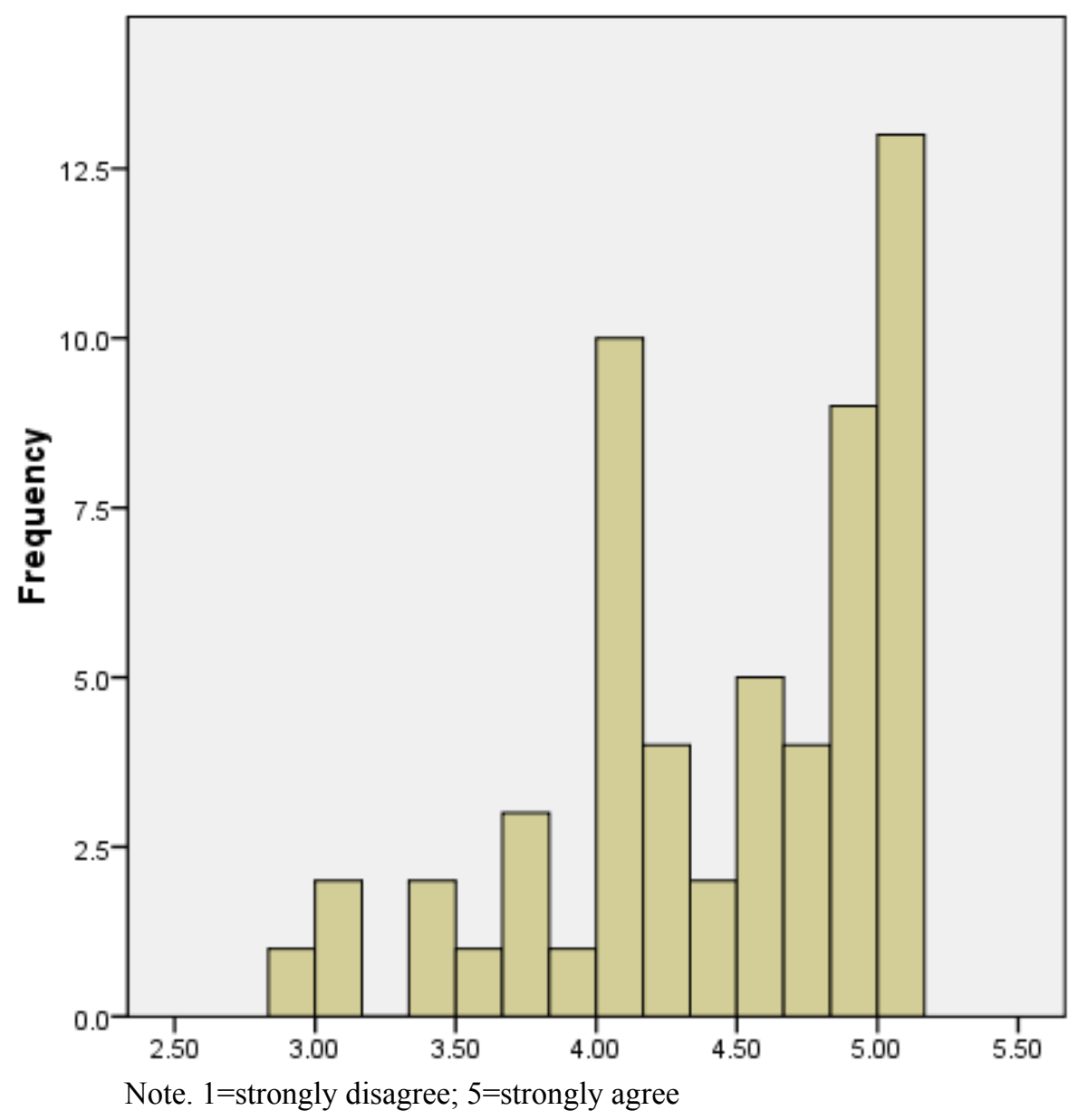

Mean $=4.37$

Std. Dev. $=0.5$
$N=57$

Note. $1=$ strongly disagree; $5=$ strongly agree 
Figure 7. Principal Encouragement

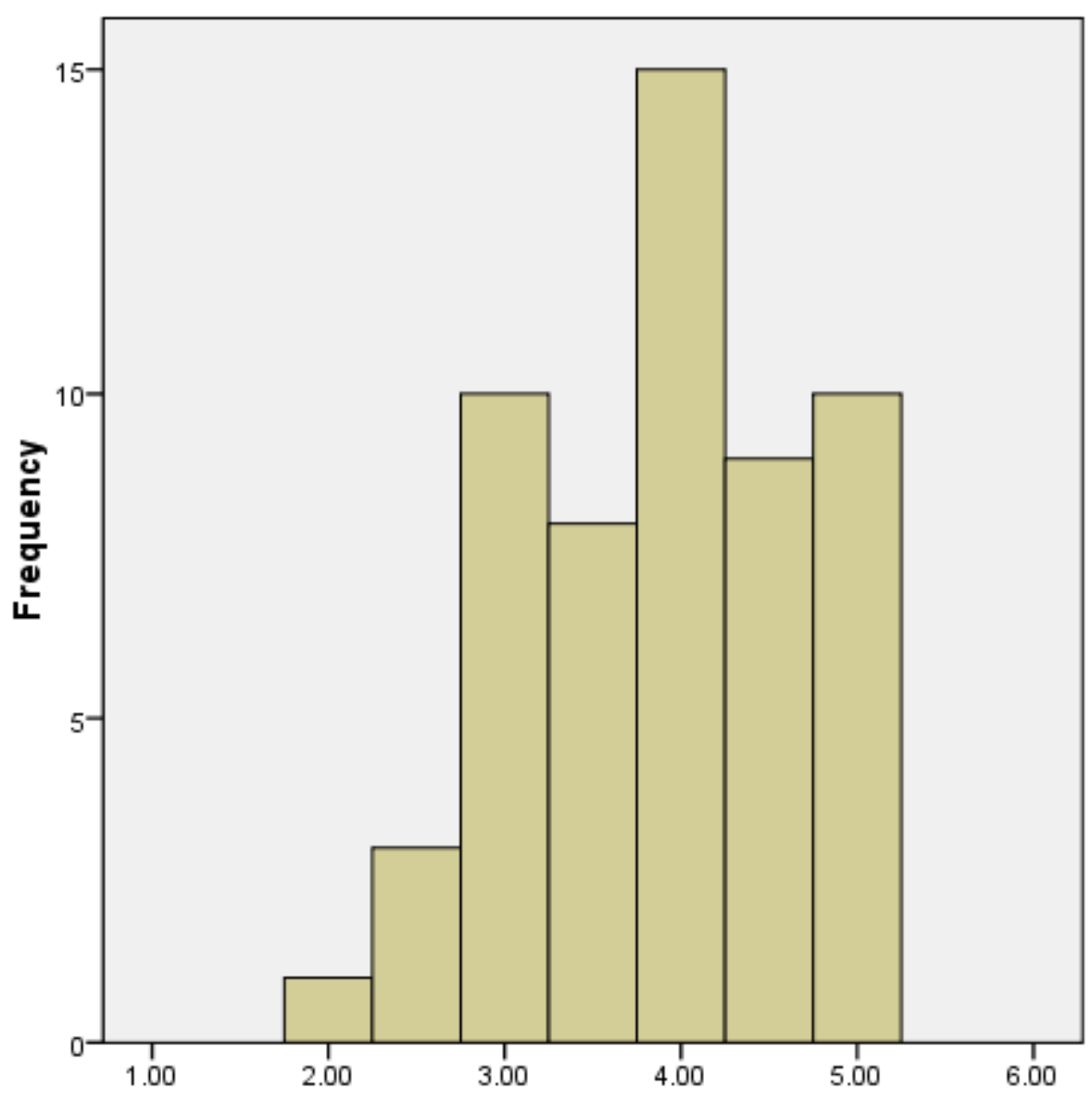

Mean $\mathbf{= 3 . 8 9}$

Std. Dev. $=0.79$

$\mathrm{N}=56$

Note. $1=$ strongly disagree; $5=$ strongly agree 
Table 7. Pearson Correlations Between Dependent, Independent, and Demographic Variables Dependent Variable

\begin{tabular}{lc}
\hline & Dosage \\
\hline Ease of program implementation & $0.32^{*}$ \\
Years working at current school & $-0.29^{*}$ \\
\end{tabular}

\begin{tabular}{lc}
\hline & $\begin{array}{c}\text { Adherence (following } \\
\text { curriculum guide closely) }\end{array}$ \\
\hline Ease of program implementation & $0.56^{* * *}$ \\
Beliefs about program's effectiveness & $0.31^{*}$ \\
Race (being non-White) & $-0.25^{+}$ \\
& \\
\hline & $\begin{array}{c}\text { Adherence (frequency using } \\
\text { interactive components) }\end{array}$ \\
\hline Ease of program implementation & $0.54^{* * *}$ \\
Beliefs about program's effectiveness & $0.32^{*}$ \\
Self-efficacy & $0.33^{*}$ \\
Race (being non-White) & $-0.25^{+}$ \\
Encouragement from district prevention & $-0.23^{+}$ \\
coordinator & \\
& \\
\hline & Adherence (modify \\
& curriculum vs. follow \\
& closely) \\
\hline Years working in schools overall & $0.33^{*}$ \\
Ease of program implementation & $0.24^{+}$ \\
Age & $0.26^{+}$ \\
\hline${ }^{+} \mathrm{p}<.10 . \quad * \mathrm{p}<.05 . \quad * * \mathrm{p}<.01$. & $* * * \mathrm{p}<.001$.
\end{tabular}


Table 8. Dosage and Adherence by Job Title

\begin{tabular}{|c|c|}
\hline Guidance Counselor & Teacher \\
\hline$(n=44-46)$ & $(n=13$ \\
\hline $35 \%$ & $31 \%$ \\
\hline $30 \%$ & $62 \%$ \\
\hline $35 \%$ & $8 \%$ \\
\hline
\end{tabular}

Follow Curriculum Guide

$\begin{array}{rcc}\text { Very closely } & 28 \% & 23 \% \\ \text { Somewhat closely } & 57 \% & 77 \% \\ \text { Not very closely } & 9 \% & 0 \% \\ \text { d not to use a guide } & 7 \% & 0 \%\end{array}$

Use of Interactive Components

All the time $\quad 27 \% \quad 39 \%$

Most of the time $\quad 39 \% \quad 39 \%$

Sometimes $\quad 32 \% \quad 15 \%$

Not at all $\quad 2 \% \quad 8 \%$

Modify or Follow Curriculum Guide

Modify curriculum

Follow curriculum

$89 \% \quad 77 \%$

$11 \% \quad 23 \%$

Table 9. Pearson Correlations Among Dependent Variables

Greater amount of program delivery

Frequency using interactive program components $0.30^{*}$

Closely following curriculum guide

$0.27^{+}$

\begin{tabular}{lc}
\hline & $\begin{array}{c}\text { Following curriculum } \\
\text { guide closely }\end{array}$ \\
\hline Frequency using interactive components & $0.39^{*}$ \\
Modifying curriculum & $0.35^{*}$ \\
\hline${ }^{+} \mathrm{p}<.10 . \quad * \mathrm{p}<.05 . \quad * * \mathrm{p}<.01 . \quad * * * \mathrm{p}<.001$. &
\end{tabular}


Table 10. Pearson Correlations Among Independent and Demographic Variables

Beliefs of program's

effectiveness

\begin{tabular}{lc}
\hline Ease of implementation & 0.54 \\
Self-efficacy & $0.26^{+}$ \\
$\begin{array}{l}\text { District prevention coordinator } \\
\text { encouragement }\end{array}$ & $0.27^{+}$ \\
Principal encouragement & $0.26^{+}$
\end{tabular}

\begin{tabular}{|c|c|}
\hline & $\begin{array}{l}\text { Ease of program } \\
\text { implementation }\end{array}$ \\
\hline Self-efficacy & $0.40^{* *}$ \\
\hline \multirow[t]{2}{*}{ Age } & $0.33^{*}$ \\
\hline & $\begin{array}{l}\text { Years teaching substance } \\
\text { use prevention overall }\end{array}$ \\
\hline Principal encouragement & $0.36^{*}$ \\
\hline \multirow[t]{2}{*}{ Self-efficacy } & $0.35^{* *}$ \\
\hline & $\begin{array}{l}\text { Years working at } \\
\text { current school }\end{array}$ \\
\hline \multirow[t]{2}{*}{ Self-efficacy } & $0.23^{+}$ \\
\hline & $\begin{array}{c}\text { District prevention } \\
\text { coordinator encouragement }\end{array}$ \\
\hline Bachelor's degree & $0.34^{*}$ \\
\hline
\end{tabular}


Table 11. Regression Findings for Amount of Program Delivery (Dosage)

Coefficients $^{\mathrm{a}}$

\begin{tabular}{|c|c|c|c|c|c|}
\hline \multirow[b]{2}{*}{ Model } & & \multicolumn{2}{|c|}{$\begin{array}{l}\text { Unstandardized } \\
\text { Coefficients }\end{array}$} & \multirow[t]{2}{*}{$\begin{array}{l}\text { Standardized } \\
\text { Coefficients }\end{array}$} & \multirow[b]{2}{*}{ Sig. } \\
\hline & & B & $\begin{array}{l}\text { Std. } \\
\text { Error }\end{array}$ & & \\
\hline \multirow[t]{13}{*}{2} & (Constant) & -1.756 & 1.640 & & .289 \\
\hline & Gender & .370 & .342 & .142 & .284 \\
\hline & Bachelor's or Master's degree & .163 & .278 & .083 & .559 \\
\hline & White & -.273 & .262 & -.131 & .303 \\
\hline & Years teaching SU overall & -.022 & .016 & -.232 & .171 \\
\hline & $\begin{array}{l}\text { Years at schools overall, including } \\
\text { this school }\end{array}$ & .018 & .012 & .226 & .149 \\
\hline & $\begin{array}{l}\text { Beliefs about program's } \\
\text { effectiveness }\end{array}$ & -.070 & .262 & -.043 & .790 \\
\hline & $\begin{array}{l}\text { Beliefs about school's } \\
\text { responsibility to teach SU } \\
\text { prevention }\end{array}$ & .363 & .264 & .176 & .175 \\
\hline & Self-efficacy & .125 & .237 & .075 & .600 \\
\hline & Ease of program implementation & .407 & .231 & .298 & $.084^{+}$ \\
\hline & Principal encouragement & .194 & .143 & .187 & .180 \\
\hline & Social desirability & .021 & .036 & .076 & .553 \\
\hline & $\begin{array}{l}\text { District prevention coordinator } \\
\text { encouragement }\end{array}$ & -.217 & .140 & -.209 & .127 \\
\hline
\end{tabular}

${ }^{+} \mathrm{p}<.10 . \quad * \mathrm{p}<.05 . \quad * * \mathrm{p}<.01 . \quad * * * \mathrm{p}<.001$. 
Table 12. Regression findings for Following Curriculum Guide (Adherence)

\begin{tabular}{|c|c|c|c|c|c|c|}
\hline \multirow[b]{3}{*}{ Model } & & \multicolumn{2}{|c|}{$\begin{array}{l}\text { Unstandardized } \\
\text { Coefficients }\end{array}$} & \multirow[t]{2}{*}{$\begin{array}{l}\text { Standardized } \\
\text { Coefficients }\end{array}$} & \multirow[b]{3}{*}{$\mathrm{t}$} & \multirow[b]{3}{*}{ Sig. } \\
\hline & & & Std. & & & \\
\hline & & B & Error & Beta & & \\
\hline \multirow[t]{13}{*}{2} & (Constant) & -1.079 & 1.645 & & -.656 & .516 \\
\hline & Gender & -.385 & .398 & -.139 & -.967 & .340 \\
\hline & White & -.347 & .256 & -.177 & -1.355 & .184 \\
\hline & Bachelor's or Master's degree & .022 & .321 & .011 & .068 & .946 \\
\hline & $\begin{array}{l}\text { Years working at schools } \\
\text { overall, including this school }\end{array}$ & .010 & .014 & .126 & .745 & .462 \\
\hline & $\begin{array}{l}\text { Years teaching SU } \\
\text { prevention overall }\end{array}$ & -.007 & .016 & -.078 & -.447 & .657 \\
\hline & $\begin{array}{l}\text { Beliefs about program's } \\
\text { effectiveness }\end{array}$ & -.056 & .274 & -.036 & -.204 & .840 \\
\hline & $\begin{array}{l}\text { Beliefs about school's } \\
\text { responsibility to teach SU } \\
\text { prevention }\end{array}$ & .284 & .315 & .128 & .902 & .373 \\
\hline & Self-efficacy & .075 & .235 & .049 & .318 & .753 \\
\hline & $\begin{array}{l}\text { Ease of program } \\
\text { implementation }\end{array}$ & .723 & .228 & .580 & 3.172 & $.003^{* *}$ \\
\hline & Principal encouragement & -.061 & .153 & -.060 & -.397 & .694 \\
\hline & Social desirability & -.002 & .036 & -.006 & -.044 & .965 \\
\hline & $\begin{array}{l}\text { District prevention } \\
\text { coordinator encouragement }\end{array}$ & .094 & .143 & .097 & .662 & .512 \\
\hline
\end{tabular}


Table 13. Regression findings for Frequency Using Interactive Components (Adherence)

\begin{tabular}{|c|c|c|c|c|c|c|}
\hline \multirow[b]{2}{*}{ Model } & & \multicolumn{2}{|c|}{$\begin{array}{l}\text { Unstandardized } \\
\text { Coefficients }\end{array}$} & $\begin{array}{l}\text { Standardized } \\
\text { Coefficients }\end{array}$ & \multirow[b]{2}{*}{$\mathrm{t}$} & \multirow[b]{2}{*}{ Sig. } \\
\hline & & B & $\begin{array}{l}\text { Std. } \\
\text { Error }\end{array}$ & Beta & & \\
\hline \multirow[t]{13}{*}{2} & (Constant) & -.029 & 1.534 & & -.019 & .985 \\
\hline & Gender & .056 & .320 & .020 & .174 & .863 \\
\hline & Bachelor's or Master's degree & .150 & .260 & .072 & .576 & .567 \\
\hline & White & -.449 & .245 & -.204 & -1.829 & $.073^{+}$ \\
\hline & $\begin{array}{l}\text { Years teaching SU prevention } \\
\text { overall }\end{array}$ & -.007 & .015 & -.074 & -.496 & .622 \\
\hline & $\begin{array}{l}\text { Years working at schools } \\
\text { overall, including this school }\end{array}$ & -.003 & .011 & -.039 & -.284 & .777 \\
\hline & $\begin{array}{l}\text { Beliefs about program's } \\
\text { effectiveness }\end{array}$ & .308 & .245 & .181 & 1.259 & .214 \\
\hline & $\begin{array}{l}\text { Beliefs about school's } \\
\text { responsibility to teach SU } \\
\text { prevention }\end{array}$ & -.320 & .247 & -.148 & -1.298 & .200 \\
\hline & Self-efficacy & .389 & .222 & .220 & 1.752 & $.086^{+}$ \\
\hline & $\begin{array}{l}\text { Ease of program } \\
\text { implementation }\end{array}$ & .374 & .216 & .260 & 1.730 & $.090^{+}$ \\
\hline & Principal encouragement & .084 & .134 & .077 & .629 & .532 \\
\hline & Social desirability & -.027 & .033 & -.092 & -.819 & .417 \\
\hline & $\begin{array}{l}\text { District prevention } \\
\text { coordinator encouragement }\end{array}$ & -.345 & .131 & -.315 & -2.628 & $.011^{*}$ \\
\hline
\end{tabular}


Table 14. Level of Encouragement from Principals and District Prevention Coordinator District Prevention Principal Coordinator

\begin{tabular}{lcc}
\hline Strongly Agree & $36 \%$ & $18 \%$ \\
Agree & $43 \%$ & $32 \%$ \\
Neither Agree or Disagree & $20 \%$ & $38 \%$ \\
Disagree & $2 \%$ & $11 \%$ \\
Strongly Disagree & $0 \%$ & $2 \%$ \\
\hline
\end{tabular}

Figure 8. Mean Percent Time Guidance Counselors Spend Per Week on Activities

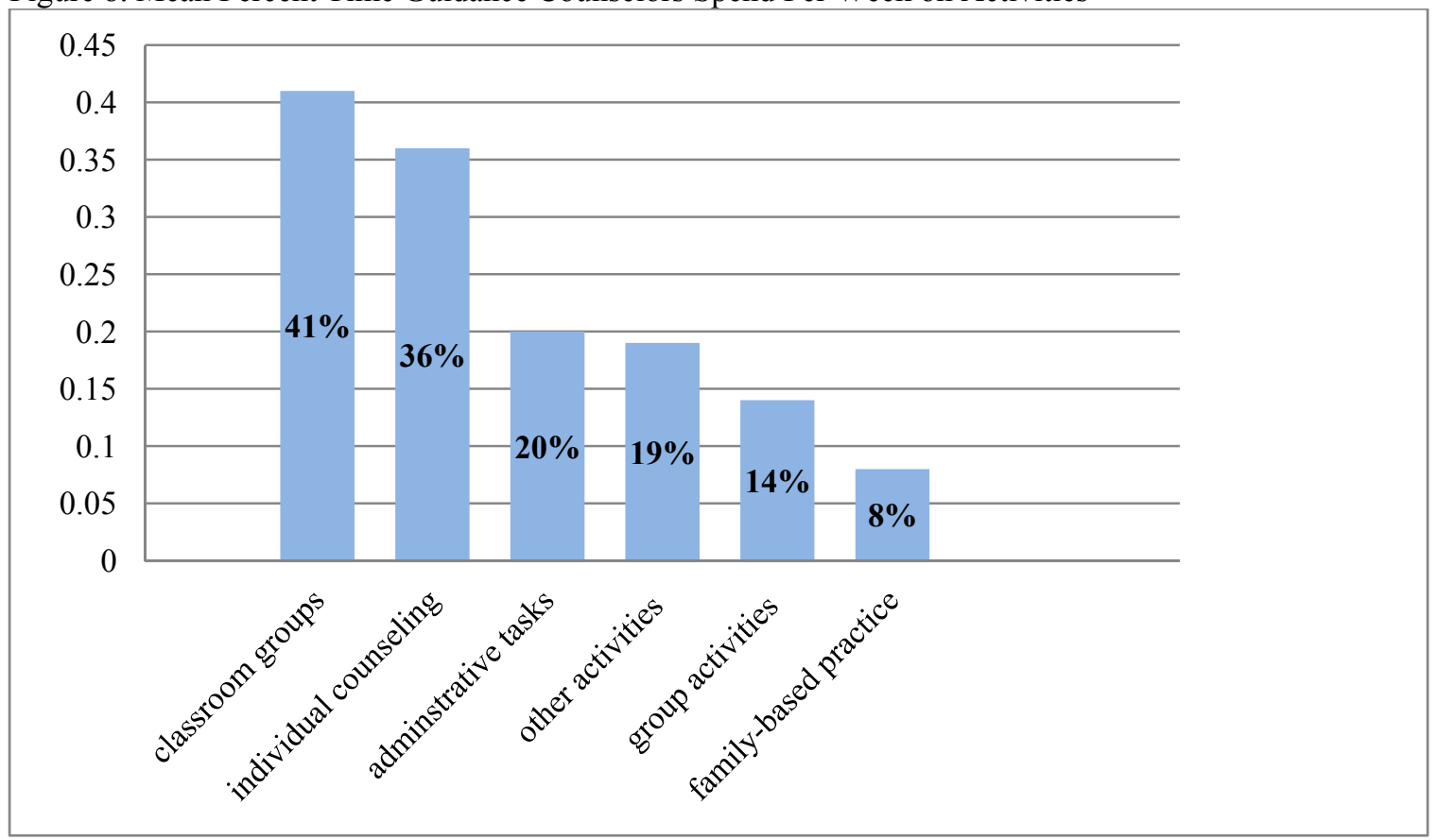

Note. Counselors' responses did not always sum to $100 \%$. 
APPENDICES

Appendix A

\section{Survey \\ Substance Use Prevention Programs School District of Palm Beach County Elementary Schools}

- This questionnaire is about substance use prevention activities in your school.

- Please answer each question honestly. Your answers are completely confidential and will not be individually shared with school officials.

○ There are no right or wrong answers. We are interested in your opinions and feelings.

Thank you for your time and feedback.

\section{Section 1: Background Information}

1. What is your gender?
a. Male

b. Female

2. What is your race? (Hispanic status is asked in the next question)
a. White
b. Black or African-American
c. Asian
d. American Indian or Alaska Native
e. Native Hawaiian/Other Pacific Islander
f. Other

3. Are you Hispanic or Latino? 

a. Yes
b. No

4. What year were you born?

5. What is your job title?
a. Teacher
b. Guidance counselor
c. School social worker
d. Other
If other, please specify

6. Please indicate your highest degree.
a. High school diploma
b. B.A./B.S
c. B.S.W.
d. M.A./M.S./M.A.T./M.Ed.
e. M.S.W.
f. Ph.D./Ed.D.
g. Other
If other, please specify

7. For each degree you have, in what area(s) did you major? (Example: Education, School Counseling, etc.)
a. B.A./B.S.
b. B.S.W.
c. M.A./M.S./M.A.T./M.Ed
d. M.S.W.
e. Ph.D./Ed.D.
f. Other degree

8. How many years have you been teaching and/or working in this school?

9. How many years have you been teaching and/or working in schools overall, including this school? 
10. What grade(s) do you currently teach?
a. Kindergarten
b. $1^{\text {st }}$
c. $2^{\text {nd }}$
d. $3^{\text {rd }}$
e. $4^{\text {th }}$
f. $5^{\text {th }}$
g. $6^{\text {th }}$
h. I do not currently teach

11. What subject(s) do you currently teach?
a. Language arts
b. Science
c. Social studies
d. Mathematics
e. General education teacher
f. Other
If other, please specify

e. I do not currently teach

12. How many years have you taught substance use prevention in this school?

13. How many years have you taught substance use prevention overall?

14. The principal supports substance use prevention programs being taught at my school.
a. Strongly agree
b. Agree
c. Neither agree or disagree
d. Disagree
e. Strongly disagree 


\section{Section 2}

\section{- The following questions are related to the most recent substance use prevention program you delivered to students.}

1. When was the most recent time you taught a substance use prevention program to students? (Please choose only one response.)

a. The current school year (2010-2011)

b. Last school year (2009-2010)

c. 2008-2009

d. 2007-2008

e. I have not taught a substance use prevention program to students in the past four years, including this year.

If you answered " $e$ ", please skip to Section 5 and complete Sections 5 - 6.

2. What was the name of the substance use prevention program that you most recently taught students? (Please circle only one response.)

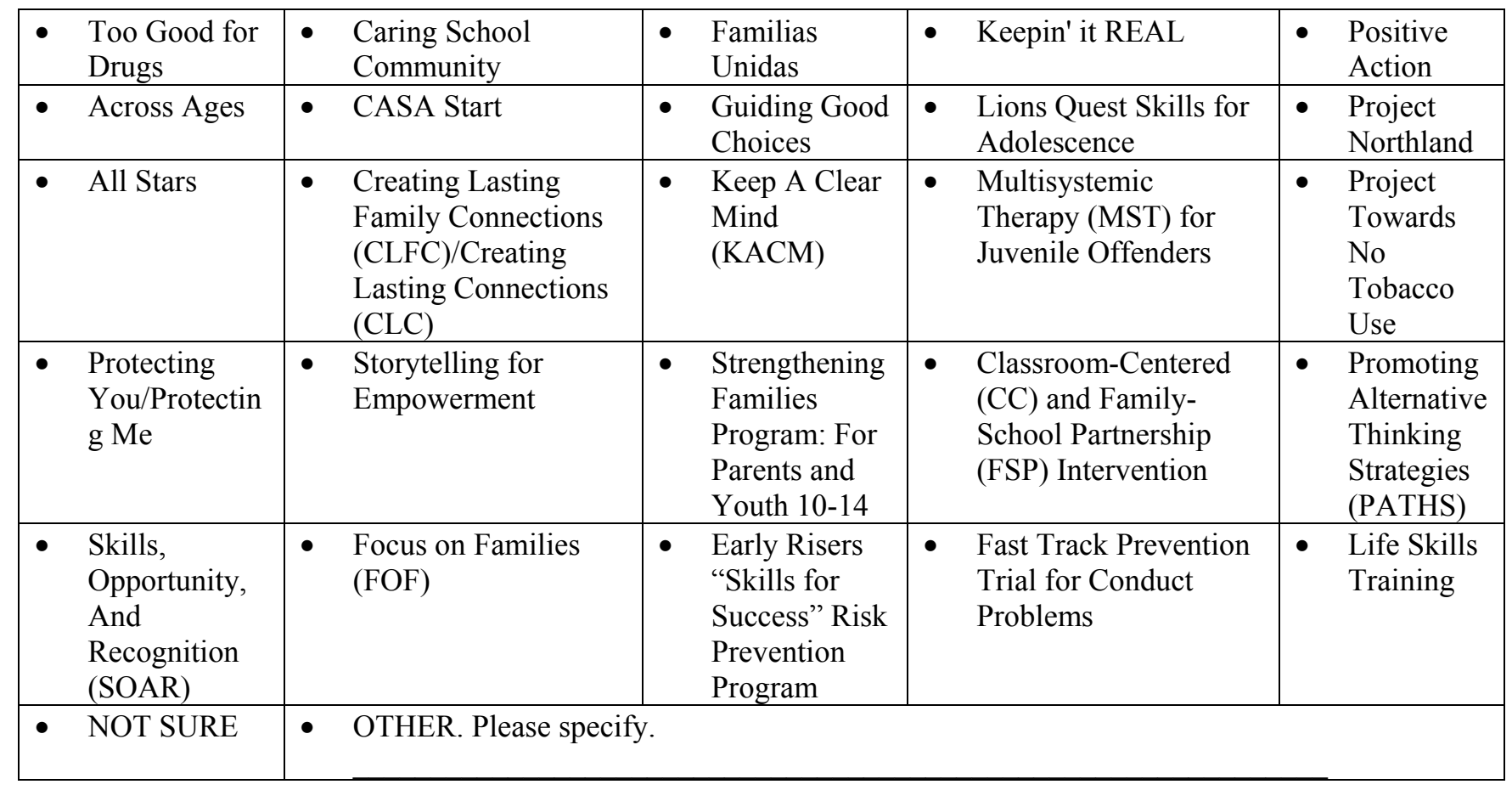


3. In what subject did you implement the substance use prevention program?
a. Language arts
b. Science
c. Social studies
d. Mathematics
e. General education classroom
f. Other
If other, please specify

4. In what grade did you implement the substance use prevention program?
a. Kindergarten
b. $1^{\text {st }}$
c. $2^{\text {nd }}$
d. $3^{\text {rd }}$
e. $4^{\text {th }}$
f. $5^{\text {th }}$
g. $6^{\text {th }}$

5. How much of the substance use prevention program did you deliver to students?
a. All program lessons $(100 \%)$
b. Most program lessons $(\geq 50 \%)$
c. Some program lessons $(<50 \%)$
d. None of the program lessons $(0 \%)$

6. How closely did you follow the curriculum guide/program manual in delivering the substance use prevention lessons?
a. Very closely ("I taught the material as specified.")
b. Somewhat closely ("I sometimes adapted the material as appropriate.")
c. Not very closely ("I frequently adapted the material as appropriate.")
d. I was not provided a curriculum guide
e. I did not use a curriculum guide 
7. If the substance use prevention program involved using interactive activities (e.g., puppets, role playing, small group activities), how often did you use these components?

a. All the time $(100 \%)$

b. Most of the time $(\geq 50 \%)$

c. Sometimes $(<50 \%)$

d. Not at all $(0 \%)$

e. The program did not require use of interactive components.

8. When delivering a substance use prevention program to students, I think it is more important to:

a. Follow the program curriculum guide closely.

b. Modify the curriculum according to the needs of my students, time, or other considerations.

9. The substance use prevention program had clear goals.
a. Strongly agree
b. Agree
c. Neither agree or disagree
d. Disagree
e. Strongly disagree

10. The substance use prevention lessons were easy to implement.
a. Strongly agree
b. Agree
c. Neither agree or disagree
d. Disagree
e. Strongly disagree

11. The curriculum guide was easy to follow.
a. Strongly agree
b. Agree
c. Neither agree or disagree
d. Disagree
e. Strongly disagree
f. I was not provided a curriculum guide.
g. I decided not to use a curriculum guide. 
12. The lecture component of the prevention program was easy to implement.
a. Strongly agree
b. Agree
c. Neither agree or disagree
d. Disagree
e. Strongly disagree
f. There were no lecture components.

13. The interactive components were easy to implement (e.g., puppets, role-playing, etc.).
a. Strongly agree
b. Agree
c. Neither agree or disagree
d. Disagree
e. Strongly disagree
f. There were no interactive components.

14. The preparation time required to deliver program lessons was acceptable.
a. Strongly agree
b. Agree
c. Disagree
d. Strongly disagree

15. My students benefit from the substance use prevention program I delivered to them.
a. Strongly agree
b. Agree
c. Neither agree or disagree
d. Disagree
e. Strongly disagree

16. I believe the substance use prevention program I delivered to students is effective in reducing substance use among young people.
a. Strongly agree
b. Agree
c. Neither agree or disagree
d. Disagree
e. Strongly disagree 
17. I see a positive difference in the way students relate to each other as a result of the program.
a. Strongly agree
b. Agree
c. Neither agree or disagree
d. Disagree
e. Strongly disagree

18. The program has positively affected students' classroom behavior.
a. Strongly agree
b. Agree
c. Neither agree or disagree
d. Disagree
e. Strongly disagree

19. The substance use prevention program I delivered to students is effective in helping them develop goal-setting skills.
a. Strongly agree
b. Agree
c. Neither agree or disagree
d. Disagree
e. Strongly disagree

20. The substance use prevention program I delivered to students is effective in helping them develop decision-making skills.
a. Strongly agree
b. Agree
c. Neither agree or disagree
d. Disagree
e. Strongly disagree

21. The substance use prevention program I delivered to students is effective in helping them get along with others.
a. Strongly agree
b. Agree
c. Neither agree or disagree
d. Disagree
e. Strongly disagree 
22. The substance use prevention program I delivered to students is effective in helping them to identify and manage their emotions.
a. Strongly agree
b. Agree
c. Neither agree or disagree
d. Disagree
e. Strongly disagree

23. The substance use prevention program I delivered to students is effective in helping them to communicate effectively with others.
a. Strongly agree
b. Agree
c. Neither agree or disagree
d. Disagree
e. Strongly disagree

24. The substance use prevention program I delivered to students is effective in helping them to develop peer pressure resistance skills.
a. Strongly agree
b. Agree
c. Neither agree or disagree
d. Disagree
e. Strongly disagree

25. When was the most recent training you received to deliver the substance use prevention program you identified on page 4 ?
a. The current school year (2010-2011)
b. Last school year (2009-2010)
c. Prior to the 2009-2010 school year
d. I have not received training to deliver the substance use prevention program.

26. What sections or components of the substance use prevention program did you not implement? 
27. What was most challenging about delivering the substance use prevention program?

\section{Section 3}

- The following questions are about your role as a substance use prevention teacher in delivering the substance use prevention program you selected on Page 4.

1. How confident are you that you can do a good job teaching the substance use prevention program?
a. Very confident
b. Confident
c. Somewhat confident
d. Not at all confident

2. How confident are you that you can do a good job delivering the interactive components of the substance use prevention program (e.g., puppets, role-playing, small group activities, etc.)?
a. Very confident
b. Confident
c. Somewhat confident
d. Not at all confident 
3. How confident are you that you can control your classroom while delivering the substance use prevention program?
a. Very confident
b. Confident
c. Somewhat confident
d. Not at all confident

\section{Section 4}

- The following items are about your principal and district prevention coordinator.

- Again, please answer the following questions based on the most recent substance use prevention program you delivered to students.

1. The principal encouraged me to teach the substance use prevention program.
a. Strongly agree
b. Agree
c. Neither agree or disagree
d. Disagree
e. Strongly disagree

2. The district prevention coordinator encouraged me to teach the substance use prevention program.
a. Strongly agree
b. Agree
c. Neither agree or disagree
d. Disagree
e. Strongly disagree 
3. Which other individuals encouraged you to teach the substance use prevention program? (Select all that apply)

a. Assistant principal

b. Guidance counselor

c. School social worker

d. Other classroom teachers

e. Parents

f. Other

If other, please specify.

\section{Section 5}

\section{The following questions are about your beliefs in the school's role in teaching substance use prevention programs.}

1. How much responsibility should schools have in teaching students goal-setting skills?
a. A lot
b. Some
c. None

2. How much responsibility should schools have in teaching students decision-making $\underline{\text { skills? }}$
a. A lot
b. Some
c. None 
3. How much responsibility should schools have in teaching students to get along with others?
a. A lot
b. Some
c. None

4. How much responsibility should schools have in teaching students to identify and manage their emotions?
a. A lot
b. Some
c. None

5. How much responsibility should schools have in teaching students to communicate effectively with others?
a. A lot
b. Some
c. None

6. How much responsibility should schools have in teaching students to develop peer pressure resistance skills?
a. A lot
b. Some
c. None

7. How much responsibility should schools have in preventing substance use among students?
a. A lot
b. Some
c. None 


\section{Section 6}

- You are almost done! This is the last section.

- These questions are about you. Please be honest when responding.

- There are no right or wrong answers.

1. I sometimes feel resentful when I don't get my way.

a. True

b. False

2. On a few occasions, I have given up doing something because I thought too little of my ability.
a. True
b. False

3. There have been times when I felt like rebelling against people in authority even though I knew they were right.
a. True
b. False

4. No matter who I'm talking to, I'm always a good listener.
a. True
b. False

5. I can remember "playing sick" to get out of something.
a. True
b. False

6. There have been occasions when I took advantage of someone.
a. True
b. False

7. I'm always willing to admit it when I make a mistake.
a. True
b. False

8. I sometimes try to get even rather than forgive and forget.
a. True
b. False 
9. I am always courteous, even to people who are disagreeable.
a. True
b. False

10. I have never been irked when people expressed ideas very different from my own.
a. True
b. False

11. There have been times when I was quite jealous of the good fortune of others.
a. True
b. False

12. I am sometimes irritated by people who ask favors of me.
a. True
b. False

13. I have never deliberately said something that hurt someone's feelings.

a. True

b. False 


\section{For guidance counselors only.}

1. How much of your time per week do you dedicate to the following activities? Please provide percentages.

a. Providing individual counseling to students

b. Offering group counseling to students

c. Engaging in family-based practice

d. Conducting classroom groups

e. Administrative tasks

f. Other activities

If listing other activities, please specify activity and percentage of time dedicated to each activity.

\section{Thank you very much for your participation!}




\section{Appendix B \\ Interview Questions}

\section{Qualitative Questions (6)}

These questions assess my independent variables:

1. What are your thoughts about the effectiveness of the substance use prevention program you delivered to students?

2. What are your beliefs about your responsibility to teach substance use prevention concepts to elementary students?

3. How confident did you feel when you delivered the substance use prevention program?

4. How easy or difficult was it to deliver the substance use prevention program?

5. What kind of encouragement, if any, did the principal offer you in terms of delivering the substance use prevention program?

6. What kind of encouragement, if any, did the district prevention coordinator offer you in terms of delivering the substance use prevention program?

\section{Dosage \& Adherence Questions (4)}

These questions assess my dependent variables:

1. How much of the substance use prevention program did you deliver to students?
a. All program lessons $(100 \%)$
b. Most program lessons $(\geq 50 \%)$
c. Some program lessons $(<50 \%)$
d. None of the program lessons $(0 \%)$ 
2. How closely did you follow the curriculum guide/program manual in delivering the substance use prevention lessons?
a. Very closely ("I taught the material as specified")
b. Somewhat closely ("I sometimes adapted the material as appropriate")
c. Not very closely ("I frequently adapted the material as appropriate")
d. I was not provided a curriculum guide
e. I did not use a curriculum guide

3. When the substance use prevention program involved using interactive activities (e.g., puppets, role playing, small group activities), how often did you use these components?
a. All the time
b. Most of the time
c. Sometimes
d. Not at all
e. The program did not require use of interactive components.

4. When delivering a substance use prevention program to students, I think it is more important to:

a. Follow the program curriculum guide closely.

b. Modify the curriculum according to the needs of my students, time, or other considerations. 


\section{APPENDIX C \\ Intercoder Reliability Process}

The steps below were pursued to assess intercoder reliability in the present study.

1. The author attended a first meeting with second coder. ${ }^{8}$ At the time of the meeting, this person worked at Florida International University in Miami, FL. He has a doctorate degree and a background in anthropology and sociology. Prior to the first meeting, the second coder did not have any specific knowledge concerning the current study.

During the initial meeting, the author gave the second coder an overview of the study. The research questions for the semi-structured interview were also shared with the second coder. The author answered and clarified any questions the second coder had about the codes and the interviews.

2. The author emailed the second coder the: (a) codebook with the definitions and examples of the codes used in the present study; and (b) interview transcripts with no codes, memos, or special notations.

3. The second coder coded one interview in ATLAS.ti with the codes the author provided.

4. The author met with second coder again. At this meeting, they went through the interview that the second coder had coded. Disagreement between assignment of codes were discussed. Any questions or issues the second coder had were answered and clarified.

5. The author narrowed down and made clearer the definition of certain codes and shared them with the second coder.

6. The author and the second coder met a third time. At this meeting, they went through all three interviews coded by the second coder and compared them to the author's coded interviews. The author answered any questions and clarified any issues that the second coder had.

7. The second coder recoded the interviews.

${ }^{8}$ All meetings took place in the second coder's office in Florida International University in Miami, FL during the month of October 2012. 
8. To assist in recording and assessing intercoder reliability, the author drafted a Coder Agreement Analysis Spreadsheet in Excel. Three columns were created. The first column consisted of the paragraph number in ATLAS.ti corresponding to the coded word or passage as well as to the code used. The second and third columns recorded the author's and the second coder's agreement on assigned codes, respectively. This was reflected by assigning either a 1 (agreement) or 0 (disagreement) to each code.

9. At the fourth and final meeting, the author and the second coder went through both of their codes for each of the three interviews and recorded whether they agreed (i.e., 1) or disagreed (i.e., 0) with each other's code assignment.

10. Cohen's kappa, an index which assesses intercoder agreement, was calculated in SPSS. 


\section{JACKIE CRUZ WAGENER}

$\begin{array}{ll}1997-2000 & \begin{array}{l}\text { Research Assistant } \\ \text { Florida State University } \\ \text { Tallahassee, FL }\end{array} \\ & \begin{array}{l}\text { B.A., Psychology } \\ \text { Florida State University } \\ \text { Tallahassee, FL }\end{array} \\ & \text { Program Associate } \\ & \text { The Children's Partnership } \\ & \text { Santa Monica, CA } \\ & \text { M.S., Family and Child Sciences } \\ & \text { Florida State University } \\ & \text { Tallahassee, FL } \\ & \text { Grant Writer } \\ & \text { Palm Beach State College } \\ & \text { Lake Worth, FL } \\ & \text { Research Assistant } \\ 2003-2008 & \text { Florida International University } \\ & \text { Miami, FL } \\ & \text { Doctoral Candidate } \\ & \text { Florida International University } \\ & \text { Miami, FL }\end{array}$

\section{PUBLICATIONS}

Cruz Wagener, J. (2001). An exploratory study into the relationship between child sexual abuse rates and the existence of child sexual abuse prevention programs. Unpublished master's thesis, Florida State University, Tallahassee, Florida.

Cruz, J., Joiner, T. E., Johnson, J. G., Heisler, L. K., Spitzer, R. L., \& Pettit, J. W. (2000). Self-defeating personality disorder reconsidered. Journal of Personality Disorders, 14 (1), 64-71 
Joiner, T. E., Pettit, J. W., Walker, R. L., Voelz, Z. R., Cruz, J., Rudd, M. D., \& Lester, D. (2002). Perceived burdensomeness and suicidality: Two studies on the suicide notes of those attempting and those completing suicide. Journal of Social and Clinical Psychology, 21(5), 531-545.

\section{FELLOWSHIPS / AWARDS}

Recognition of Excellence in Research, Department of Psychology, Florida State University, 1998

Dissertation Year Fellowship, Florida International University, 2011 - 2012

\section{COMMUNITY INVOLVEMENT}

Mentor, Take Stock in Children, Palm Beach County, FL 2011 - Present 